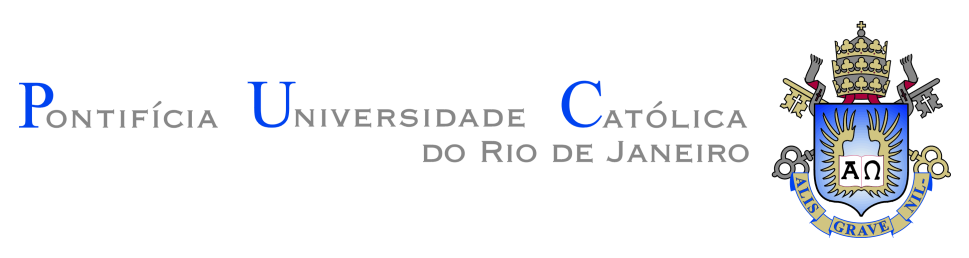

Gláucia Fernandes

Risk control models for Brazilian hydropower investments: A proposal

Tese de Doutorado

Thesis presented to the Programa de Pós-graduação em Administração de Empresas of PUC-Rio in partial fulfillment of the requirements for the degree of Doutor em Administração de Empresas.

Advisor: Prof. Luiz Eduardo Teixeira Brandão 


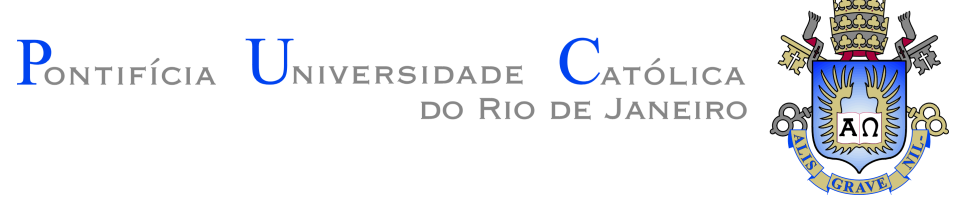

Gláucia Fernandes

\section{Risk control models for Brazilian hydropower investments: A proposal}

Thesis presented to the Programa de Pós-graduação em Administração de Empresas of PUC-Rio in partial fulfillment of the requirements for the degree of Doutor em Administração de Empresas. Approved by the undersigned Examination Committee.

Prof. Luiz Eduardo Teixeira Brandão

Advisor

Departamento de Administração - PUC-Rio

Prof. Leonardo Lima Gomes

Departamento de Administração - PUC-Rio

Prof. Davi Michel Valladão

Departamento de Engenharia de Produção - PUC-Rio

Prof. Carlos de Lamare Bastian-Pinto

Departamento de Administração - IBMEC

Prof. Marta Corrêa Dalbem

Pesquisador - Autônomo

Prof. Augusto Cesar Pinheiro da Silva

Coordenador Setorial do Centro de Ciências Sociais - PUC-Rio

Rio de Janeiro, January 12th, 2018 
All rights reserved.

\section{Gláucia Fernandes}

Graduated in Economics at the Federal University of Viçosa in 2011 and obtained her M.Sc. Degree in Economics from the Federal University of Juiz de Fora in 2013.

Ficha Catalográfica

Fernandes, Gláucia

Risk control models for Brazilian hydropower investments: A proposal / Gláucia Fernandes; orientador: Luiz Eduardo Teixeira Brandão. - 2018.

v., 119 f: il. color. ; $30 \mathrm{~cm}$

Tese (doutorado) - Pontifícia Universidade Católica do Rio de Janeiro, Departamento de Administração.

Inclui bibliografia

1. Administração - Teses. 2. Brasil;. 3. Setor elétrico; 4. Risco hidrológico;. 5. Seguro;. 6. Contrato de energia. I. Teixeira Brandão, Luiz Eduardo. II. Pontifícia Universidade Católica do Rio de Janeiro. Departamento de Administração. III. Título. 


\section{Acknowledgments}

To God.

To my advisor Prof. Luiz Brandão for his guidance and assistance in this journey. Without his support, talent for accomplishing things, and determination to open paths for his students, this thesis and other works would not be possible.

To my co-advisor Prof. Leonardo Gomes for his invaluable support.

To Prof. Jim Dyer who received me at the University of Texas at Austin during my stay at McCombs and opened the door to new knowledge.

To Professors John Butler and Joe Hahn for their incentive and help in Austin, and Prof. Carlos Bastian-Pinto for his support and help during these years.

To CAPES, PUC-Rio and Queiroz Galvão Energia for the aid granted, without which this work would not have been possible.

To the researchers and friends of NUPEI, who have so often helped me solve problems and gave me encouragement to move forward.

To the secretaries of IAG who brought their energies to our work environment.

To my parents and family, Maria Silva, Raimunda Moreira, José Epfanio, Amanda Fernandes and Felipe Moreira for the affection and the formation that I received.

To Gabriel Vasconcelos, for the tireless support and encouragement in the difficult hours.

To Prof. Fernanda Perobelli, whose guidance and encouragement was fundamental for me follow the academic path, and to my friends Layla Mendes, Larissa Resende, Luiz Sacramento, Fernando Ormonde, Diogo Sena, Hilário Alencar for the collaboration and help. 


\section{Abstract}

Fernandes, Gláucia; Teixeira Brandão, Luiz Eduardo (Advisor). Risk control models for Brazilian hydropower investments: A proposal. Rio de Janeiro, 2018. 119p. Tese de Doutorado Departamento de Administração, Pontifícia Universidade Católica do Rio de Janeiro.

This thesis studies the consequences of hydrological risk for hydropower generators in Brazil and proposes four models to mitigate this risk. In the first part, a model is developed considering the redesigning of hydro energy contracts so that the generators are allowed to sell part of their energy per availability. This solution allows the financial settlement of the accounts to more closely mimic the operation of the system, where energy sources can be optimally switched between hydro and thermal plants depending on water availability. In the second part, three derivative options, namely swap, collar and collar by difference are developed. In the swap model, the generators define a protection level and from that level they exchange energy with the consumers through a power delivery factor. In the collar model, the generators define a generation floor to protect themselves against financial losses in the market in such way they would be long at a high spot price. Also, the generators define a generation cap from which they would be short at a low price. The collar by difference is a collar formed by two distinct agents through a trader. In this case, the generators set an option with an exercise value, while the customers set an opposite position with that same exercise with the trader. To test the efficiency of these four models, two thousand monthly simulations of energy price and power generation for 2016 were generated. The results indicate that by adding flexibility to the contracting rules, hydrological risk is mitigated. Also, the results suggest that the generators with existing contracts may respectively opt for the swap, collar by difference and collar derivatives, while the generators with new energy would opt to sell a portion of their energy in contracts by availability. In the long-term energy tariffs may decrease in future energy auctions due to the reduction in the risk to hydropower generators under these models.

\section{Keywords}

Brazil; Electricity sector; Hydrological risk; Hedge; Energy contracts 


\section{Resumo}

Fernandes, Gláucia; Teixeira Brandão, Luiz Eduardo. Modelos de controle de risco para investimentos em energia hidrelétrica no Brasil: Uma proposta. Rio de Janeiro, 2018. 119p. Tese de Doutorado - Departamento de Administração, Pontifícia Universidade Católica do Rio de Janeiro.

Esta tese estuda as consequências do risco hidrológico para os geradores hidrelétricos no Brasil e propõe o desenvolvimento de quatro modelos para mitigar esse risco. Na primeira parte, um modelo é desenvolvido considerando o redesenho de contratos de energia hidrelétrica para que os geradores possam vender parte da energia por disponibilidade. Esta solução permite que a liquidação financeira das contas espelhe a operação do sistema, em que as fontes de energia podem ser alternadas entre usinas hidrelétricas e térmicas, dependendo da disponibilidade de água. Na segunda parte, são desenvolvidos três derivativos de opções, denominados swap, collar e collar por diferença. No swap, os geradores definem um nível de proteção a partir do qual trocam energia com os consumidores através de um fator de entrega de energia. No collar, os geradores definem um piso de geração para se proteger de perdas financeiras no mercado de energia e a partir do qual eles estão comprados em um preço teto de mercado. Neste caso, os geradores também definem um teto de geração no qual eles estão vendidos a um preço piso. O collar por diferença é formado por dois agentes distintos por meio de um comerciante. Neste caso, os geradores definem uma opção e um valor de exercício, enquanto que os clientem definem uma posição contrária com o mesmo valor de exercício com o comerciante. Para testar a eficiência desses quatro modelos, foram geradas duas mil simulações mensais de preço e geração de energia para o ano de 2016. Os resultados indicam que ao adicionar flexibilidade às regras de contratação, o risco hidrológico é mitigado. Os resultados também sugerem que os geradores com contratos existentes de energia podem optar respectivamente pelos derivativos swap, collar por diferença e collar, enquanto que geradores com energia nova optariam por vender parte da energia em contratos por disponibilidade. No longo prazo as tarifas de energia diminuiriam devido a redução do risco de geração sob esses modelos.

\section{Palavras-chave}

Brasil; Setor elétrico; Risco hidrológico; Seguro; Contrato de energia 


\section{Table of contents}

1 Introduction $\quad 12$

$\begin{array}{lll}1.1 & \text { Research objectives } & 13\end{array}$

$\begin{array}{ll}1.2 \text { Main contributions } & 14\end{array}$

$\begin{array}{lll}1.3 & \text { Related work } & 14\end{array}$

$\begin{array}{ll}1.4 \text { Background and Motivation } & 17\end{array}$

$\begin{array}{lll}\text { 1.4.1 The risks of hydropower generation } & 18\end{array}$

$\begin{array}{ll}1.5 \text { Organization of thesis } & 19\end{array}$

2 The Brazilian Electric System $\quad 21$

2.1 The Brazilian interconnected power system 21

2.2 Energy trading 24

$\begin{array}{ll}2.3 & \text { Physical guarantee } \\ 2.4 & 26\end{array}$

2.4 Energy Reallocation Mechanism 28

2.4.1 Application of ERM 30

2.5 Exposure to non-hydrological risks 33

2.6 Renegotiation of the hydrological risk 35

$\begin{array}{lll}2.7 & \text { Risk Management } & 35\end{array}$

3 Redesigning Energy Contracts in Brazil $\quad 38$

$\begin{array}{lll}3.1 & \text { Financial accounts settlements } & 38\end{array}$

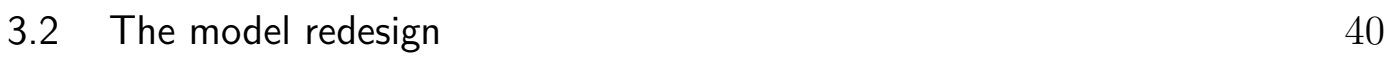

3.3 Pricing the contracts 43

$\begin{array}{lll}3.4 & \text { Risk assessment } & 47\end{array}$

4 Numerical Example: contracts redesign $\quad 51$

4.1 Model calibration $\quad 51$

4.2 Illustration of the model $\quad 55$

4.3 Case 1: two thermals $\quad 58$

4.4 Case 2: the system 63

4.5 Case 3: sensitivities 68

4.5.1 Demand and base energy 68

$\begin{array}{ll}\text { 4.5.2 Externalities for hydropower } & 70\end{array}$

4.5.3 Long-term energy tariff 72

5 Derivatives in Energy Markets $\quad 73$

$\begin{array}{lll}5.1 \text { Swap } & 74 \\ 5.2 & \text { Plain call and put }\end{array}$

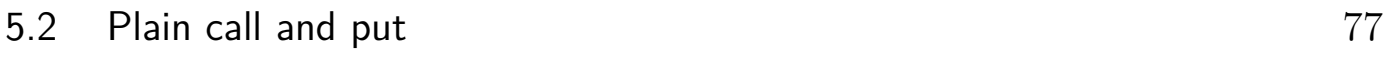

$\begin{array}{lll}5.3 \text { Collar } & 77\end{array}$

$\begin{array}{lll}5.4 & \text { Derivatives in the national electricity sector } & 79\end{array}$

6 Options as Instruments in Electricity Contracts 82

6.1 Swap $\quad 83$

6.2 Collar $\quad 85$

6.3 Collar by difference $\quad 88$ 
7 Numerical Example: option instruments $\quad \mathbf{9 0}$

$\begin{array}{lll}7.1 & \text { The base case } & 90\end{array}$

$\begin{array}{lll}7.2 & \text { Swap result } & 92\end{array}$

$\begin{array}{lll}7.3 & \text { Collar result } & 94\end{array}$

$\begin{array}{lll}7.4 & \text { Collar by difference (CBD) result } & 96\end{array}$

$\begin{array}{ll}7.5 & \text { Comparing the models } \\ \end{array}$

8 Conclusion 100

$\begin{array}{ll}\text { APPENDICES } & 117\end{array}$

$\begin{array}{ll}\text { A Premium values of hydrological renegotiation } & 118\end{array}$ 


\section{List of figures}

2.1 Installed capacity of NIS. 21

2.2 National Interconnected System. 22

2.3 Monthly SPD to Brazilian submarkets. 25

$\begin{array}{lll}2.4 & \text { Calculation of the physical guarantee. } & 27\end{array}$

2.5 Physical guarantee and real generation. 29

2.6 Comparison between ERM generation and PG when $G S F=1 . \quad 31$

2.7 Comparison between ERM generation and PG when $G S F>1 . \quad 32$

2.8 Comparison between ERM generation and PG when $G S F<1 . \quad 33$

2.9 Evolution of the NIS's installed capacity. 34

3.1 Model Comparison 41

3.2 Historical ERM adjustment factor (GSF). $\quad 50$

4.1 Average of power generation for 2016.

4.2 SPD histogram. 54

4.3 Average of spot price for 2016.

4.4 An example of the model. $\quad 55$

4.5 CCEE and hydropowers' revenue accounting. $\quad 57$

4.6 Varying $u v c$ for plants 1 and 2. 62

4.7 Hydropower generators' monthly risk in the CCEE. 63

4.8 Quarterly distribution of generators' revenue. 64

4.9 Consumers' monthly risk. 65

4.10 Quarterly distribution of consumers' result. 66

4.11 Sensitivity of hydropowers' revenue to the price premium. 67

4.12 Sensitivity of the demand. 69

4.13 Sensitivity of the base energy. $\quad 69$

4.14 Reserve energy in 2015. $\quad 70$

4.15 Impact of the reserve energy on revenue and cost. 71

4.16 Sensitivity of the reserve energy and the demand. 71

$\begin{array}{lll}5.1 & \text { Swap of energy tariff. } & 75\end{array}$

5.2 Zero-cost collar.

6.1 Swap derivative. $\quad 83$

6.2 Factor of protection from the physical guarantee. 84

6.3 Collar design. 86

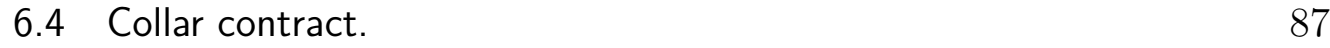

6.5 Collar by difference. $\quad 88$

$\begin{array}{lll}7.1 & \text { GSF histogram. } & 91\end{array}$

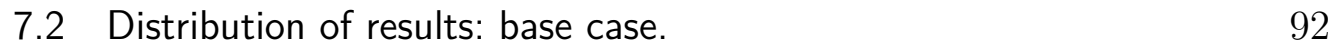

$\begin{array}{ll}7.3 & \text { Distribution of results: swap case. }\end{array}$

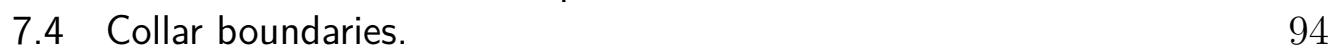

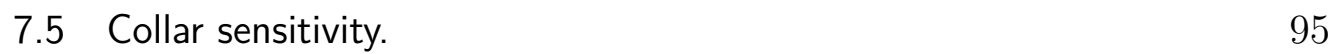

7.6 Distribution of results: collar case. 96

$\begin{array}{ll}\text { 7.7 Distribution of results: CBD case. } & 97\end{array}$ 


\section{List of tables}

2.1 Comparison of PG and generation in GW per submarket: $G S F=1 \quad 30$

2.2 Comparison of PG and generation in GW per submarket: $G S F>131$

2.3 Comparison of PG and generation in GW per submarket: GSF $<132$

4.1 Contract Description. $\quad 52$

4.2 Descriptive statistics 53

4.3 Contract data $\quad 56$

4.4 Relationship between installed capacity and physical guarantee 58

4.5 New modalities for hydropower contracts 58

$\begin{array}{lll}4.6 & \text { Results of the models } & 60\end{array}$

4.7 Comparison between the two contract models 67

7.1 Values at risk for different contract levels (\$ millions) 91

$\begin{array}{ll}7.2 & \text { Dispatch of the contract by availability }\end{array}$

7.3 Results of the swap 93

$\begin{array}{ll}7.4 \text { Collar example } & 95\end{array}$

$\begin{array}{lll}7.5 & \text { The models' result } & 97\end{array}$

7.6 Comparison between collar and CBD 98

A.1 Products for the renegotiation of the hydrological risk in the ACR, a result to be reimbursed with the renegotiation and the term of postponement of payment of the risk premiums. 


\section{List of Abbreviations}

BES - Brazilian Electricity System (SEB)

CCEE - Electric Energy Clearing Chamber

EPE - Energy Research Company

ERM - Energy Reallocation Mechanism (MRE)

FCE - Free Contracting Environment (ACL)

GSF - Generation Scaling Factor

GW - Gigawatt-hour

MCE - Marginal Cost of Expansion (CME)

MCO - Marginal Cost of Operation (CMO)

MME - Ministry of Mines and Energy

MWh - Megawatt-hour

ANEEL - National Electricity Regulatory Agency

NIS - National Interconnected System (SIN)

OET - Optmization Energy Tariff (TEO)

ONS - Operator of the National System

PG - Physical Guarantee (GF)

RCE - Regulated Contracting Environment (ACR)

SE - Secondary Energy

SHP - Small Hydropower (PCH)

SPD - Settlement Price of Difference (PLD)

UVC- Units Variable Cost (CVU) 


\section{1 \\ Introduction}

Hydropower is considered the best option for electricity power generation, due to its lower cost and lower emission of greenhouse gases (1, 2). Hydro energy markets, however, are designed in such a way that investors must take into account a wide range of risks that can affect their attractiveness and profitability. The sources of these risks are many: energy prices, cost overruns, hydrological risk, regulatory framework and others $(3,4)$. Therefore, hydro systems are vulnerable to seasonal water inflow variations at different times of the year (5), as well as extreme situations such as severe droughts, which is a function of climate risk.

In order to protect against these risks, hydropower generators in predominantly hydro-based systems such as Brazil use conventional energy sales contracts, where they sell their energy to power distributors under fixed quantity contracts, i.e., they provide a fixed amount of energy at a given price. Particularly in Brazil, these contracts are backed by the plant's physical guarantee, which is determined considering a $95 \%$ certainty that this generation will be achieved. The system supply reliability is assured within the calculation of the physical guarantee of each plant (6).

The prolonged drought of the years 2013-2015 in Brazil, however, evidenced the exposure of the hydropower generators to the hydrological risk and other exogenous factors. In this period, the hydropower generation was intense reduced and the generators needed to buy the energy deficit in the market, being subjected to the oscillations in the spot prices, to fulfill their contracts. The energy shortage caused significant financial loss for many of these generators (7). By the end of 2015, the aggregate value of these losses reached nearly 10 Billion US dollars (8). As a result, the generators charged numerous court cases on the grounds of the difficulty of quantifying and financially assuming the hydrological risk, that is beyond the hydrological issue itself. The actions reached the point of suspending the liquidation of the spot market, obliging the Federal government to bring a solution to this problem. After a long period of debate, the government proposed to renegotiate the hydrological risk. The issue of this thesis, however, is that the energy contracting rules that allowed this problem to arise in the first place are still 
in force, and hydropower generators continue to be exposed to the hydrological risk.

In this context, we aim to develop four novel mechanisms capable of mitigating the hydrological risk. First, we propose a new contract design based on contracting part of the plant's physical guarantee by quantity and the remainder by availability. In this contract, the hydroelectric plant only generates energy if there is water available. The implementation of this model would require the government to make public policies to define the rules of energy auctions for water availability. Second, we propose a new approach to the use of swap and collars to mitigate the hydrological risk. These derivatives protect the generators against high spot prices, where the portion of energy offered by quantity is exposed. All these mechanisms are innovative once first there are no such design of contracts in the country, and second because energy options are currently modeled to protect the generators' income during periods of low spot prices, while in this thesis these derivatives are modeled to protect generators during periods of low generation, which coincides with high prices.

\section{1}

\section{Research objectives}

Given the importance and share of hydropower in the Brazilian energy matrix, the objective of this thesis is to develop quantitative risk management models that can assist energy investors to mitigate hydrological risk. This goal requires strategies that consider opportunities available not only to a single isolated agent, but also simultaneously to all agents. Also, considering that energy projects are long-term risky investments, there is also a need for a model that describes the stochastic evolution of the main uncertainties.

Specifically, the objectives of this thesis are twofold.

- First, a novel contract category for the hydroelectric agents is proposed and developed. According to this design, part of the plant's physical guarantee is contract by availability. This model is convenient to implement and the outcomes convey important economic insights that help understand the risk assessment and prioritization under market dynamics.

- Second, new applications to some of the most commonly used energytraded derivatives are developed. We offer novel uses of energy derivatives, including swap, collar and collar by difference, describing how these contracts can be traded and priced in the Brazilian energy market. 
Extensive numerical experiments are performed to verify the models.

\section{2 \\ Main contributions}

The new hydrological risk control techniques developed in this thesis help the energy investors to analyze hydroelectric investment opportunities in a systematic way, evaluate the marginal value of hedging instruments when they are added to the existing portfolio and foresee the impact of specific risk factors to the investment value.

The results of these models are, therefore, of interest to hydropower generators, as it eliminates a significant portion of their hydrological risk. In addition, consumers in the short-term receive the right over the hydropower generation that exceeds the system's physical guarantee, and in the long-term they may benefit from lower costs, when the energy tariffs may be reduced. The results are also of interest to policy makers in Brazil, who are responsible for the regulation of energy auctions in the country. Moreover, researchers would be interested in the risk-control models proposed in this thesis.

\section{3 \\ Related work}

The recent electricity crisis in Brazil in the last years due to the prolonged drought increased the discussion on the need for instruments to protect against the hydrological risk, especially after some unexpected policy decisions made by the Brazillian government during this period. Besides climate factors, hydropower generation has decreased due to government decisions that include energy importation, dispatch of expensive thermoelectric plants, use of reserve energy and delays in construction of transmission line.

Over the years, researchers have been showing the importance of managing hydrological risk and improve the existing protection mechanisms. Barroso et al. (9), for instance, analyzed the hydrological risk faced by power plants in hydropower based markets in the early 2000s and suggested the insertion of a thermoelectric (or hydroelectric) plant into the hydro portfolio to work as a back-up. Some years later, Melo et al. (10) analyzed two mechanisms of economic regulation (the energy reallocation mechanism and the system service charges) employed in the Brazilian energy system to control the risk of hydropower generation during the crisis of 2014 and 2015. As this crisis significantly affected the national economy, the Government decided to renegotiate the hydrological risk (Law $\mathrm{n}^{\mathrm{O}} 13.203$ from December $8,2015)$ to generators that integrate the energy reallocation mechanism 
with energy contracted in the regulated contract environment. The impact of this renegotiation for hydropower generators was studied by Brito (11), who analyzed different scenarios of GSF and spot prices, which were built by simulating the hydrothermal system operation with the models Newave and Suishi. This renegotiation, however, did not provide a long term solution to the problem.

One of the main points deliberated during the electricity crisis was the type of energy sales contract that hydropower generators are subject to. Energy auctions of new hydroelectric plants in Brazil are carried out in contracts by quantity through the national regulated market environment (12), where the price and quantity of energy is established between the buyer and seller (13), and the energy amount is guaranteed by the seller. In this case, the costs arising from the hydrological risks in this modality are assumed by the generators. A reasonable solution in this case would be, for example, to expand the form of contracting of energy, allowing hydropower generators to participate in auctions of new energy contracted by availability, as suggested in the paper of Fernandes et al. (14). Auctions for energy by availability are only applied to thermoelectric plants, where, the owner is reimbursed by the buyers for the plant's operational cost. Contracts by availability for hydropower generators don't currently exist in the country. In this thesis, then, we propose a design of contracts by availability for national hydropower generators. This proposal is close to the paper of Fernandes et al. (15), in which the authors present a simple model to explain how the hydropower generators would benefit from this type of contract. Our model differs from others because we show how the introduction of this contract design affects other agents in the energy market and how to price this contract.

Moreover, derivatives could also be used as efficient mechanisms of risk control. Derivatives are used to reduce the exposure of agents in the market, because they represent risk transfer instruments (16). The derivative is an efficient measure for structuring hedge operations, once it offers an opportunity to take advantage of adverse scenarios. According to Studart (17), derivatives provide the possibility of risk sharing, protection against unexpected variations and several options in the construction of instruments of protection. Among the most traded electricity derivatives in the over-the-counter market are swaps and collars.

Options differ from other contracts because of a degree of flexibility over future deliveries. The option is a financial instrument that gives the holder (or buyer) a future right over something, but not an obligation. In this case, the seller has a future obligation only if requested by the buyer of the contract. The 
buyer pays at the present date the premium, which is the seller's remuneration for assuming the risk of taking a certain position in the market at a future date (18). The use of these derivatives may be one of the means of mitigating the risks associated with the electricity sector (16), since they act as an instrument that provides an alternative form of insurance against adverse contingencies identified a priori (19).

The options of put, call, collar and swap are exercised by risk averse agents in the electricity market. A put (call) option gives the buyer the right to sell (buy) or not from the option launcher, on an agreed date, for a predetermined price, a pre-set amount of electric power. Using the put (call) option, the option buyer will be able to sell (purchase) energy to (from) the option launcher at a price higher (lower) than the market price. A collar is a protective option strategy that an investor can create by purchasing a put option while it simultaneously writes a call option. In a collar, the investor has a long position in an asset, so he benefits when it increases in price. To implement a successful collar strategy, the strike price for the call he's selling needs to be above that of the put he's buying. Both options should also have the same expiration date. The primary benefit of a collar is to limit downside risk. Collars also limit profits on the upside, which is why they are most frequently used during down markets. A swap is an agreement between two parties to exchange cash flow sequences over a period. In this case, both parties must have mutually exclusive risks. According to Mattos (20), energy swap is an adaptation of financial operations in the derivatives market to the electricity market, where swap operations consist of cash flow exchanges between agents (21). Swaps are one of the most effective ways to hedge against fluctuations in rates, asset indexes or liabilities (22).

Hedge instruments in energy markets are of interest in the international literature $(23,24,17,25)$. According to Sioshansi (26), there is an exponential growth in the use of energy derivatives due to the presence of high electricity price volatility. As Deng and Oren (27) emphasize, the electricity price in liberalized markets is much more volatile than that of any other commodity. According to Blanco et al. (28), specific characteristics of energy markets present a challenge to the simulation of the electricity price, which increase the level of sophistication of instruments used in this sector.

In Brazil, Arfux (29) proposed a risk management model for an agent that operates in the over-the-counter market with options derivatives of swap and collar. Tonelli (30) developed a computational model to manage the risks in different types of energy contracts. The author created an automatic portfolio capable of recognizing, managing and optimizing swap and collar 
contracts, producing analyzes to support decision making. According to him, in energy markets, the swap application is exclusive of the sub-market risk mitigation operations in which there are differences between marginal costs between sub-markets. Domingues et al. (31) optimized portfolios of physical assets in electricity generation considering the derivative instrument of collar. They adjusted the behavior of uncertain variables by the Geometric Brownian motion and Mean Reversion stochastic processes. Nonetheless, the use of derivatives in the Brazilian electricity market is underdeveloped, and, therefore, this thesis proposes analyze some options that could be implemented by national hydropower generators. Moreover, all the cited models are concerned with protecting the option holders against low spot prices, which is not efficient to protect hydropower generators with contract by quantity, since the (hydrological) risk of these agents is low generation, which coincides with high spot market prices.

In summary, two important gaps are observed in the literature. First, a contractual design that allow hydropower generators to sell their energy per availability could be developed. Second, different approaches of the use of swaps and collars to hedge the generators against low power generation could be investigated. These gaps are studied and developed in this thesis to assist hydropower generators in their investment decisions. These operations can mitigate the hydrological risk to which these agents are subjected.

\section{4}

\section{Background and Motivation}

Auctions of energy sales in Brazil are carried out within the scope of the regulated contracting environment, coordinated by the Electric Energy Trading Chamber (or Câmara de Comercialização de Energia Elétrica - CCEE) (32). The auctions are divided according to the investment type: whether it is new or existing (33). Auctions of existing energy are those destined to serve distributors in the year subsequent to that of the contracting (named A-1). Auctions of new energy are intended for contracting energy from plants under construction, which may provide energy in 3 (A-3) or 5 (A-5) years ahead of the time of contracting (34).

The contracts resulting from the auctions can be by quantity or availability (35). Contracts by quantity provide a fixed amount of energy at a given price. In this modality, generally used for hydraulic energy, the generators are subject to risks of energy deficits, which are settled at the spot price. The Settlement Price of Differences (SPD or spot price) is calculated by the CCEE for the valuation of the amounts settled in the spot market. The SPD is limited 
by a minimum price and a maximum price, established by the National Electric Energy Agency (Agência Nacional de Energia Elétrica - ANEEL).

Contracts by availability, on the other hand, are mostly used by thermoelectric plants and provide a fixed remuneration to these agents, regardless of what is actually generated. In these contracts, the fixed portion is destined to cover the fixed costs for the availability of the plant to the system. However, when these plants are dispatched, the distributors must pay for the use of the fuel, which will be passed on to consumers at the time of the tariff readjustment $(32,35)$.

To ensure the reliability of the system, the Energy Research Company (Empresa de Pesquisa Energética - EPE) and the Ministry of Mines and Energy (or Ministério de Minas e Energia - MME) establish and assign to each plant a physical guarantee, which is the maximum amount of energy that each enterprise can sell under contracts. The EPE criterion for physical guarantee assignment admits a $5 \%$ maximum risk of deficit.

\subsection{1}

\section{The risks of hydropower generation}

Under Brazil's centralized dispatch mode of operation, the Operator of the National System (ONS) is responsible for the dispatch of hydroelectric plants (36). The ONS operation is concerned on minimizing costs for the system, which means that the generators have no control over their power generation and are subject to ONS operations.

If, for instance, the ONS decides to reduce the dispatch of hydroelectric plants, due to concerns over low reservoir levels and the extent of a drought, the hydropower generation may fall short, and the difference needed to fulfill the contract must be purchased in the market $(37,38)$. If this situation is severe enough to affect the majority of the hydropower generators, which account for about $69 \%$ of the country's energy supply $(39,40,41)$, the increase in demand of energy will drive spot prices up (9). Consequently, any energy short fall must be bought in the spot market at high market prices (42), which will cause significant financial losses for the hydropower generators.

The risk of this operation is shared among the hydroelectric plants through the Energy Reallocation Mechanism (ERM). The ERM was created with the aim of sharing energy among the hydroelectric plants, transferring the surplus from those that generated beyond their physical guarantee to those which generated below it (10). All hydroelectric plants with installed capacity greater than $30 \mathrm{MW}$ participate compulsorily in the ERM.

The relation between the volume of energy effectively generated by the 
ERM and the total physical guarantee is given by the Generation Scaling Factor (GSF). If the GSF is below one, this means that there is an energy deficit among the participants of the ERM, otherwise, energy generation exceeded the contracted amounts, in which case there is a surplus, or, Secondary Energy (SE) (43). Between 2005 and 2012 the ERM participants had favorable hydrological conditions. The average annual GSF during these years were higher than $100 \%$, which indicates that in most of the months of these years the ERM generated energy beyond its physical guarantee and had secondary energy revenues (11).

From 2013 forward, however, the average annual GSF was extremely low. The prolonged drought of these years resulted in an energy shortage, pushing the GSF down (44), which associated with some unexpected measures taken by the ONS to preserve falling reservoir levels $(36,45)$, resulted in a significant reduction of power generation to the ERM participating agents. Since the generators are required to purchase the energy shortfall in the market to fulfill the contract volume (46), they faced a significant financial loss, which led many of these generators to default on their financial obligations (7).

In light of this situation, the CCEE, the agency responsible for the settlement of accounts in the electricity market, was forced to temporarily suspend all trading on the electricity market exchange until a short-term solution was found (47). The solution of the Brazilian government was to renegotiate the hydrological risk (48) of the last years. The government proposal, however, doesn't solve the problem in the long-term. This thesis, therefore, moves forward towards a solution to the hydrological risk.

\section{5}

\section{Organization of thesis}

This doctoral thesis is organized into two central parts, which are in independent article formats, but which cover each of the research topics formulated in this introduction.

The first central part includes sections 2, 3 and 4 and is related to the redesign of hydropower's long-term contracts in such way the sale of energy by availability becomes a hedge against the hydrological risk. Section 2 presents the main aspects and particularities of the Brazilian electricity system in order to contextualize the contractual structure used by hydropower generators and the use of the ERM as a weak instrument for the mitigation of the hydrological risk. From this context, section 3 presents a portfolio composed of contracts by quantity and availability, where of the amount of the plant's physical guarantee, only the firm energy is contracted by quantity, while the rest is contract by 
availability. The pricing of the contract by availability is calculated from the optimization of the system cost. Section 4 exhibits a numerical comparison between the proposed model and the conventional contract by quantity.

The second central part includes sections 5, 6 and 7 and is related to the development of options to mitigate the hydrological risk in existing energy sales contracts. Section 5 presents the description of these derivative contracts and how they are currently used in the energy market. After understanding the construction and operation of these derivatives, section 6 develops three risk instruments based on an adaptation of swaps and collars techniques. The first model is a swap contract in which part of hydropower generation would be exchanged with captive consumers. The second model is the collar contract in which the generators seek protection from the purchase of energy deficit in the spot market, in exchange for the reduction of their revenue with the secondary energy. The third model is a collar by difference, which only considers the bottom trigger of the collar. Section 7 presents a numerical example for all these derivatives and compares them to the conventional contract by quantity.

Finally, the conclusion and discussion of the results are presented in section 8 . 


\section{2}

\section{The Brazilian Electric System}

\section{1}

\section{The Brazilian interconnected power system}

The Brazilian National Interconnected System (NIS) presents a diversity of sources in its electricity matrix with hydro generation accounting for about $62 \%$ of the supply in 2014, with the remainder provided by thermal plants, wind farms and biomass $(40,39)$. Figure 2.1 shows the proportion of each generation source in the Brazilian energy matrix. The strong presence of hydroelectricity in the country's energy matrix is justified by its geographical feature, which favors the use of potential hydraulic energy.

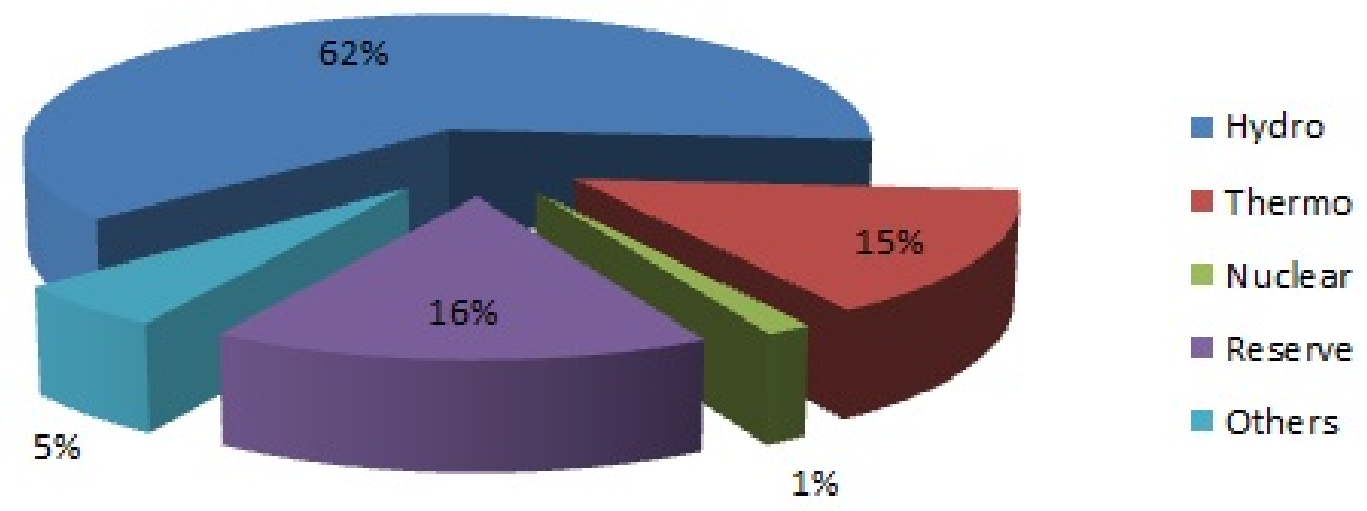

Source: Adapted from (49).

Figure 2.1: Installed capacity of NIS.

Compared to other energy sources, hydropower has several advantages: it is a non-polluting renewable source of energy that contributes to the reduction of greenhouse gas emissions, has negligible operating costs as it relies on the natural water influx of rivers for fuel, and is an environmentally sustainable source of energy $(40,1)$. However, hydropower is highly dependent on rainfall, which is seasonal and uncertain (5), making the generators vulnerable to extreme climate fluctuations such as droughts (50) and to substantial variations in the total affluent throughout the year, i.e., to hydrological risk.

To control the variability of the rivers inflows in Brazil, a very complex reservoir system was built in the country, composed of dams organized in cascade along the rivers and distributed in several river basins. The reservoirs 
are used to store water in the rainy season and are depleted in the dry season to increase the total generation to meet the demand. Also, an extensive transmission network was built to interconnect all regions of the country, creating the NIS. In the light of energy security, conventional thermoelectric plants were also built in order to regularize the hydroelectric plants generation.

Due to transmission constraints, though, the NIS was subdivided into four sub-systems: South, Southeast/Midwest/Acre/Rondônia, Northeast and North/Manaus (S, SE/MW/Acre/Rondônia, NE, N/Manaus). Figure 2.2 illustrates the integration of the NIS. This structure has the benefit of plants that are in more favorable hydrological conditions to assist those that are in dry periods, and vice-versa when the hydrological periods are inverted. Note that this gain would not exist if the dams were operated individually.

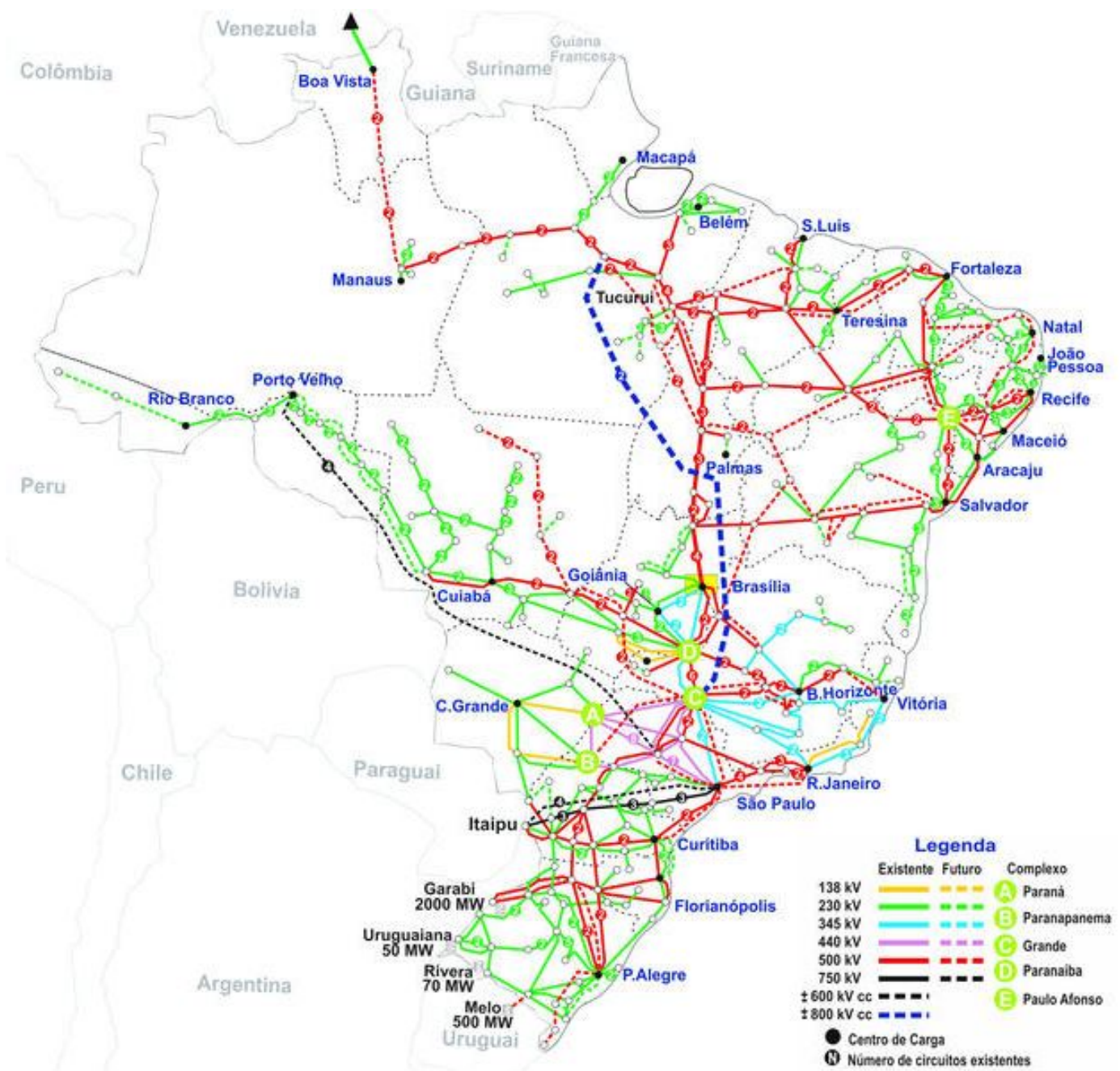

Source: From ONS.

Figure 2.2: National Interconnected System.

The national system operator centralizes the operation of the plants to maximize the system's energy gains. Until 1997 the Brazilian Electricity System (BES) was organized as a government monopoly operated by federal 
and state owned firms. In that year, the Federal government initiated a privatization process aimed at unbundling the energy generation, distribution, transmission and trading business (51), where the government's responsibility would be restricted to the formulation of energy policies and industry regulation (52). Full privatization was never completed, and a sizable portion of the system still remains in the hands of government-owned firms to this date.

Nowadays, the Brazilian regulatory framework is based on a centralized dispatch model that seeks to maximize the inter-temporal utilization of the energy available in the hydroelectric reservoirs and minimize the total operational cost of the system. This model is driven by reservoir levels, expected future reservoir affluence and energy demand forecasts, thermal power plant operating costs and by the energy deficit cost set by the Regulatory Agency (5). In addition, the model calculates the marginal cost of operation, which is used to settle the settlement price of differences (SPD) in the spot energy market (53). Section 2.2 explains better this spot market.

In order to obtain maximum operating gains from an interconnected hydrothermal system, it is necessary to operate the system in an integrated manner, jointly optimizing the operation of all sub-systems and sub-stores. This problem is, then, achieved in stages where models with different degrees of detail are used to represent the system with different horizons such as the long and medium term - Newave model, the short-term - Decomp model (model of operation of hydrothermal interconnected systems of short-term) and the scheduling of daily operation - Dessem model (short-term hydrothermal dispatch model).

The Newave program, used in this work, was developed by the electrical energy research center (or Centro de Pesquisas de Energia Elétrica - Cepel) for application in the long and medium term planning of the operation of hydrothermal interconnected systems, with aggregate representation of the hydroelectric park and calculation of the operation policy based on stochastic dual dynamic programming. The Newave program is used in some activities of the Brazilian Electric Sector, such as expansion Planning, operation Planning, commercialization - calculation of the SPD, definition and Calculation of Physical Assurance and Assured Energy of Generation Projects and elaboration of Guidelines for Energy Auctions. 


\section{2 \\ Energy trading}

Since 2004, there have been two distinct environments for energy trading in Brazil, one regulated (Regulated Contracting Environment - RCE) and another one free (Free Contracting Environment - FCE). The main difference between these submarkets is that while in the RCE the agents buy and sell their energy under strict government rules and policies, in the FCE the agents can freely negotiate bilateral contracts $(54,51)$.

The RCE is the environment in which the energy is traded between generators and distributors, and the contract is formalized through energy trading contracts in the regulated environment. On the other hand, in the FCE, generators and consumers negotiate among themselves the quantities of energy, contract prices and the term of the agreement. In this case, it is the generators' responsibility to formalize the agreement on the CCEE platform, which is the venue for processing the accounting of the energy generated and consumed in the country (52).

Generators can choose to operate in the RCE, FCE or both (55). Captive consumers are required to purchase energy in the regulated market through government organized public auctions, which are conducted by the CCEE based on studies and forecasts of demand made by the ANEEL and the MME (33). Captive consumers are those who buy energy from concessionaires with tariffs regulated by the Government. Free consumers buy energy directly from generators through bilateral contracts. Most consumers have their energy supply from the regulated market, which corresponds to approximately $70 \%$ of the country's consumption, the rest being sold on the free energy market.

The basic unit traded in energy contracts is megawatt-hour (MWh) and the prices are negotiated in BRL (Brazilian Reais) per megawatt-hour $(\mathrm{R} \$ / \mathrm{MWh})$. If the generation is lower than the contract by quantity, the difference (expense) must be purchased in the market at the spot price to honor the contractual obligation. Otherwise, the difference should be sold (revenue) in the spot market (38). A Settlement Price of Difference, i.e., the SPD, settles the differences determined in the energy supply accounting.

The SPD is a value determined weekly by CCEE for each load level (light, moderate and heavy) based on the marginal cost of operation (MCO), limited by a maximum (133.45 $\$$ /MWh in 2017) and minimum (8.42 $\$ /$ MWh in 2017) price, defined annually by ANEEL, for each calculation period and for each submarket. In Brazil, the SPD is also known as spot price and historically presents low values due to the large share of hydroelectric plants in the operation of the system. On the other hand, the SPD shows great volatility 
due to the inflows that reach the subsystems and the storage levels of the reservoirs.

Figure 2.3 shows a comparison between the spot price behavior and the $\%$ of stored energy (i.e., \% Energia Armazenada - EAR) to the SE/MW (Sudeste/Centro-Oeste) submarket. It is observed that in a period of low affluence, the prices reach very high values. Note that the sharp drop in SPDs in 2015 is due to a reduction of more than 50\% (from 205.71 \$/MWh in 2014 to $97.12 \$ /$ MWh in 2015) of the maximum stipulated SPD.

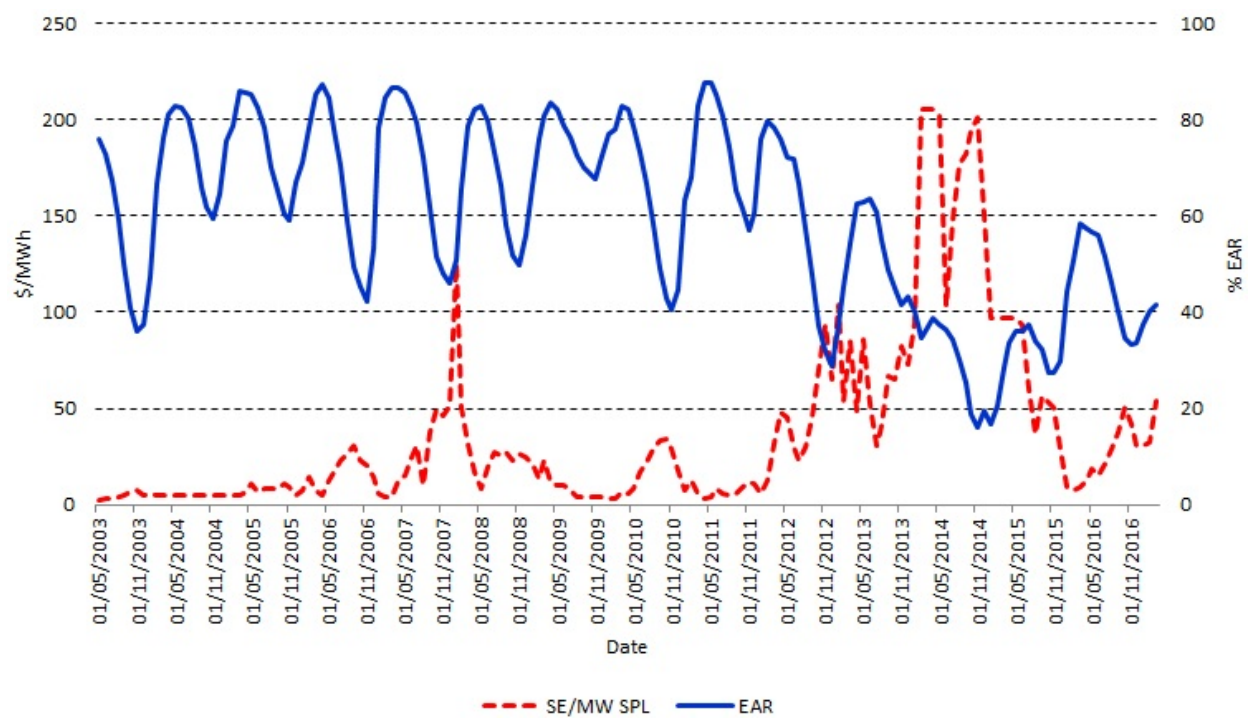

Figure 2.3: Monthly SPD to Brazilian submarkets.

The volatility of spot prices due to hydrological variability, is what is known as hydrological risk. Hydrological risk is the probability of failure occurring on any hydraulic system attributable to extremely low or high water flows (56). These failures can be structural or operational in nature. Structural failure may be caused by a dam break, while operational failure can be caused by an excess of water, such as a flood, or a water shortage, due to a drought (57). Several authors, in Brazil and abroad, have shown that climate impact on power systems, caused by droughts, appears in the form of increased outage, reduction in generation efficiency, shortage of cooling water, higher mean water temperature and increased evaporation from water surface $(39,58,59,60,61,62,63,64,65,66)$.

In energy sales, the hydrological risk is assumed by generators or transferred to consumers depending on the following modalities of contracts:

Energy Quantity Contracts, which are generally applied to hydroelectric projects, whose energy (hydrological) risks are assumed by generators. 
Energy Availability Contracts, which are applied to thermoelectric generation, where the risks of variation of energy generation are allocated to distributors and passed on to captive consumers. In this modality of contract, the generators receive fixed revenue to cover fixed expenses with the construction of the project and, when dispatched, a variable income to cover operating costs.

In contracts for quantity, the entrepreneur is committed to deliver a certain volume of energy and will be remunerated for it, whereas in the contracts by availability the generators will be dispatched only when it is necessary and at the request of the system operator. Then, in contracts by availability, the distributors assume the hydrological risk and eventual financial exposures in the spot market, with the right of passing on tariffs to final consumers in the annual tariff adjustment.

\section{3}

\section{Physical guarantee}

A relevant detail of energy arrangements is that the generators are not allowed to market all the energy the plant is able to generate, being limited to selling an amount of energy that corresponds to a portion of its maximum generation capacity (67). Therefore, there is a difference between the plant's capacity and the energy that can be contracted.

The commercialization of energy is backed by the generation physical ability, i.e., the Physical Guarantee (PG) is the maximum amount of power, in MW, that the generators are allowed to sell in contracts. Each generator receives from the MME an amount of physical guarantee that can be sold to back up consumption. The physical guarantee is the basis for long-term contracts. After receiving the PG certificate, the entrepreneur may select to sell the entire $\mathrm{PG}$ of the plant or part of it in the regulated market, being possible to negotiate the surplus in the free contracting environment.

The physical guarantee is calculated by the EPE using an official methodology, currently established by the ordinance $n^{\circ} 268$ from MME as of 2008, and simulations performed on the Newave and MSUI (Modelo de Simulação a Usinas Individualizadas) models. The physical guarantee of the NIS is defined as the highest load that can be met, given a set of generators (hydroelectric, thermoelectric), while meeting a criterion of guarantee of supply (annual risk of deficit of less than 5\%) and an economic criterion, based on equality between the cost of expanding the system by building new plants, i.e, the Marginal Cost of Expansion (MCE), and the Marginal Cost of Operating (MCO) the system (68). 
Simulations of the operation of the hydrothermal system, from the Newave model, is used to determine the total energy supply for the year of interest. The total supply is distributed in two large blocks of energy, hydro supply and thermal supply, by multiplying the total energy supply, respectively, by a hydropower factor and a thermal factor, which correspond to the share of hydro and thermal generation in total generation. The allocation of the hydro supply, then, is made to each plant in function of its firm energy. The thermal block is divided to each plant in function of its generation resulting from the Newave simulation (68).

Figure 2.4 shows the calculation of the physical guarantee. It is based on the study by which the MME legally defines the physical guarantee of each new plant, authorizing the commercialization of the corresponding energy in the auctions of new energy.

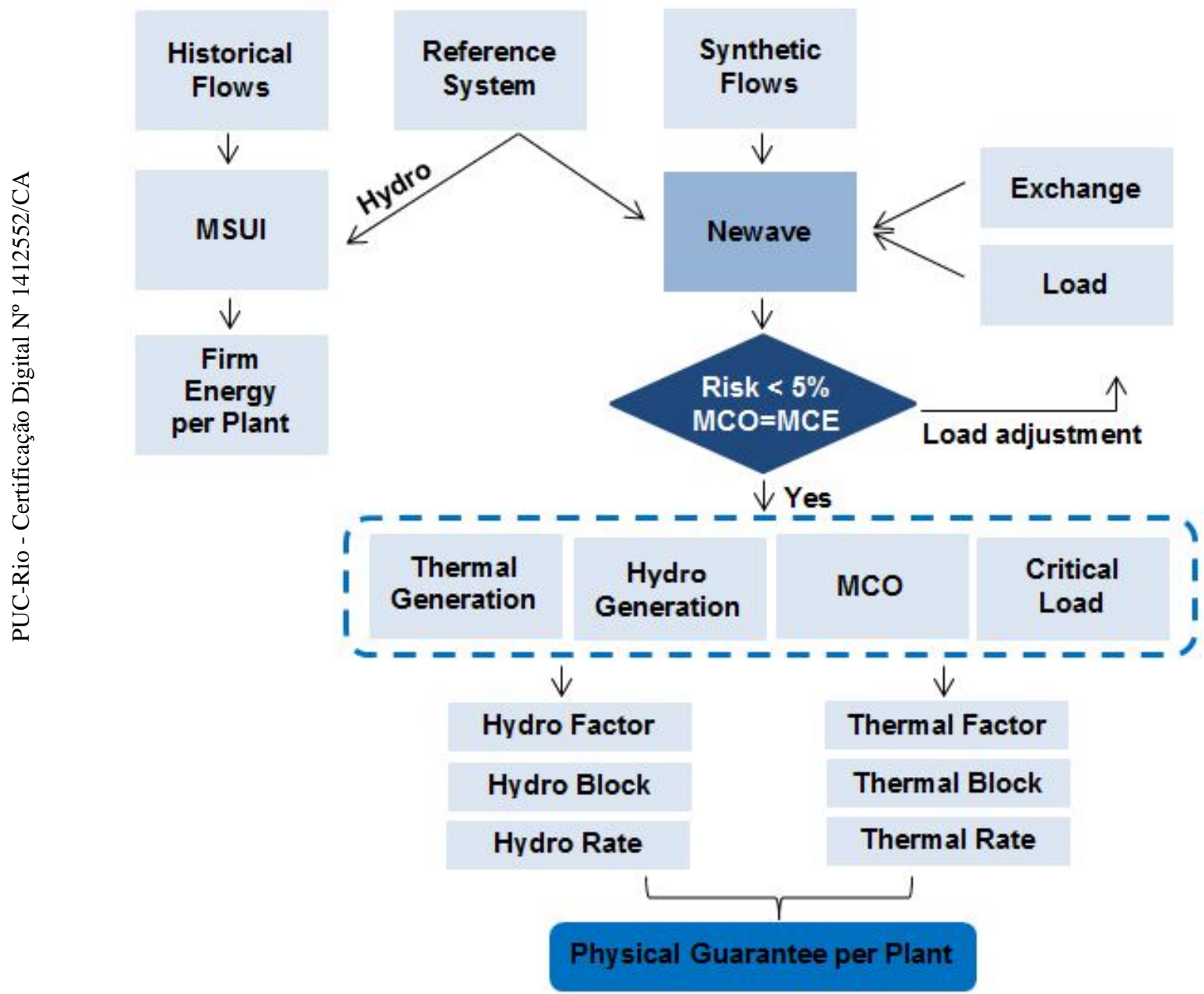

Source: Adapted from (11).

Figure 2.4: Calculation of the physical guarantee.

The PG must be reviewed on a periodic basis (every five years), according to Decree $N^{\circ} 2.655 / 1998$, or extraordinarily if, for example, changes occur in the physical operating characteristics of the plant. In any case, reductions in 
the physical guarantees are limited by $5 \%$ at each revision and by no more than $10 \%$ of the value defined in the concession agreement (11).

\section{4}

\section{Energy Reallocation Mechanism}

As the operation decision of the NIS's hydroeletric plants is due to the ONS, the hydropower generators are exposed to financial risks once they have contractual obligations of supplying energy with consumers. In a contract by quantity, the agent assumes the risk of volume, which means that if it does not generate sufficient energy to fulfill the contract, it should buy energy in the spot market, with a possibly high spot price. The hydroelectric plant has, therefore, risks at both ends: if it is under-contracted, it is exposed to low prices in the spot market; and if it is heavily contracted, it is exposed to the risk of being forced to buy energy at high prices (69).

In light of this, in 1998 a Energy Reallocation Mechanism (ERM) was created to address the issue of hydrological risks for hydropower generators, protecting them from eventual spot price exposures (70). The ERM is compulsory for all hydroelectric plants that are dispatched centrally by the ONS. Small hydropower plants' (SHPs) entrepreneurs choose to either participate in this mechanism or not.

This instrument incorporates a set of rules for the transfer of energy among plants belonging to the ERM, or the hydroelectric "club" (71). In other words, the main objective of the ERM is the distribution of gains when generation is satisfactory and there is minimization of losses during periods of unfavorable hydrology. The ERM reallocates the energy, transferring the surplus of the hydroelectric plants that generated beyond their physical guarantees in a period of commercialization to those that generated below. Figure 2.5 presents an example where a plant would be donating energy to the ERM between November and March and would be receiving energy from the ERM between April and August. The ERM, thus, provides the hydroelectric plants their levels of physical guarantee for the contracts. 


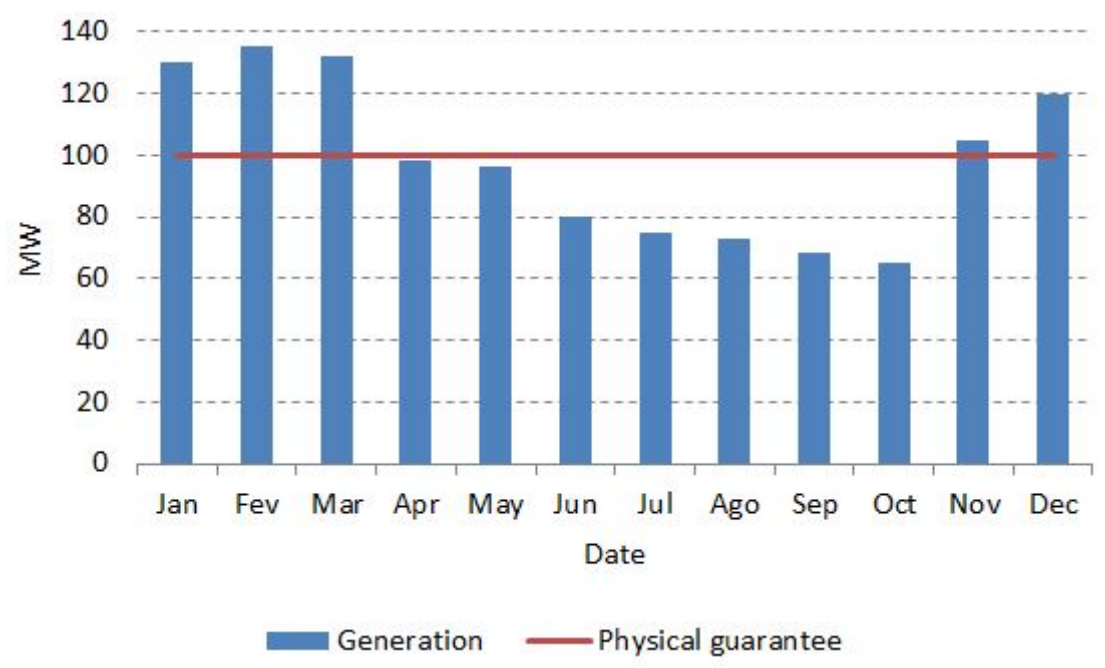

Figure 2.5: Physical guarantee and real generation.

A monthly analysis is done in order to check whether the total generation of the ERM was sufficient to meet the physical guarantee of all participants (72). The monthly adjustment of the ERM is based on a factor known as GSF (Generation Scaling Factor), calculated in each period, $\tau$, by the ratio between the generated energy $(G)$ and the physical guarantee $(P G)$ in the ERM,

$$
G S F_{\tau}=\frac{G_{\tau}}{P G_{\tau}}
$$

GSF >1: there will be a surplus of energy, called Secondary Energy (SE), to be apportioned by the ERM members in proportion to their PGs.

$\mathbf{G S F}=\mathbf{1}$ : the ERM generation is exactly equal to the sum of the plant's physical guarantees, which means the participating agents will be able to comply with their contracts without any financial gain or loss in the spot market.

GSF $<1$, the system will be deficient and this lack of energy is also distributed among all members of the ERM in the proportion of their PGs. In this situation, the agents may be deficient in relation to their contracts and must liquidate the deficit in the spot market.

The ERM is able to diversify part of the hydrological risk, since the total hydropower generation of the NIS is much less volatile than the individual generation. However, as already mentioned in other studies $(73,74)$, the ERM does not totally eliminate the risks of exposure to the spot market. In cases where the hydrological conditions are extremely severe, the whole system will be affected, resulting in all the plants participating of the ERM generating an amount of energy below their physical guarantee and buying the energy deficit in the spot market to cover their contractual obligations to a high SPD. In 
this sense, hydrological risk management is an important component in the business analysis of hydroelectric generating agents.

The variable costs associated with the operation and financial compensation for the use of water, related to the generation of energy that is reallocated within the ERM, are reimbursed by the Optimization Energy Tariff (OET or Tarifa de Energia de Otimização) associated to each plant participating in the mechanism. This rate, stipulated in $11.58 \mathrm{R} \$ / \mathrm{MWh}$ by ANEEL for the year 2017, has the objective to cover the incremental costs of operation and maintenance of hydroelectric plants and the payment of the financial compensation related to energy exchanged in the ERM (75).

\subsection{1}

\section{Application of ERM}

To better understand the ERM dynamics, this section illustrates three cases, each one for the situation where the GSF is equal, greater and smaller than 1. According to the ERM rules, priority is given to the allocation of the energy among the plants located in the same submarket. Then, the remaining energy is made available to the plants of other submarkets. For simplicity, the NIS is divided into two submarkets with a total of four plants, all with the same physical guarantee.

\section{- Example 1: $G S F=1$}

Suppose that the hydropower generation and the physical guarantee, in GW, in a given period are equal to the values shown in Table 2.1. In this case, note that the total generation of the two submarkets ensures the PG of the ERM. As result, the GSF is equal to the unit $(G S F=1)$.

Table 2.1: Comparison of PG and generation in GW per submarket: GSF $=1$

\begin{tabular}{lccc|c|ccc}
\hline Plants & Submarket & Generation & $\begin{array}{c}\text { Physical } \\
\text { Guarantee }\end{array}$ & GSF & $\begin{array}{c}\text { Allocation of } \\
\text { generation in } \\
\text { submarket 1 }\end{array}$ & $\begin{array}{c}\text { Allocation of } \\
\text { generation in } \\
\text { submarket 2 }\end{array}$ & $\begin{array}{c}\text { Generation } \\
\text { plus allocated } \\
\text { physical guarantee }\end{array}$ \\
\hline P1 & 1 & 130 & 100 & & -30 & 0 & 100 \\
P2 & 1 & 60 & 100 & 1.0 & 30 & 10 & 100 \\
P3 & 2 & 120 & 100 & & 0 & -20 & 100 \\
P4 & 2 & 90 & 100 & 0 & 10 & 100 \\
\hline Total & 400 & 400 & & 400 \\
\hline
\end{tabular}

Figure 2.6 shows the comparison between the PG and the total generation of the two submarkets presented in Table 2.1. In this example, the plants P1 and P3 generate energy beyond the PG, while P2 and P4 have energy deficit. Consequently, the first submarket has an energy deficit of $10 \mathrm{GWd}$, while the second submarket has an energy excess of $10 \mathrm{GW}$. The energy excess of the 
second submarket is, then, transferred to the first submarket. As the plants P1 and P3 generate more than the PG, the OET fee reimburses them.
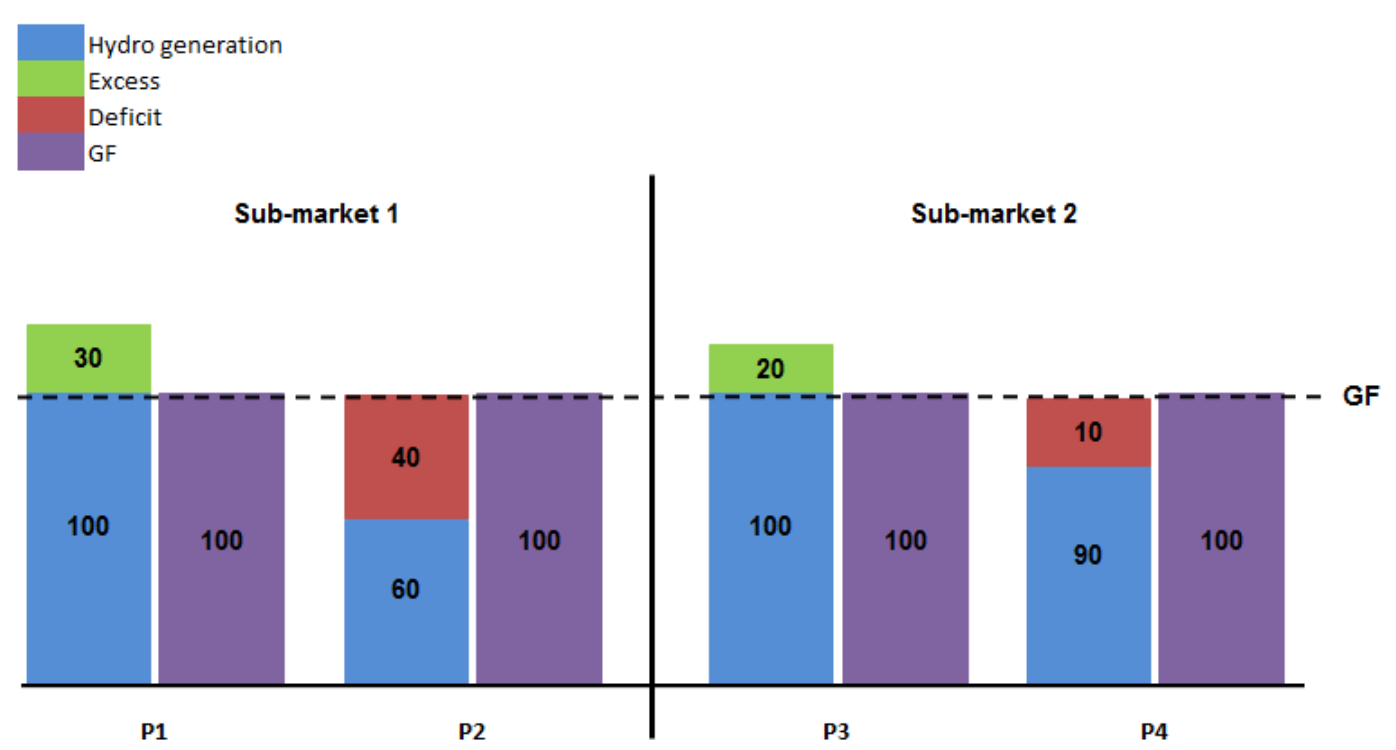

Figure 2.6: Comparison between ERM generation and PG when $G S F=1$.

\section{- Example 2: $G S F>1$}

Suppose now that the hydropower generation and the physical guarantee, in GW, in a given period are equal to the values shown in Table 2.2. In this case, the total generation of the two submarkets is greater than the PG of the ERM, resulting in a GSF of 1.05. Note that, since the GSF is larger than the unit, there is secondary energy for all ERM participating plants, including those that generated below their PG. The total secondary energy of the system, which is $20 \mathrm{GW}$, is distributed among all the plants proportionally to its PG.

Table 2.2: Comparison of PG and generation in GW per submarket: GSF > 1

\begin{tabular}{lccc|c|ccccc}
\hline Plants & Submarket & Generation & $\begin{array}{c}\text { Physical } \\
\text { guarantee }\end{array}$ & GSF & $\begin{array}{c}\text { Allocation of } \\
\text { generation in } \\
\text { submarket 1 }\end{array}$ & $\begin{array}{c}\text { Allocation of } \\
\text { generation in } \\
\text { submarket 2 }\end{array}$ & $\begin{array}{c}\text { Generation } \\
\text { plus allocated } \\
\text { physical guarantee }\end{array}$ & $\begin{array}{c}\text { Allocation of } \\
\text { secondary } \\
\text { energy }\end{array}$ & $\begin{array}{c}\text { General } \\
\text { power } \\
\text { allocation }\end{array}$ \\
\hline P1 & 1 & 140 & 100 & & -40 & 0 & 100 & 5 & 105 \\
P2 & 1 & 50 & 100 & 1.05 & 40 & 10 & 100 & 5 & 105 \\
P3 & 2 & 140 & 100 & & 0 & -40 & 100 & 5 & 105 \\
P4 & 2 & 90 & 100 & & 0 & 10 & 100 & 5 & 105 \\
\hline Total & 420 & 400 & \multicolumn{5}{|r}{} \\
\hline
\end{tabular}

Figure 2.7 shows the comparison between the PG and the total generation of the two submarkets presented in Table 2.2. Here, the energy excess, of 30 GW, of plant P1 is transferred to plant P2, since they belong to the same submarket. Next, the energy excess of plant P3, of $40 \mathrm{GW}$, is first transferred to plant P4, to cover its deficit of $10 \mathrm{GW}$, and then transferred to plant P2, to cover its deficit of $10 \mathrm{GW}$. The secondary energy, of $20 \mathrm{GW}$, is distributed 
among the NIS plants. Regarding the energy excess, the plant P1, for example, has the right to receive $35 \cdot O E T+5 \cdot S P D$.

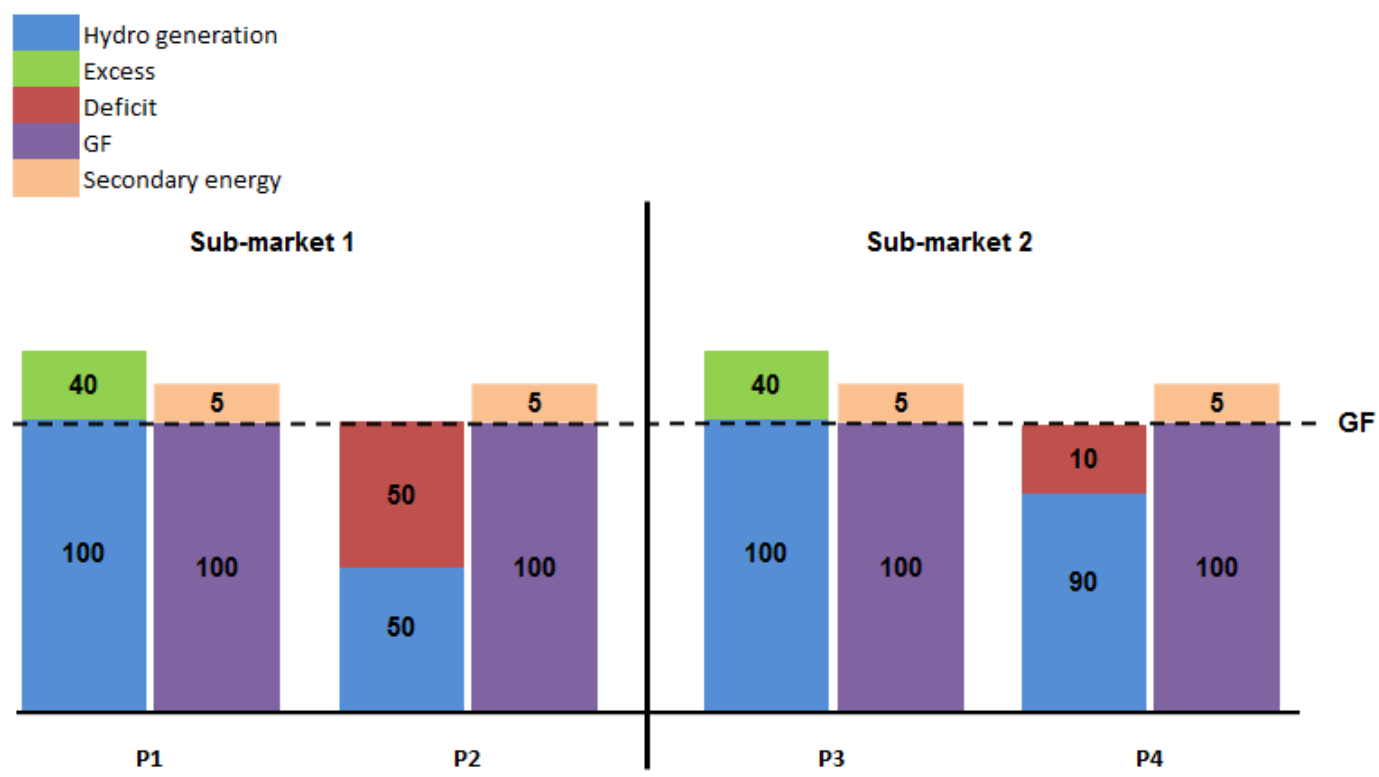

Figure 2.7: Comparison between ERM generation and PG when GSF $>1$.

\section{- Example 3: $G S F<1$}

Finally, suppose that the hydropower generation and the physical guarantee, in GW, in a given period are equal to the values shown in Table 2.3. In this case, the total generation of the NIS is not enough to meet the PG of the system, resulting in a GSF of 0.90 . The physical guarantee of the plants, in this situation, is reduced in all submarkets, by applying the adjusted PG.

Table 2.3: Comparison of PG and generation in GW per submarket: GSF $<1$

\begin{tabular}{lccc|c|cccc}
\hline Plants & Submarket & Generation & $\begin{array}{c}\text { Physical } \\
\text { guarantee }\end{array}$ & $\begin{array}{c}\text { Adjustment } \\
\text { factor } \\
\text { GSF }\end{array}$ & $\begin{array}{c}\text { Adjusted } \\
\text { Physical } \\
\text { guarantee }\end{array}$ & $\begin{array}{c}\text { Allocation of } \\
\text { physical guarantee } \\
\text { in submarket 1 }\end{array}$ & $\begin{array}{c}\text { Allocation of } \\
\text { physical guarantee } \\
\text { in submarket 2 }\end{array}$ & $\begin{array}{c}\text { Generation } \\
\text { plus allocated } \\
\text { physical guarantee }\end{array}$ \\
\hline P1 & 1 & 100 & 100 & & 90 & -10 & 0 & 90 \\
P2 & 1 & 70 & 100 & 0.90 & 90 & 10 & 10 & 90 \\
P3 & 2 & 110 & 100 & & 90 & 0 & -20 & 90 \\
P4 & 2 & 80 & 100 & & 90 & 0 & 10 & 90 \\
\hline Total & \multicolumn{7}{c}{400} \\
\hline
\end{tabular}

Note from Figure 2.8 that after the internal energy allocations, the remaining energy (surplus) is reallocated to the plants with energy deficit and even so, the plants do not reach the PG of the ERM. The physical guarantee, in this case, is set to a lower level to all the plants of the system, including those that generated above its PG. The plant P1, for example, should buy 10 GW in the spot market to fulfill its contract, despite generating its PG. 


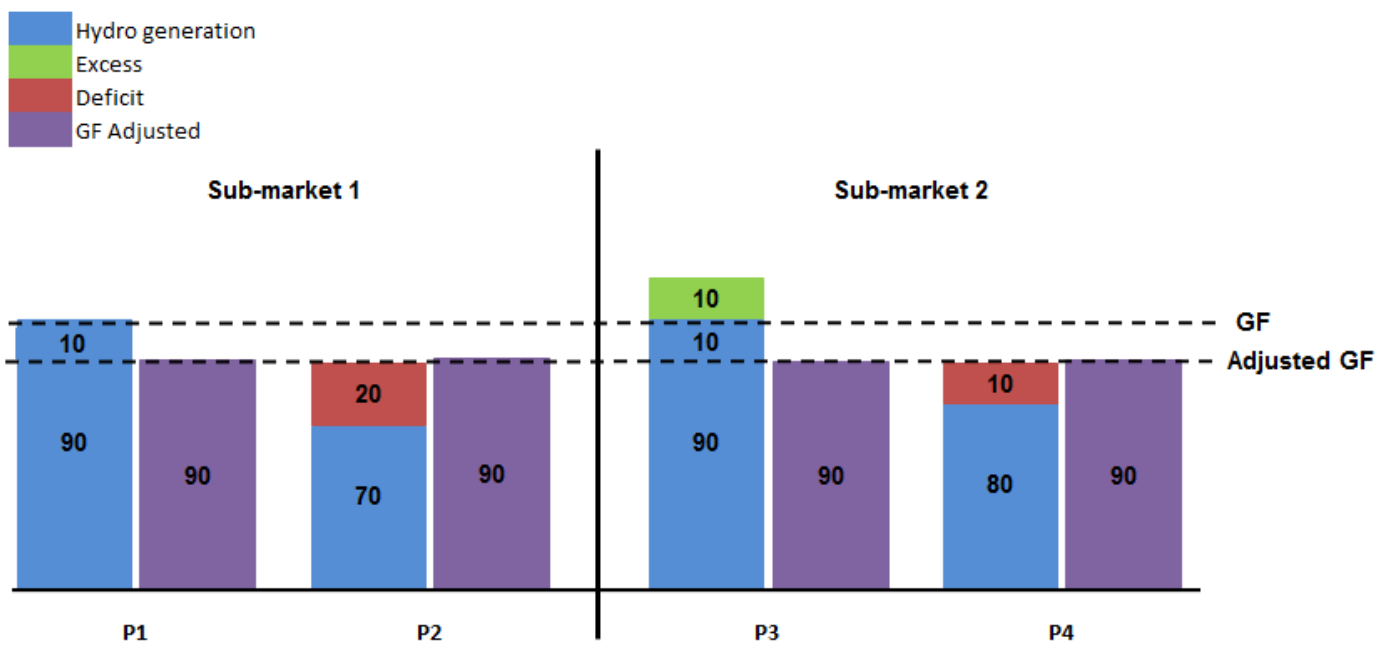

Figure 2.8: Comparison between ERM generation and $\mathrm{PG}$ when $G S F<1$.

\section{5}

\section{Exposure to non-hydrological risks}

In the last years, the ERM generating agents have faced, in addition to hydrological risks, negative externalities that have been reducing their generation. In the Technical Note $N^{\circ} 038 / 2015$ of ANEEL some reasons why the hydroelectric generation has been reduced are described (41). According to the Note, a number of regulatory issues related to the expansion planning and the operation of the system would be causing too much exposure of hydropower agents to the spot market, such as:

- The creation of the Reserve Energy in 2008, to increase security in the supply of energy to NIS, have became a negative externality for hydroelectric plants, since the dispatch of this type of energy is a priority to that of hydroelectric plants;

- The auctions of Alternative Sources initiated in 2007 have also reduced hydro generation, since wind generation is dispatched as a priority. Note that the insertion of other sources into the Brazilian energy matrix, especially renewable sources such as wind, solar and biomass, is very important and strategic for the country, however, it is fundamental to recognize its negative impacts on the ERM;

- The alteration of the Minimum Flow Limits of the national rivers, reduces the hydrpower generation, although it aims to preserve the reservoirs level;

- The dispatch of Thermoelectric generation outside the Order of Merit of cost reduced the hydropower generation. 
- The uncertainties regarding the review of the physical guarantee of the existing projects, in principle scheduled for 2004 and then postponed to 2016 ;

- The reduction of the energy demand in 2015, associated with the stagnation of the economic growth and the increase of tariffs due to the hydrological crisis.

All these aspects have an affect in the generation of the ERM hydroelectric plants, exposing the generating agents to risks not only related to the lack of water, but also to other exogenous factors.

Figure 2.9 shows the expected evolution of the NIS's installed capacity by generation source for future years. According to the government's energy expansion plan (49), despite the continued predominance of water in the Brazilian energy matrix, it is expected that in 2024 the generation of hydropower drops to approximately $53 \%$ of the total energy capacity. Moreover, by the end of this period, it is expected the double of the thermal plants' capacity and that the generation of alternative energies, such as biomass, wind, solar and SHP, increases by more than $150 \%$.

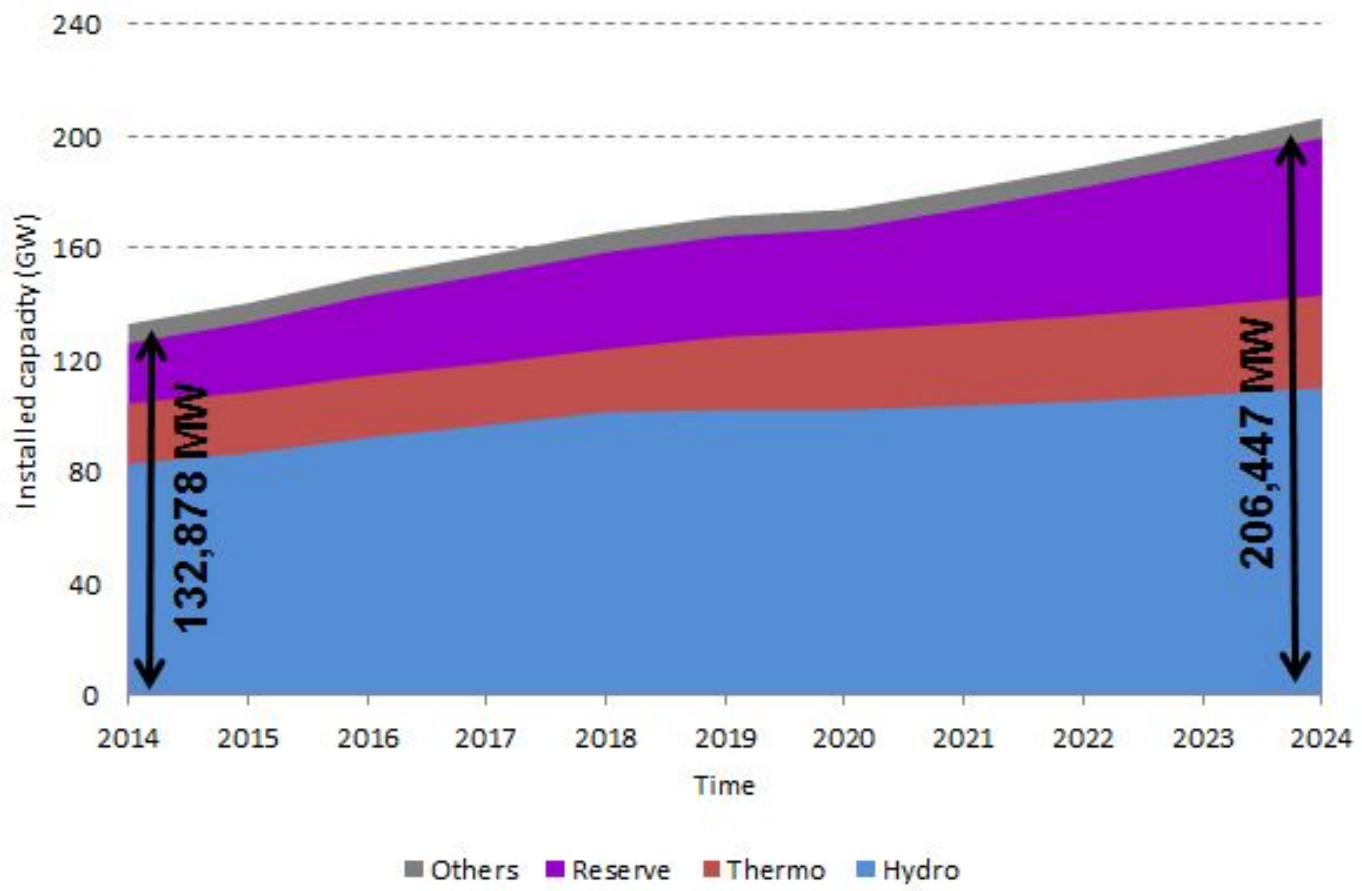

Source: Adapted from PDE 2024 (49).

Figure 2.9: Evolution of the NIS's installed capacity. 


\section{6}

\section{Renegotiation of the hydrological risk}

The hydrological risk renegotiation is a measure created by the Brazilian Government, by the Provisional Measure $N^{\circ} 688$ of August 18, 2015, then transformed into Federal Law $\mathrm{N}^{\circ}$ 13.203, to mitigate the financial losses suffered by the ERM participating hydropower generating agents caused by a non-manageable exposure to hydrological risk $(76,77)$. This law proposes to renegotiate the hydrological risk from the negative balance accumulated in 2015, as long as the generators accept the requirements of ANEEL.

Hydropower agents with contracts in both the RCE and the FCE can renegotiate the hydrological risk of their plants. In the $\mathrm{RCE}$, the agents must have contracts of energy sale with a power distribution concessionaire of at least one year. The plants that can renegotiate the hydrological risk in the FCE are those who weren't sold in the RCE and those that do not meet the criteria defined for the regulated environment $(78,79)$.

The renegotiation in the regulated contracting environment is similar to an insurance linked to a fund offered to the generating agents participating in the ERM so that in times of unfavorable hydrology they do not suffer great losses, either by the operational decisions of the ONS due to the lack of water resources or any other decision made at the time. Thus, like any insurance, the renegotiation of the hydrological risk requires the payment of a premium to the tariffs account (or conta bandeira), in exchange for the benefits offered.

The generators may choose to renegotiate any of the following product classes: (i) class $\mathrm{P}$, in which the generators remain with the property of the secondary energy; (ii) class SP, in which the secondary energy is also transferred to the consumer; (iii) class SPR, in which, in addition to the secondary energy, the generators transfer to the consumers the risk of reduction of the physical guarantee. For the classes $\mathrm{P}$ and SP, the generators must define the level of insufficiency ( $f$ ) of generation of the ERM that it will undertake, established between zero and $11 \%$, and for the class SPR the factor $\mathrm{f}$ will be zero. Table A.1, in appendix, shows the premium values for each level of protection offered in each product class.

\section{7}

\section{Risk Management}

According to Jin and Jorion (80), the art of managing risk is to decide which elements are important for the model. The electricity sector presents risks in all stages from generation, transmission until its final consumption and it is up to the agents to assess these risks and define how to control them 
(81). Risk aversion techniques can be used to control risks for the managers in the Brazilian electricity sector. Through these tools, a hydroelectric generating agent can define the reservoir operation and the sale decision policies in order to avoid low financial performance at the end of a pre-defined period (82).

A widely used risk measure is the Value at Risk (VaR). Generally, the definition of $\mathrm{VaR}$ is given as the maximum loss, which should not be exceeded during a specified period of time with a given probability level $(83,84)$. $\operatorname{VaR}_{t}^{d}(1-\alpha)$ denotes the loss (taken with a positive sign) which should not be exceeded during the period of $d$ business days with probability $1-\alpha$, as can be seen in Equation 2-1.

$$
P\left(X^{d} \leq-\operatorname{VaR}_{t}^{d}(1-\alpha)\right)=\alpha
$$

where $X^{d}$ denotes the change in the portfolio value during the period of $d$ business days. In typical examples, we often consider $d=10$ days and $\alpha=5 \%$ or $\alpha=1 \%$ ( $\alpha$ is the probability of a loss exceeding VaR).

VaR depends on the volatility of value of the investment. Assume that the profit and loss distribution during a period of $d$ business days is known. Then $\operatorname{VaR}_{t}^{d}(1-\alpha)$ can be calculated as the $\alpha$ quantile of this distribution (taken with the opposite, i.e. positive sign), as shown in Equation 2-2.

$$
\operatorname{VaR}_{t}^{d}(1-\alpha)=-\sup \left\{x \in \mathbb{R} \mid P\left(X^{d} \leq x\right) \leq \alpha\right\}
$$

The VaR, however, does not respect some requirements, which makes the use of VaR not the most appropriate measure for energy markets. Let $X$ be a stochastic variable on the set $G$, where $G$ is the set of all possible outcomes. In our case this is all possible risks. A risk measure, $\rho$, then is the mapping:

$$
\rho: G \rightarrow \mathbb{R}
$$

According to Artzner et al. (85), a risk measure is coherent if the following properties are fulfilled: (1) Monotonicity, $\forall X_{1}, X_{2} \in G$ such that $X_{1} \leq X_{2}$, we have that $\rho\left(X_{2}\right) \leq \rho\left(X_{1}\right)$; (2) Positive homogeneity, if $\alpha \geq 0$ and $X \in G$ then $\rho(\alpha \cdot X)=\alpha \cdot \rho(X)$; (3) Sub-additivity, if $X_{1}, X_{2} \in G$ then $\rho\left(X_{1}+X_{2}\right) \leq \rho\left(X_{1}\right)+\rho\left(X_{2}\right)$; (4) Translation Invariance, if $X \in G$ and $\alpha \in \mathbb{R}$ then $\rho(X+\alpha)=\rho(X)-\alpha$. The $V a R_{\alpha}$ function does not respect the convexity requirement, even when revenues are convex. VaR does not capture the impact of the company's results when extreme events occur: there is always the possibility to occur outliers that should be considered when measuring risk.

The Conditional Value-at-Risk (CVaR), proposed by Rockafellar and Uryasev (86), becomes, therefore, one of the most widely used risk measures 
for three reasons: first, it is a coherent risk measure; second, it has a clear and suitable economic interpretation $(87,88)$; and last, but not least, it can be written as a linear stochastic programming model. For these reasons, the CVaR has been applied to static and even to dynamic model.

Suppose there exist $n$ risky assets for an investor to construct portfolios. Let the random vector $y=\left(y_{1}, \ldots, y_{n}\right)^{T} \in \Re^{n}$ denote uncertain returns of the $n$ assets, and $x=\left(x_{1}, \ldots, x_{n}\right)^{T} \in X \subseteq \Re^{n}$ denote the amount of the portfolio to be invested in the $n$ risky assets, where means transposition. Then the portfolio return is defined as $x^{T} y$, and the loss function is the negative of the return, i.e., $f(x, y)=-x^{T} y . \pi(y)$ is the probability distribution. The CVaR is defined as the conditional expectation of the loss of the portfolio exceeding or equal to VaR, i.e.,

$$
C \operatorname{VaR} R_{\alpha}(x, \pi)=\frac{1}{1-\alpha} \int_{f(x, y) \geq \operatorname{VaR}(x, \pi)} f(x, y) \pi(y) d y
$$

The risk of the investment can also be defined as the difference between the potential loss and what is expected (89),

$$
\operatorname{risk}(\tilde{R})=E[\tilde{R}]-C V a R_{\alpha}(\tilde{R})
$$

Where $\tilde{R}$ refers to the generators' revenues and $\alpha$ is a risk aversion parameter. 


\section{Redesigning Energy Contracts in Brazil}

\section{1}

\section{Financial accounts settlements}

The generation required by the national system is driven by the demand for electricity $(d)$ in time $\tau$ (Equation 3-1), and is equal to the sum of the generation of hydroeletric plants $\left(g_{h}\right)$, thermoelectric plants $\left(g_{t}\right)$ and nuclear $\left(g_{n}\right)$. We assume that all these plants are part of the integrated national power grid and are subject to ONS dispatch.

$$
d_{\tau}=g_{h, \tau}+g_{t, \tau}+g_{n, \tau}
$$

Captive consumers, represented by the power distribution companies, are required to purchase all the energy needed to meet their expected full load demand. As shown in Equation 3-2, the total energy purchased in auctions $\left(q_{c}\right)$ is broken down by source: hydroeletric plants $\left(q_{h}\right)$, thermoeletric units $\left(q_{t}\right)$ and nuclear $\left(q_{n}\right)$.

$$
q_{c, \tau}=q_{h, \tau}+q_{t, \tau}+q_{n, \tau}
$$

Nuclear, in this thesis, refers to the energy that is part of the base of the Brazilian energy system (BES), also called existing quantity, and which is generated by nuclear, wind, solar and biomass plants. This energy has priority for dispatch over other sources. The generation of thermoelectric plants depends on fuel costs and electricity spot prices. If fuel costs are lower than the spot price, thermal units are dispatched; otherwise, they remain idle and existing hydroeletric plants are dispatched to meet the demand.

The cost of these contracts to consumers $\left(c_{c}\right)$ is the sum of the costs of all contracted plants that were dispatched, plus the net result of spot market CCEE settlements. Therefore, the national cost of power generation for consumers is the sum of the hydro generation cost $\left(c_{h}\right)$, the thermal power generation cost $\left(c_{t}\right)$, the nuclear generation cost $\left(c_{n}\right)$ and the consumers' result from CCEE $\left(\right.$ res $\left._{c}\right)$, as shown in Equations 3-3 to 3-9. 


$$
\begin{gathered}
c_{c, \tau}=c_{h, \tau}+c_{t, \tau}+c_{n, \tau}+\operatorname{res}_{c, \tau} \\
c_{h, \tau}=q_{h, \tau} \cdot p_{h, \tau} \\
c_{t, \tau}=c_{t, \tau}^{x}+c_{t, \tau}^{v} \\
c_{t, \tau}^{x}=q_{t, \tau}^{x} \cdot p_{t, \tau}^{x} \\
c_{t, \tau}^{v}=\sum_{j=1}^{J} i c_{j} \cdot u v c_{j} \\
c_{n, \tau}=q_{n, \tau} \cdot p_{n, \tau} \\
r e s_{c, \tau}=\left(q_{h, \tau}+q_{n, \tau}+g_{t, \tau}-d_{\tau}\right) \cdot p_{m, \tau}
\end{gathered}
$$

where $p_{h}, p_{t}$ and $p_{n}$ are, respectively, the prices of the hydropower, thermal and nuclear auctions, $p_{m}$ is the spot market price, $c_{t}^{x}$ and $c_{t}^{v}$ are, respectively, the fixed and variable cost of the termoeletric plants, uvc is the thermal units variable cost and $i c$ refers to the installed capacity of termoeletric plants $j(j=1, \ldots J)$. The variable cost only occurs when the termoeletric plants are dispatched.

The costs of hydro and nuclear power are fixed, but the generation cost of termoeletric plants varies with the amount of power that is dispatched by ONS. Thus, both thermal cost $\left(c_{t}\right)$ and consumers' result $\left(r e s_{c}\right)$ are subject to the operation of the system. In addition, if the national generation is above the system demand, $\operatorname{res}_{c}$ always returns a positive value.

Moreover, it is important to note that there are two major agents in the BES: captive consumers, represented by the public utility companies in charge of energy distribution, and the hydropower generators. The system total cost $\left(c_{s}\right)$ is the sum of the cost of generation for consumers $\left(c_{c}\right)$ plus spot market settlement costs, i.e., the spot market result of generation for hydropower generators $\left(r e s_{h}\right)$ in time $\tau$, as illustrated in Equation 3-10.

$$
c_{s, \tau}=c_{c, \tau}+\operatorname{res}_{h, \tau}
$$

Hydropower generators earn their revenue $\left(R_{h}\right)$ in part from fixed price long-term quantity contracts, where $\left(p_{h}\right)$ is the price and $\left(q_{h}\right)$ is the amount of energy contracted. The difference between the contracted and actual energy generated $\left(g_{h}\right)$ is settled on the spot market at the prevailing price $\left(p_{m}\right)$. The financial settlement of spot market sales of hydropower generation above or below contracted levels is done by the CCEE.

Given that the operating cost for hydro generation is negligible, as there are no fuel costs, net income is assumed to be equal to net revenues, as shown 
in Equation 3-11.

$$
R_{h, \tau}=p_{h, \tau} \cdot q_{h, \tau}+\left(g_{h, \tau}-q_{h, \tau}\right) \cdot p_{m, \tau}
$$

For simplicity, assume that all physical guarantee $(P G)$ is contracted, i.e., $P G$ is equivalent to $q_{h}$, the generators receive a fixed income for it. The generation, however, is uncertain and may vary over time. It is important to mention here that an usual way to mitigate the hydrological risk is contracting less than the physical guarantee. In this case, our model could easily be adapted to support this hedge mechanism by adjusting the contract by water availability.

As shown in Equation 3-12, if the national generation exceeds the total physical guarantee of the system there is a power surplus, or secondary energy $(S E)$. This excess can be sold in the spot market in benefit of the generators. On the other hand, if the total national hydropower generation turns out to be less than the physical guarantee, as may occur if there is insufficient rainfall, hydropower generators must purchase their energy shortfall in the short-term market. In both cases, the difference between the generation and the physical guarantee is settled in the spot market at the prevailing price.

$$
S E_{\tau}=\left\{\begin{array}{rll}
g_{h, \tau}-P G_{h, \tau}, & \text { if } \quad g_{h, \tau}>P G_{h, \tau} \\
0, & \text { if } \quad g_{h, \tau} \leq P G_{h, \tau} .
\end{array}\right.
$$

The financial result of hydropower generation is conditional on whether the generation is above or below the physical guarantee (Equation 3-13), which is verified by the CCEE. Equation 3-14 shows the Generation Scaling Factor $(G S F)$ that measures the ratio of the total hydropower generation of the system to the total national physical guarantee.

$$
\begin{gathered}
r e s_{h, \tau}=\left(G S F_{\tau}-1\right) \cdot P G_{h, \tau} \cdot p_{m, \tau} \\
G S F_{\tau}=\frac{g_{h, \tau}}{P G_{h, \tau}}
\end{gathered}
$$

Note that if GSF is lower than 1, hydropower generators will suffer financial losses; otherwise, they will obtain a positive result by selling the excess energy in the spot market. Since these plants can only generate if dispatched by the systems operator, the operation of the BES by ONS has financial consequences for hydropower generators.

\section{2}

\section{The model redesign}

This work proposes that the current confidence level of hydropower generation be raised from $95 \%$ to $99 \%$, thus reducing the risk that hydropower 
generators will be unable to meet their load requirements. This can be achieved by lowering the amount of energy the hydropower generators sell through quantity contracts, from the current "assured" to the "firm" energy level. As previously noted, the "assured" energy level, which is also known as the physical guarantee of the plant, is the maximum generation that can be continuously maintained assuming a 5\% risk of failure, and tends to represent approximately $50 \%$ of the installed capacity of the plant. On the other hand, the "firm" level of energy is the average energy during a historical critical period. This means that despite the low probability, due to the annual hydrological cycle, there is a risk of $1 \%$ of deficit.

This work proposes the difference between the "assured" and "firm" energy be contracted per availability (Fig. 3.1). As a reduction of the amount of energy sold through quantity contracts also reduces the potential revenue for hydropower generators, the contract by availability ensures a level of revenue at least equal to the current contract. In addition, the proposed change in the design of the hydroelectric contracts gives the consumer the right over the secondary energy. The idea of this model is that during wet periods the hydropower will be dispatched and the secondary energy is transferred to the consumer, while during dry periods, if the hydropower generation is low due to adverse hydrological conditions, there will be no penalty for the generators.

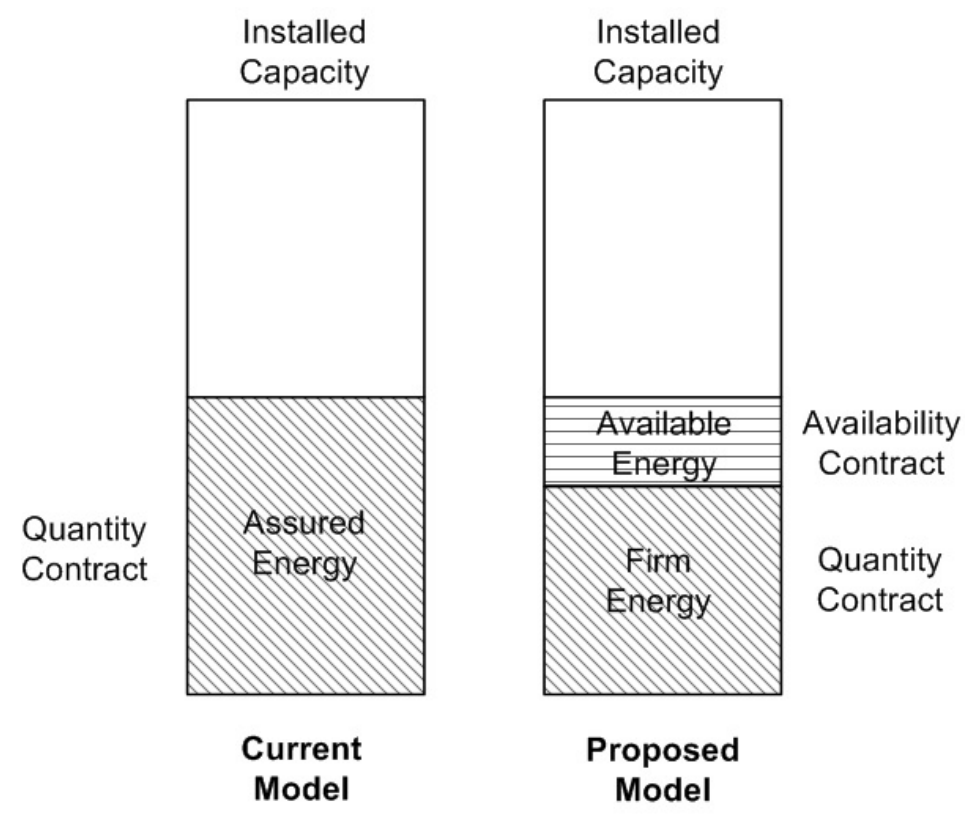

Figure 3.1: Model Comparison

The solution proposed here also helps close the gap between ONS operations and CCEE financial settlements. As shown in eq. 3-15, a portion of 
the hydropower generators physical guarantee will be auctioned per quantity $\left(q_{h}^{f}\right)$ as is currently done, and the remainder auctioned per availability. This way, the financial switch between hydro and thermal power becomes possible.

$$
\begin{gathered}
q_{h}=\alpha_{1} q_{h}+\alpha_{2} q_{h} \\
q_{h}^{f}=\alpha_{1} q_{h} \\
q_{h}^{a}=\alpha_{2} q_{h}
\end{gathered}
$$

Where $\alpha_{i}, i=1,2$, are constants of the model that represents the weight of each contract modality in the total contract of the generators and $\sum_{i} \alpha_{i}=1$.

The intuition of the model is shown in Equation 3-16, where $g^{a}$ is the hydropower dispatched from the available portion that will be switched $(S W)$ with the energy from thermal sources. The firm energy generation is the total hydro energy that can be generated considering the minimum flow of Brazilian rivers even in periods of prolonged drought. The difference between firm energy and the physical guarantee is the available portion. In other words, the switch is triggered whenever the generation is greater than the contract of firm energy.

$$
S W=\left\{\begin{array}{lll}
g_{h, \tau}^{a}>0 \text { and } g_{t, \tau}=0, & \text { if } \quad p_{m, \tau}<u v c_{1}, \\
g_{h, \tau}^{a}=0 \text { and } g_{t, \tau}=\sum_{j=1}^{J} g_{j, \tau}, & \text { if } \quad p_{m, \tau} \geq u v c_{1} .
\end{array}\right.
$$

The adoption of this model does not require any changes in the operational side of the BES. The energy generation of the system, i.e., the demand for electricity $d$, continues to be provided by the same three sources of energy as shown by equation 3-1.

The only change occurs in the financial accounting for hydropower generators and consumers once hydropower energy sales contracts are redesigned. The current contracts are to be divided into two parts: one to account for the firm energy generation (contract by quantity $-q_{h}^{f}$ ) and one for the water availability (contract by availability $-q_{h}^{a}$ ),

$$
q_{h, \tau}=q_{h, \tau}^{f}+q_{h, \tau}^{a}
$$

The new hydropower's revenue $\left(R^{*}\right)$ is the sum of a quantity contract and an availability contract, as shown in Equation 3-17. Hereafter, the asterisk indicates the proposed model.

$$
R_{h, \tau}^{*}=p_{h, \tau}^{f} \cdot q_{h, \tau}^{f}+p_{h, \tau}^{a} \cdot q_{h, \tau}^{a}
$$

where $p_{h}^{f}$ and $p_{h}^{a}$ are, respectively, the prices of the contract of quantity and availability. 
In the proposed model, the amount of energy that is negotiated in the contract by quantity is calculated considering a confidence level of $99 \%$. In this case, there is a low probability that generators will need to buy energy in the spot market during dry periods and, therefore, we consider the $G S F$ constant at 1 , as shown in equation 3-18. Importantly, the fact that there is a (low) probability of having energy deficit makes our model to coexist with the current mechanisms of energy reallocation. Because we consider a constant GSF, the settlement of hydropower energy by CCEE is zero in the proposed (see eq. 3-19) as there is no longer a shortfall or excess (secondary energy) relative to the physical guarantee of the national system. Therefore, the difference between the contracted and actual measured energy is no longer settled in the spot market, as this difference is already considered in the price of the availability contract. In other words, the result in the CCEE and, consequently, the generator's revenue and the consumer's cost in the proposed model, are deterministic with very high probability.

$$
\begin{gathered}
G S F_{\tau}^{*}=100 \% \\
r e s_{h, \tau}^{*}=\left(G S F_{\tau}^{*}-1\right) \cdot P G_{h, \tau} \cdot p_{m, \tau}=0
\end{gathered}
$$

Equations 3-20 to 3-22 show the changes in the consumers' costs. The main changes were made in the hydropower cost $\left(c_{h}^{*}\right)$ and in the CCEE settlement costs $\left(\right.$ res $\left._{c}^{*}\right)$, which now consider both contract's cost. Other costs remain the same.

$$
\begin{gathered}
c_{c, \tau}^{*}=c_{h, \tau}^{*}+c_{t, \tau}+c_{n, \tau}+r e s_{c, \tau}^{*} \\
c_{h, \tau}^{*}=q_{h, \tau}^{f} \cdot p_{h, \tau}^{f}+q_{h, \tau}^{a} \cdot p_{h, \tau}^{a} \\
r e s_{c, \tau}^{*}=0
\end{gathered}
$$

A model that increases total system cost would be inefficient, then, the model is constructed so that the net present value of the total system cost under the proposed model is equal to the cost of the current model. From now on, current model refers to the model with only contract by quantity, while proposed model indicates the model with a mix of contracts by quantity and water availability.

\section{3}

\section{Pricing the contracts}

In the electricity power market, the price of a bilateral contract is determined by the revenue that the entrepreneur is willing to accept to cover 
the cost of the project plus a profit margin (90). The cost of the spot market exposures is considered through a probabilistic form.

The issue of this thesis then is to define the price of the proposed contract by water availability, which is calculated in this section. The proposed model is marked with an asterisk. For simplicity, the subscript of time $\tau$ was omitted from all equations.

We begin the model by defining the new category of contract and the price premium as the difference between the price of electricity in quantity and availability contracts.

Assumption 1: There are two contracts possibilities for the sale of hydroelectric energy, named contract by quantity and contract by availability. The amount of energy traded in each contract is given by $q_{h}^{f}$ and $q_{h}^{a}$, respectively. The price of the contract by quantity is given by $p_{h}^{f}$ and the price of the contract by availability is $p_{h}^{a}$. The indices $a$ and $f$ refer to the availability and firm energy.

Equation 3-23 shows the price premium $(\pi)$, which is set as the difference between the price of the contract by quantity $\left(p_{h}^{f}\right)$ and the price of the contract by availability $\left(p_{h}^{a}\right)$. Here, if $\pi=0, p_{h}^{a}=p_{h}^{f}$, but, if $\pi>0, p_{h}^{a}<p_{h}^{f}$ and if $\pi<0$, $p_{h}^{a}>p_{h}^{f}$.

$$
\pi=p_{h}^{f}-p_{h}^{a}
$$

By rearranging this equation, we note that the price of the contract by availability is the difference between the price of the contract by quantity and the price premium. To calculate the price of the contract by availability, therefore, we need to estimate the price premium.

Before calculating the price premium, however, a step back is necessary to define the variations in spot market settlements and consumers' total cost between the models with different contract profiles. Assumption 2 defines the relationship between the results in the spot market of the hydropower generators and the consumers in any scenario.

Assumption 2: There is no reserve energy in our model. In other words, the result of the hydropower generators in the spot market $\left(\right.$ res $\left._{h}\right)$, in the current model, is the negative value of consumers' result $\left(r e s_{c}\right)$ in the CCEE, as illustrated by equation 3-24. A sensitivity of this assumption is conducted in section 4.5.2.

$$
r e s_{h}=-r e s_{c}
$$

The financial result in CCEE is an adjustment between the purchase and sell of electricity by the two main agents of the Brazilian electricity sector: 
hydropower generators and captive consumers. Under fixed quantity contracts, if the hydropower generators produce above the contracted amount, they can sell this energy excess, also known as secondary energy, to the consumers at the prevailing spot market price. In this case, the consumers pay the spot price which the generators receive. On the other hand, if electricity production falls short, then the generators must purchase this energy shortfall at the prevailing spot price. In this case, when the consumers have a gain in market, the generators have a loss with the same magnitude.

The result of the spot market in the proposed model is defined in Assumption 3.

Assumption 3: There is no liquidation of energy in the spot market in the new model, i.e., the result of the hydropower generators in CCEE is null, as shown in equation 3-25.

$$
r e s_{h}^{*}=0
$$

It happens because we consider the GSF constant at 1. Thus, the revenue of the hydropower generators under the proposed model is given by $p_{h}^{f} \cdot q_{h}^{f}+p_{h}^{a} \cdot q_{h}^{a}$.

Note 1: Since in the new model the generators no longer sell/buy energy in the spot market (Assumption 3), from Assumption 2 we note that the result of the consumers in CCEE in the new model is also zero (see eq. 3-26).

$$
r e s_{c}^{*}=0
$$

Note 2: As the consumers' result in CCEE is negatively related to the generators' result, according to 3-27, a reduction (increase) on the variation of the result of hydropower generators in CCEE between the models implies an increase (reduction) on the variation of consumers' result in CCEE.

$$
\Delta r e s_{h}=-\Delta r e s_{c}
$$

The relationship between the variation of the result in CCEE and the variation in the generation cost is defined in Hypothesis 1.

Assumption 4: The variation of the hydropower contract cost between the two models is equal to the variation of the hydropower's result in CCEE. As shown in equation 3-28, an increase (reduction) in the contract cost between the two models is associated with a increase (reduction) in the result of hydropower generators in CCEE.

$$
\Delta r e s_{h}=\Delta c_{h}
$$

The variation of both, the results of hydropower generation in CCEE and the cost of hydropower generation between the models are fundamental 
to calculate the variation of the consumers' total cost between the models.

Hypothesis 1: The expected cost for consumers remain the same between the models. This result is presented in equation 3-29. This assumption is assumed because an optimum price for the availability energy does not overtax the system and neither makes the contract non-profitable for generators. A high price increases the generators' revenue, but also increases the cost for consumers. On the other hand, a far below price reduces the consumers' cost, but also reduces the revenue from generators.

$$
E\left[\Delta c_{c}\right]=0
$$

Proof

$$
\begin{gathered}
E\left[\Delta c_{c}\right]=E\left[c_{c}^{*}-c_{c}\right] \\
E\left[\Delta c_{c}\right]=E\left[\left(c_{h}^{*}+c_{n}+c_{t}+r e s_{c}^{*}\right)-\left(c_{h}+c_{n}+c_{t}+r e s_{c}\right)\right] \\
E\left[\Delta c_{c}\right]=E\left[\Delta c_{h}+\Delta r e s_{c}\right] \\
E\left[\Delta c_{c}\right]=E\left[-\Delta r e s_{c}+\Delta r e s_{c}\right] \\
E\left[\Delta c_{c}\right]=0
\end{gathered}
$$

Note 3: We derive from Hypothesis 1 that the expected value of the Brazilian electricity system remains the same between the models, as it can be observed in equation 3-30.

$$
E\left[\Delta c_{s}\right]=0
$$

Proof

$$
\begin{gathered}
E\left[\Delta c_{s}\right]=E\left[c_{s}^{*}-c_{s}-\Delta r e s_{h}\right] \\
E\left[\Delta c_{s}\right]=E\left[\left(c_{c}^{*}+r e s_{h}^{*}\right)-\left(c_{c}+r e s_{h}\right)-\Delta r e s_{h}\right] \\
E\left[\Delta c_{s}\right]=E\left[\Delta c_{c}+\Delta r e s_{h}-\Delta r e s_{h}\right] \\
E\left[\Delta c_{s}\right]=E\left[\Delta c_{c}\right] \\
E\left[\Delta c_{s}\right]=0
\end{gathered}
$$

Note 4: It can be observed from Hypothesis 1 that the variation of the contract model does not alter the consumers' total cost, thus, 


$$
\begin{gathered}
E\left[\Delta c_{h}+\Delta r e s_{c}\right]=0 \\
E\left[c_{h}^{*}-c_{h}+\Delta r e s_{c}\right]=0 \\
E\left[\left(p_{h}^{f} \cdot q_{h}^{f}+p_{h}^{a} \cdot q_{h}^{a}\right)-\left(p_{h}^{f} \cdot\left[q_{h}^{f}+q_{h}^{a}\right]\right)+\Delta r e s_{c}\right]=0 \\
E\left[\left(p_{h}^{a}-p_{h}^{f}\right) \cdot q_{h}^{a}\right]+E\left[\Delta r e s_{c}\right]=0 \\
E\left[\left(p_{h}^{f}-p_{h}^{a}\right) \cdot q_{h}^{a}\right]=E\left[\Delta r e s_{c}\right]
\end{gathered}
$$

Since the variation of the consumers' result in CCEE is the negative of the variation of hydropower generators' result in CCEE (Note 2), we have

$$
\begin{gathered}
E\left[\left(p_{h}^{f}-p_{h}^{a}\right) \cdot q_{h}^{a}\right]=E\left[-\Delta r e s_{h}\right] \\
E\left[p_{h}^{f}-p_{h}^{a}\right]=\frac{E\left[r e s_{h}\right]}{q_{h}^{a}} \\
\pi=\frac{E\left[r e s_{h}\right]}{q_{h}^{a}}
\end{gathered}
$$

Considering this, the price of the contract by availability is, therefore, given by equation 3-32,

$$
p_{h}^{a}=p_{h}^{f}-\frac{E\left[r e s_{h}\right]}{q_{h}^{a}}
$$

which is the sum of the price of the contract by quantity and the negative of the price premium.

Note that the price of the contract by water availability is constructed in such a way that keeps unchanged the expected value of the system cost. In this case, the hydrological risk is mitigated, without overtaxing consumers. However, if the contract by availability is auctioned at a price above the equilibrium price, the generators will receive a higher revenue, but the consumers' cost will increase. On the other hand, if the auction price is lower than the equilibrium price, consumers will have a reduced cost, but the income of the generators will reduce. We illustrate this fact in case 1 of section 4.3.

\section{4}

\section{Risk assessment}

This section analyzes the mitigation of the hydrological risk for hydrpower generators and captive consumers.

Note that the contracted amount of hydroelectric power is the same in both models - with and without the contract by availability, because the energy 
demand was not changed, i.e., $q_{h}=q_{h}^{f}+q_{h}^{a}$. This means there are no changes in the operation of the Brazilian electricity system, conducted by national operator. In addition, observe that the proposed model was constructed in such a way that it generates the same expected value. In this sense, the model with availability mitigates the hydrological risk without overtaxing consumers or being non-profitable for generators.

In the model with contract by availability, generators are no longer exposed to the market risk due to a climatic variation. The contract by water availability ensures that part of the energy will only be generated if there is water availability. Therefore, both market and hydrological risks are completely mitigated. Furthermore, in the future, as a consequence of this risk reduction, the discount rate may be affected, which impacts the weighted average cost of capital of hydropower investments.

In other words, the risk change considering the contract by availability can be calculated using the portfolio theory, once the generators' revenue can be seen as a mix of contracts by quantity and availability:

\section{Hydropower generator:}

In the model without availability, i.e., only with contract by quantity, the generators make a commitment to provide a certain amount of electricity in exchange for (receiving) a price set in the contract. The difference between the generation, which is uncertain, and the contracted quantity is settled in the spot market $(91)$. In this case, the contract risk $\left(\sigma_{h}\right)$ is given by the standard deviation of the market return $(r)$,

$$
\sigma_{h}=\sqrt{\frac{\sum_{i=1}^{T}\left(r_{i}-\bar{r}\right)^{2}}{n-1}}
$$

From a different perspective, the generators' risk in the conventional model can also be calculated as

$$
\operatorname{risk}\left(\tilde{R}_{h}\right)=E\left[\tilde{R}_{h}\right]-C \operatorname{VaR} R_{\alpha}\left(\tilde{R}_{h}\right)
$$

This equation is used in the next chapter to calculate the risk of the electricity market participants.

The proposed model with water availability can be seen as a portfolio, where the generators have a mix of contracts by quantity and contracts by availability. In this case, the risk of the contract by quantity $\left(\sigma_{h, 1}^{*}\right)$ is null, 


$$
\begin{gathered}
r_{h}^{f}=\underbrace{p_{h}^{f} \cdot q_{h}^{f}}_{\text {Deterministic }} \\
r e s_{h}^{*}=0
\end{gathered}
$$

Where the index $f$ refers to the firm energy from the system. Here, the contract by quantity is set considering the minimum Brazilian river flow with $99 \%$ of confidence level and, therefore, the market risk is mitigated.

In the proposed model, the risk of the contract by availability $\left(\sigma_{h, 2}^{*}\right)$ is also null,

$$
r_{h}^{a}=\underbrace{p_{h}^{a} \cdot q_{h}^{a}}_{\text {Deterministic }}
$$

Considering $\rho_{1,2}$ as the correlation of these two contracts, the portfolio risk $\left(\sigma_{h}^{*}\right)$ is, consequently, given by

$$
\sigma_{h}^{*}=\sqrt{\omega_{1}^{2} \cdot \sigma_{h, 1}^{* 2}+\omega_{2}^{2} \cdot \sigma_{h, 2}^{* 2}+\omega_{1}^{2} \cdot \omega_{2}^{2} \cdot \sigma_{h, 1}^{* 2} \cdot \sigma_{h, 2}^{* 2} \cdot \rho_{1,2}}=0
$$

The hydrological risk is, therefore, mitigated for the hydropower generator.

\section{Captive consumers:}

Since there is no reserve energy, the captive consumers' result in the spot market is negative related to that of hydropower generators. When the hydroeletric plants have input to generate more (less) than the required by the contract, the balance of the accounts in spot market results in a positive (negative) value for generators and a negative (positive) value for consumers. Thereby, once the generators contracts for availability, there is no liquidation in the market, and, consequently, the consumers' risk in the spot market is also null.

In addition, in the proposed model the secondary energy is transferred to the consumers. The secondary energy is already priced in the cost of the contract by water availability and the consumers don't need to pay for the excess of hydropower production during wet periods. Despite the recent crisis, as illustrated in Figure 3.2, the climatic conditions in Brazil are in general favorable to hydropower generation. Note that the average annual GSF between 2005 and 2012 was higher than 100\%, which indicates that the ERM generated energy beyond its physical guarantee and had secondary energy revenues. 


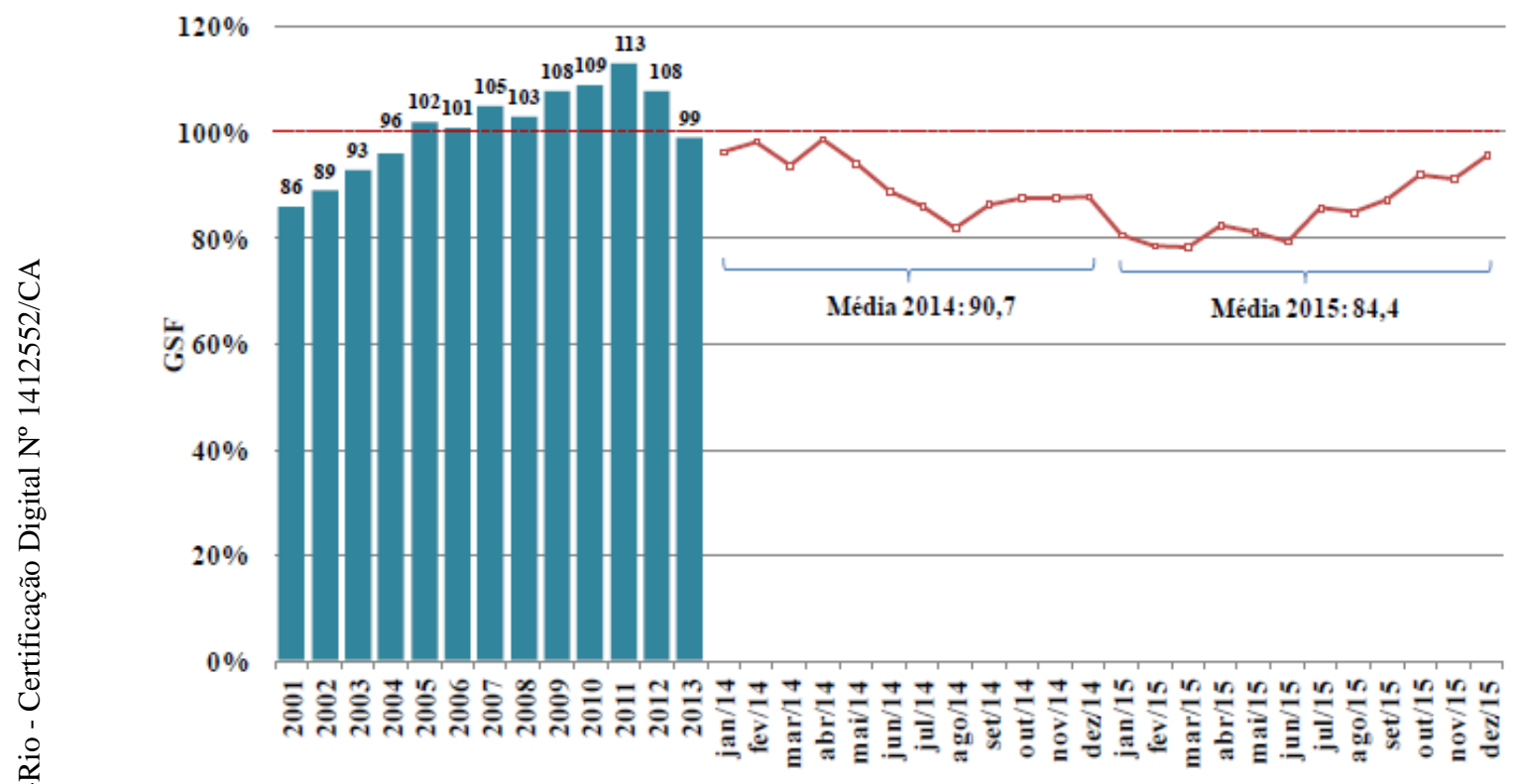

Source: From Brito (11).

Figure 3.2: Historical ERM adjustment factor (GSF). 


\section{4}

\section{Numerical Example: contracts redesign}

This section presents some numerical results for the model introduced in section 3, using real data for the Brazilian electricity sector. In order to facilitate the reader's understanding of the proposed model, the results are divided in three cases. In the first case, we consider that only two thermoeletric plants supply the thermal energy. This simplification is assumed because the objective in this case is to explain the impact on the system given the redesign of the hydropower contract. In this case, we are not worried about calculating the price of the contract by water availability, but simply to show the dynamics of the model. In the second case, the thermal supply curve is introduced. In this case, the price of the contract for availability is calculated considering the system operation. In the third case, some sensitivities are conducted, considering the impact of climatic and operational factors on the model.

Before presenting the results for each case, however, a simplified illustration of the model is shown for the contractual model of case 1, in only two scenarios of hydrology; one dry and the other one wet. In all cases, the values are in nominal $\mathrm{U} \$$ million dollars (\$ 4 BRL/USD).

\section{1}

\section{Model calibration}

In line with the data presented in the government plan (Plano Decenal de Expansão de Energia, PDE 2015-2024) (49), it is considered that the national electricity demand is $66.5 \mathrm{GW}$ for the year 2016. Also, it is assumed that the energy demand is mainly served by three different sources: hydroelectric, thermal and nuclear.

In the present study, two contract cases are considered, as it can be seen in Table 4.1. The first case is simple to show the intuition behind the proposed model. In this case, the demand is considered inelastic in $66 \mathrm{GW}$. It is important to note, however, that the demand uncertainty can be evaluated under alternative scenarios (5).

In the second case, it is considered that the energy contract is approximately $10.5 \%$ beyond the demand requirements of $66.5 \mathrm{GW}$, which is a common practice of the sector (42). In this case, it is considered an annual 
contract with the hydropower generators of $53.2 \mathrm{GW}$ at a price of $32.5 \$ / \mathrm{MWh}$, a contract with the nuclear generators of $10.8 \mathrm{GW}$ with the same price and a contract with the thermopower generators of $9.5 \mathrm{GW}$ at a price of $17.5 \$ / \mathrm{MWh}$ (92). If the thermoeletric plant is dispatched, the generators receive a refund of the operation cost through the spot price. The values of price and amount of the contract with each one of these sources are based on the historical data available on the ONS website (93). Note that in the contract by quantity, the hydropower generators demand an additional price to compensate inflows uncertainties (94).

Table 4.1: Contract Description.

\begin{tabular}{llccccc}
\hline Type & Auction & Variable & $\begin{array}{c}\text { Case 1 } \\
\text { GW }\end{array}$ & $\begin{array}{c}\text { Case 2 } \\
\text { GW }\end{array}$ & Variable & $\begin{array}{c}\text { Price } \\
\$ / \mathrm{MW}\end{array}$ \\
\hline Demand & & & & & & \\
Demand & & $d$ & 66 & 73.5 & & \\
\hline Contract & & & & & & \\
Hydro & Quantity & $q_{h}$ & 50 & 53.2 & $p_{h}$ & 32.5 \\
Nuclear & Quantity & $q_{n}$ & 8 & 10.8 & $p_{n}$ & 32.5 \\
Thermo & Availability & $q_{t}$ & 8 & 9.5 & $p_{t}$ & 17.5 \\
\hline
\end{tabular}

The contract data with the hydropower generators were collected in the government market report (Relatório de Mercado) (95), the thermal data were collected in the monthly operation program (Programa Mensal da Operação) (96) and the nuclear data in the monthly operation program as well as in the Brazilian electrical system monitoring report (Boletim de Monitoramento do Sistema Elétrico Brasileiro) (96, 97).

The spot prices and the power generation used in this work are simulated for the Southeastern part of Brazil using the Newave model, which is a program that uses the method of Monte Carlo to simulate 2,000 sample paths in the following 12 trading months. The monthly simulations are made from June 2015 to the year 2016 (Jan to Dec). The descriptive statistics of these simulations are presented in Table 4.2. The minimum and maximum value of hydropower occurs respectively in July and February, while the minimum and maximum value of the thermopower occurs in April and July, respectively. The lowest nuclear generation is simulated in February and the highest in August. 
Table 4.2: Descriptive statistics

\begin{tabular}{lcccc}
\hline & Spot price & \multicolumn{3}{c}{ Generation $(\mathrm{GW})$} \\
\cline { 3 - 5 }$(\$ /$ MWh $)$ & Hydro & Thermo & Nuclear \\
\hline Minimum & 7.6 & 36.9 & 5.1 & 5.6 \\
Maximum & 97.1 & 58.5 & 17.7 & 10.2 \\
Average & 36.1 & 50.7 & 7.6 & 8.3 \\
Medium & 26.6 & 50.7 & 6.2 & 8.9 \\
Stand. Dev. & 30.3 & 4.1 & 2.8 & 1.9 \\
\hline
\end{tabular}

The average of the power generation simulations, the histogram of the spot price simulations and the average of the spot prices are presented in Figures 4.1, 4.2 and 4.3.

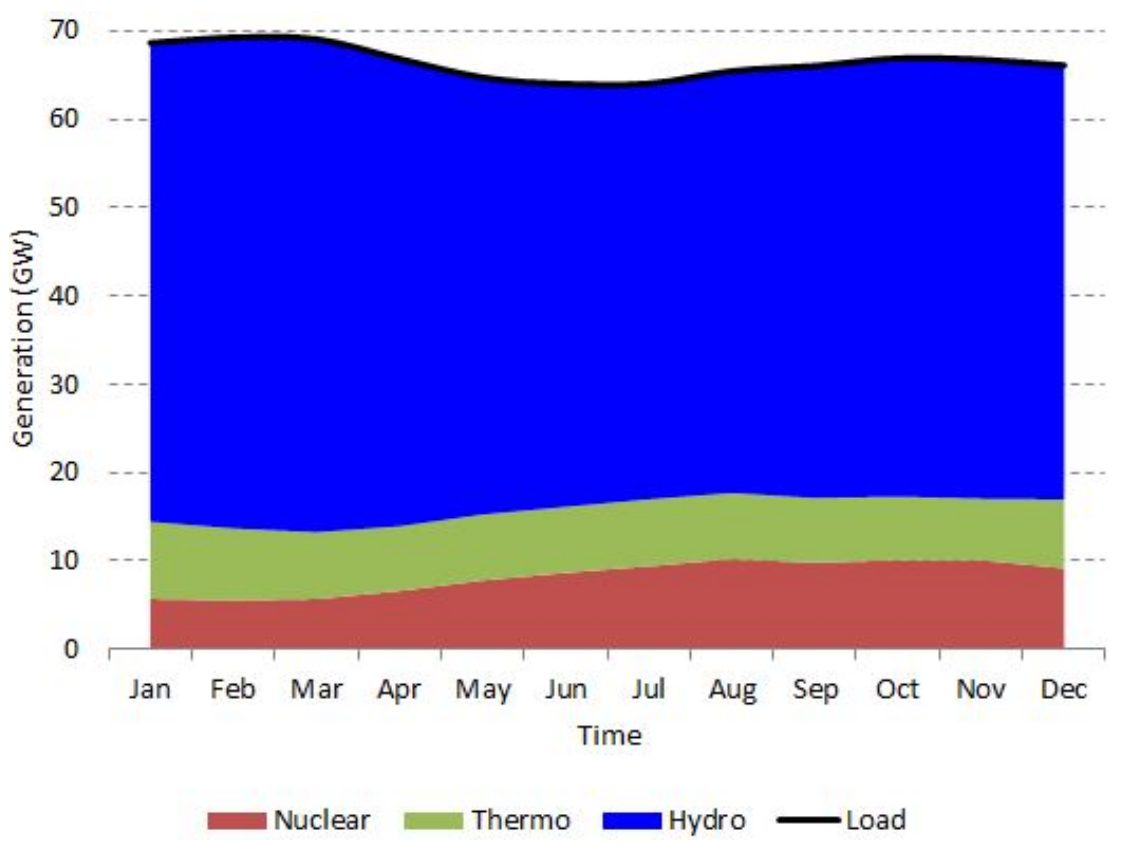

Figure 4.1: Average of power generation for 2016. 


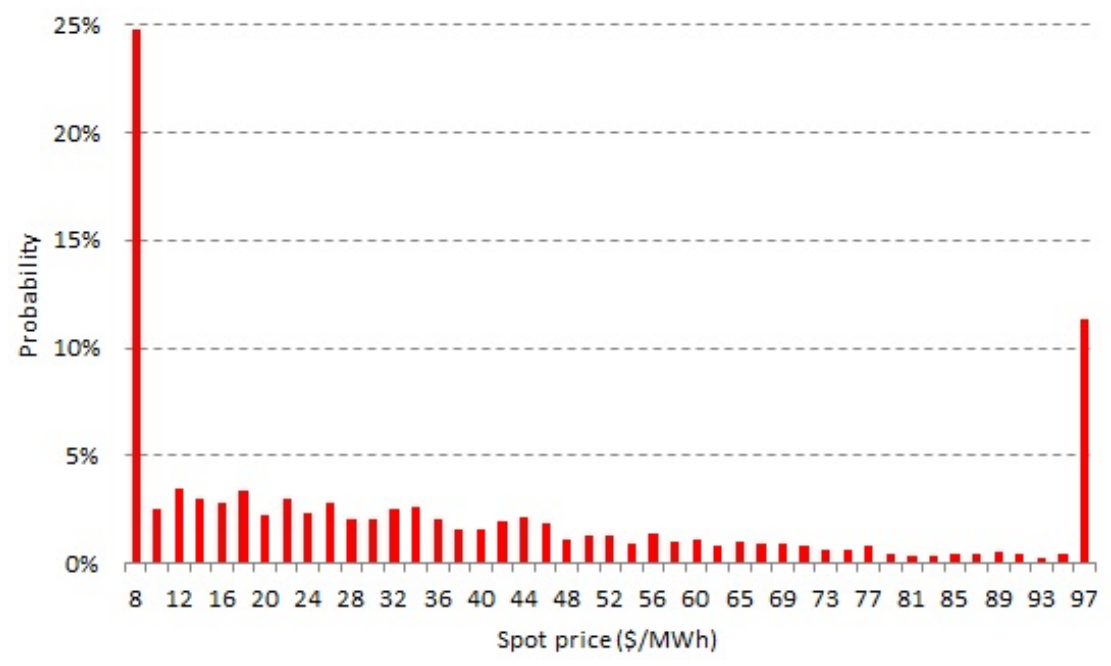

Figure 4.2: SPD histogram.

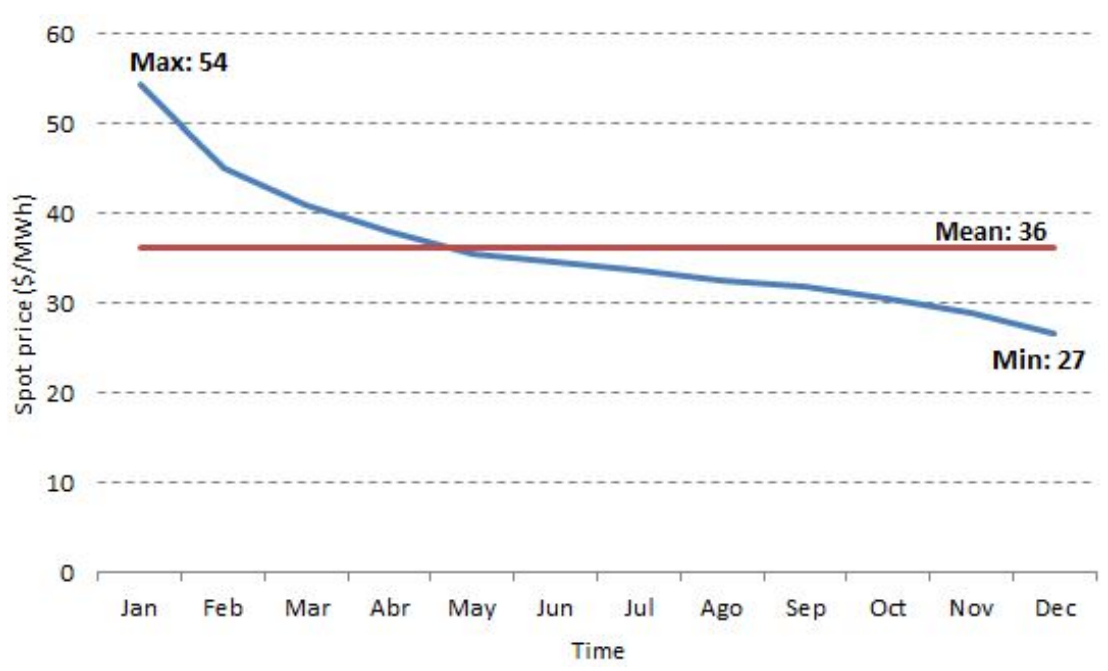

Figure 4.3: Average of spot price for 2016.

The spot price has a probability of $23 \%$ of being under $28 \$ / \mathrm{MWh}, 45 \%$ of being between $28 \$ / \mathrm{MWh}$ and $75 \$ / \mathrm{MWh}$ and $31 \%$ of being above $75 \$ / \mathrm{MWh}$. The reservoirs were unusually low throughout all of 2015 and, when taken into account in the simulations, this resulted in very high spot prices during that year. 


\section{2}

\section{Illustration of the model}

Figure 4.4 illustrates the model for the contract data presented in Table 4.3 for two hydrological scenarios: i) a restrictive "dry"scenario where water is scarce and spot prices are high and ii) a "wet"scenario with excess water, low spot prices and hydropower generation that generates secondary energy. The left side of Figure 4.4 shows the amount of energy that is contracted by captive consumers (i.e., power distribution companies). The first column on the right represents the physical operation of the system by ONS, while the last two represent the financial CCEE settlement of this operation under the current model and under the proposed model. At this point, it is important to note that although the figures are presented in GW, our entire model is structured in financial terms, considering the liquidations in the spot market. Therefore, the excess energy delivered to consumers in the "dry"scenario, for example, refers to the financial difference between the values of the spot price and the fuel cost of the thermal plants.

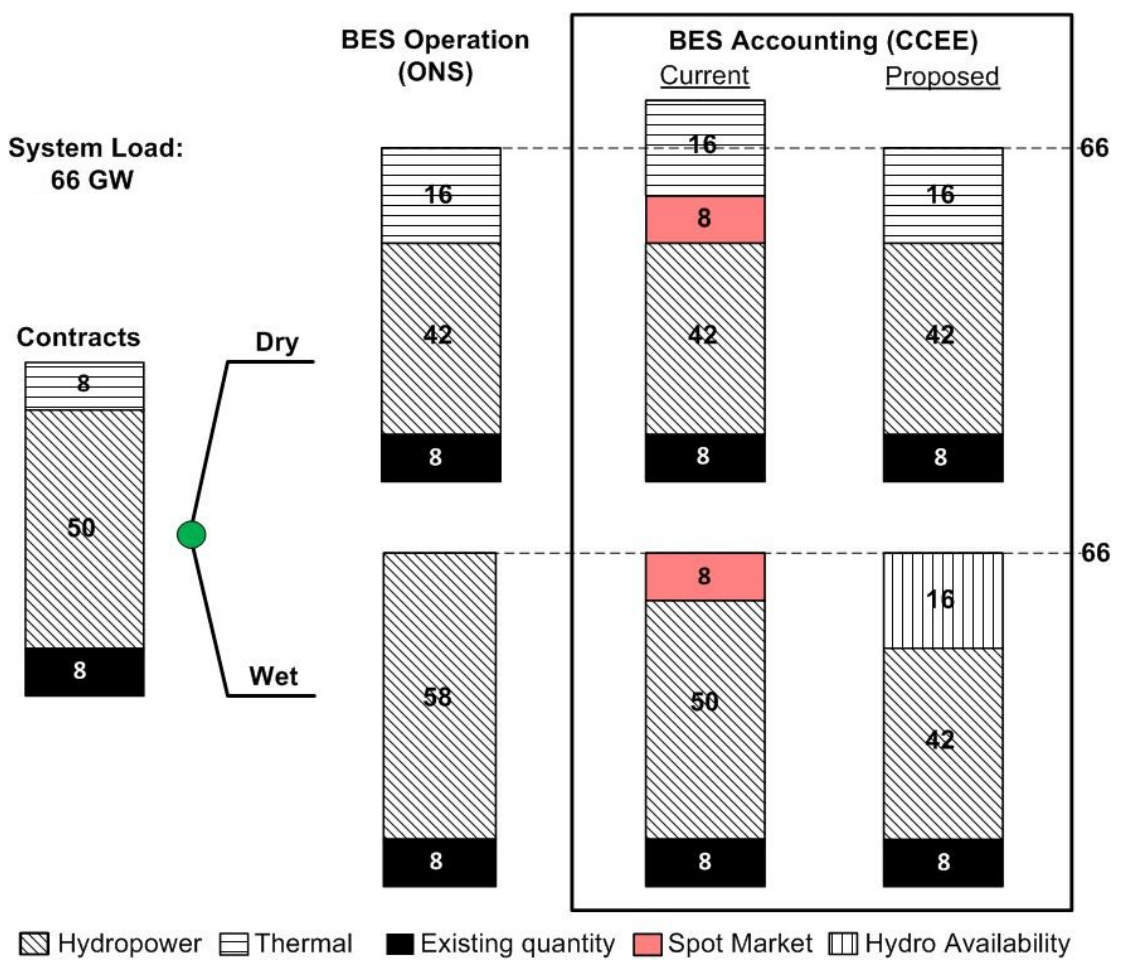

Figure 4.4: An example of the model. 
Table 4.3: Contract data

\begin{tabular}{lll}
\hline Contract & GW & $\$ /$ MWh \\
\hline Demand & 66 & \\
Hydropower (98 GW) & & \\
Physical Guarantee & 50 & 32.5 \\
Firm energy & 42 & 32.5 \\
Nuclear & 8 & 32.5 \\
Thermopower (16 GW) & & \\
Physical Guarantee & 8 & 17.5 \\
\hline
\end{tabular}

The existing quantity ( $8 \mathrm{GW}$ in black) is the energy that is permanently dispatched by ONS, while the rest of the demand is met by hydroelectric and thermoelectric plants in different proportions, depending on the scenario. In the wet scenario, ONS is able to meet the entire demand with energy from hydro sources. In this case, current settlement rules require that the hydropowers' secondary energy (8 GW in red) be purchased in the spot market by captive consumers. The financial accounting under the proposed model shows that this is not necessary as hydroeletric plants are now contracted by quantity and by availability. Thus, in the proposed model, hydroeletric plants are already contracted and, therefore, captive consumers are not subject to price uncertainties.

In the dry scenario, on the other hand, ONS is unable to meet the required demand solely with hydro energy, and therefore must dispatch thermoeletric plants which will generate the energy shortfall needed to meet the demand. In this case, under current settlement rules the hydropower generators that fail to produce their contracted energy must buy their energy deficit in the spot market. Under the proposed model, the hydropower generators will produce energy amounts that correspond to their quantity contract, while the thermal sources produce the rest. In this case, it is not necessary to buy energy in the spot market and the demand is met more efficiently. Therefore, the proposed model settles the financial accounting of electric power generation and the switch occurs when there is an exchange between hydro and thermal power generation.

From a different perspective, Figure 4.5 shows the accounting of the electricity generation for the hydropower generators in the CCEE and in their revenue, according to the current (column 1) and the proposed model (column 2 ). The third column shows the difference between the two (column 3). In this case, the wet and dry scenarios have respectively a q and (1-q) probability of occurring. 


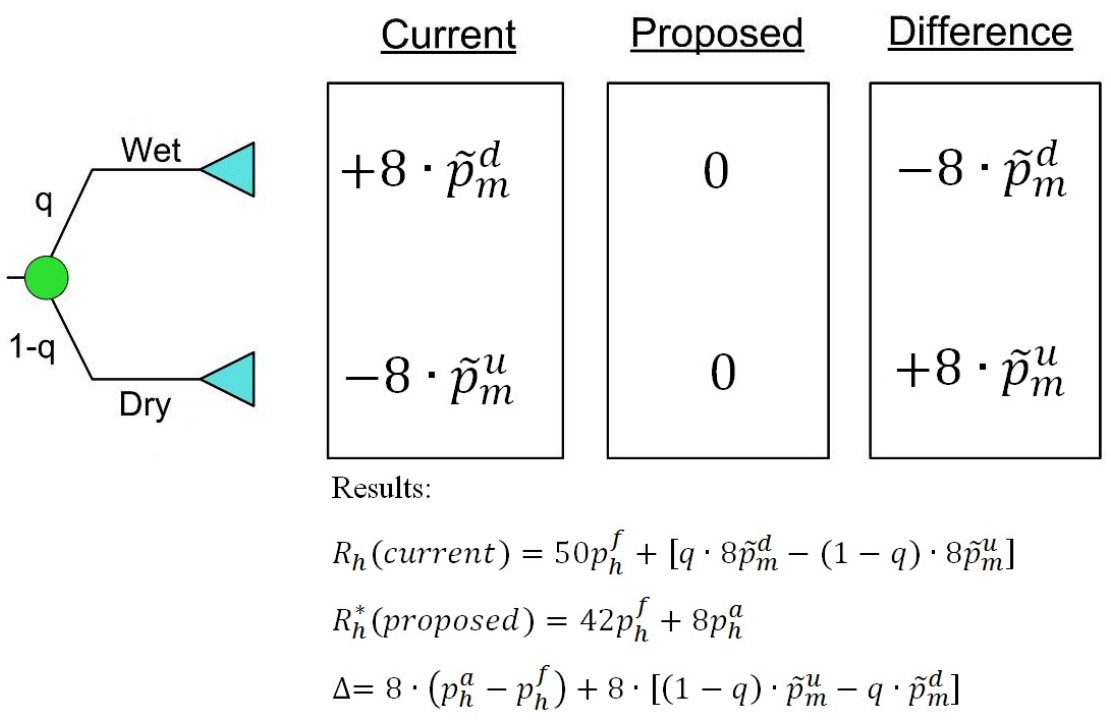

Figure 4.5: CCEE and hydropowers' revenue accounting.

In the wet scenario, under the current model the hydropower generators produce $8 \mathrm{GW}$ above what was contracted. This energy must be sold in the spot market, thus, the generators have a gain of 8 times the spot price in the wet scenario, $8 \cdot \tilde{p}_{m}^{d}$. In the proposed model the generators' financial result is null because the price of the contract per availability already includes the cost of over-generation. The difference between the two models in this scenario is a negative result of $-8 \cdot \tilde{p}_{m}^{d}$ to hydropower generators.

In the dry scenario, under the current model, the hydropower generators are unable to produce $8 \mathrm{GW}$, so the ONS switches this generation to the thermoeletric plants. But as the hydropower generators have a commitment to quantity contracts, they are required to purchase this shortfall in the spot market. Thus, the generators loss 8 times the spot price in the dry scenario, $8 \cdot \tilde{p}_{m}^{u}$. In the proposed model, the consumers have a null financial result. The difference between these two models in this scenario is a surplus of $+8 \cdot \tilde{p}_{m}^{u}$ to hydropower generators.

Considering these values, the result of a contractual modification is, therefore, given by $8 \cdot\left(p_{h}^{a}-p_{h}^{f}\right)+8 \cdot\left[(1-q) \cdot \tilde{p}_{m}^{u}-q \cdot \tilde{p}_{m}^{d}\right]$. Moreover, if $p_{h}^{f}=p_{h}^{a}$, this value is $8 \cdot\left[(1-q) \cdot \tilde{p}_{m}^{u}-q \cdot \tilde{p}_{m}^{d}\right]$. Where $\tilde{p}_{m}^{\text {ddown }}$ and $\tilde{p}_{m}^{u p}$ refers, respectively, to the spot price in the wet and dry scenarios. Therefore, under the proposed model, there is a change in the financial result of the spot market and in the revenue of the generator, but the ONS operation remains unchanged. 


\section{3}

\section{Case 1: two thermals}

To focus our attention on the hydro-thermal complementarity, this section assumes a simplified system with only one representative hydro and two thermal power plants operating without transmission constraints or losses. As it can be seen in Table 4.4, the supply of thermopower is separated in two blocks $(j=1,2)$ : i) a block that offers power at a lower cost and ii) a block with the highest cost. The total installed capacity is the sum of each block. These blocks will be dispatched respecting the cost merit order of thermoeletric plants, i.e., the cheaper block will be dispatched first.

Table 4.4: Relationship between installed capacity and physical guarantee

\begin{tabular}{|c|c|c|c|}
\hline Variable & Description & Power & \\
\hline \multicolumn{4}{|c|}{ Thermal powers } \\
\hline$i c_{t}$ & Installed capacity & 16 & GW \\
\hline$P G_{t}$ & Physical guarantee & 8 & GW \\
\hline \multicolumn{4}{|c|}{ Block 1 with uvc $28 \$ / M W h$} \\
\hline$i c_{t, 1}$ & Installed capacity & 10 & GW \\
\hline$P G_{t, 1}$ & Physical guarantee & 5 & GW \\
\hline \multicolumn{4}{|c|}{ Block 2 with uvc $75 \$ / M W h$} \\
\hline$i c_{t, 2}$ & Installed capacity & 6 & GW \\
\hline$P G_{t, 2}$ & Physical guarantee & 3 & GW \\
\hline \multicolumn{4}{|c|}{ Hydropower } \\
\hline$i c_{h}$ & Install & 98 & GW \\
\hline$P G_{h}$ & Physical guarantee & 50 & GW \\
\hline
\end{tabular}

Table 4.5 shows the division between the amount of energy contracted by quantity and availability, as well as the contract prices. The contract by quantity is determined based on the maximum amount of energy that can be produced under the minimum flow of Brazilian rivers, which is $42 \mathrm{GW}$ with a $99 \%$ confidence level. The difference between this amount and the physical guarantee $(50 \mathrm{GW}), 8 \mathrm{GW}$, is the size of the contract by availability. Note that it is assumed that the price of both contracts is the same as the current value of the contract by quantity $(32.5 \$ / \mathrm{MWh})$, which facilitates the comparison between the models. In a next step, this value will be changed.

Table 4.5: New modalities for hydropower contracts

\begin{tabular}{lcccc}
\hline Type & Variable & Power & Variable & Price \\
\hline Quantity & $q_{h}^{f}$ & 42 & $p_{h}^{f}$ & 32.5 \\
Availability & $q_{h}^{a}$ & 8 & $p_{h}^{a}$ & 32.5 \\
\hline \multicolumn{4}{l}{ Note: The power is in GW and the price is in $\$ / \mathrm{MWh}}$.
\end{tabular}

Table 4.6 shows the results for the hydropower generators and captive consumers, considering the price simulations from Newave for 2016. Panels 
A and B show the average results for the current and proposed models, respectively. 
Table 4.6: Results of the models

\begin{tabular}{lllc}
\hline Panel A: Current model & & & \\
& & & \\
Generation & & & \\
Hydro generation & $g_{h}$ & $\mathrm{GW}$ & 52 \\
Adjustment factor & $G S F$ & & 1.05 \\
& & & \\
Hydropower & & & \\
Result in CCEE & $r e s_{h}$ & $\$$ million & -68 \\
Revenue & $R_{h}$ & $\$$ million & 1.121 \\
& & & \\
Consumer & & & \\
Hydro contract & $c_{h}$ & $\$$ million & -1.189 \\
Other contracts & $c_{t, q}$ & $\$$ million & -441 \\
Result in CCEE & $r e s_{c}$ & $\$$ million & 68 \\
Consumers' cost & $c_{c}$ & $\$$ million & -1.562 \\
& & & \\
National system & & & \\
Total result & $c$ & $\$$ million & -1.630 \\
\hline
\end{tabular}

Panel B: Proposed model

$$
\underline{p_{h}^{a}=32.5}
$$

Generation

Generation - quantity

Generation - availability

Hydro generation

Adjustment factor

$\begin{array}{llc}g_{h}^{f} & \mathrm{GW} & 42 \\ g_{h}^{a} & \mathrm{GW} & 10 \\ g_{h}^{*} & \mathrm{GW} & 52 \\ G S F^{*} & & 1\end{array}$

Hydropower

Result in CCEE

$r e s_{h}^{*} \quad \$$ million $\quad 0$

Revenue

$R_{h}^{*} \quad \$$ million $\quad 1.189$

Consumer

Hydro contract by quantity

Hydro contract by availability

Hydro contract

Other contracts

Result in CCEE

Consumers' cost

$\begin{array}{llc}c_{h}^{f} & \text { \$ million } & -999 \\ c_{h}^{a} & \text { \$ million } & -190 \\ c_{h}^{*} & \text { \$ million } & -1.189 \\ c_{t, q} & \text { \$ million } & -441 \\ r e s_{c}^{*} & \text { \$ million } & 0 \\ c_{c}^{*} & \text { \$ million } & -1.630\end{array}$

National system

Total result

$c^{*} \quad \$$ million

$-1.630$ 
Observe that despite the separation of the hydropower contract into two modalities, quantity and availability, the total hydropower generation is the same in both models, $52 \mathrm{GW}$, as there is no change in the system. In addition, note that despite the fact that the expected $G S F$ value in the current model is 1.05, in most cases $G S F$ falls below 1, in which case hydropower generators are unable to comply with their obligations. These generators will, then, have lower than expected revenues and captive consumers will have a power gain above the demand. In the proposed model, however, GSF becomes constant at 1 , i.e., the hydropower generators are no longer exposed to uncertainties of market price and, therefore, the financial results of the hydroelectric in the CCEE become null. Also, note that the revenue of the generators is sensitive to the price of the contract by availability. In this case, the revenue increases proportionally to the reduction of the loss in the CCEE.

Additionally, observe three main changes on the consumers' side in the proposed model. First, the cost of hydropower generation has been broken into two parts, one contracted by quantity and the other one by availability. Second, the consumers' result in the CCEE became null, because the consumers don't need to buy energy in the spot market as it already has a contract for supply of energy with both hydroelectric and thermoelectric plants. Third, the total consumers' cost increases, because they stop to receive the liquidations of the hydropower generators in the CCEE and, in this case, it was assumed that the price of the contract by availability is equal to the contract by quantity. Moreover, the total cost of the national system does not change, compared to the current model.

Finally, figure 4.6 shows the sensitivity of the price of the contract by quantity to the unit variable cost $(u v c)$ of the two thermoeletric plants. The columns in this figure show the difference between the prices of both contracts. 


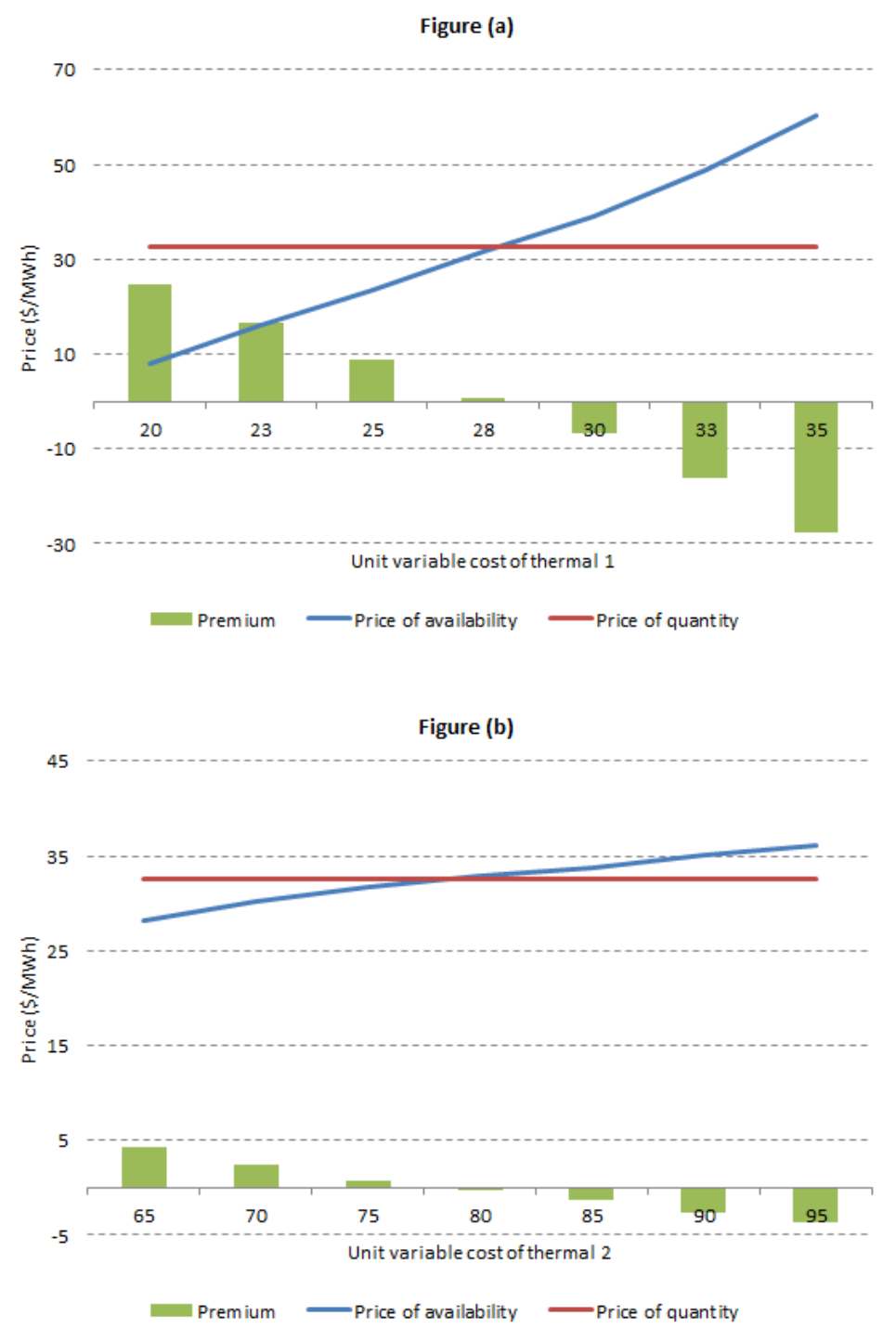

Figure 4.6: Varying $u v c$ for plants 1 and 2.

Observe that as the fuel cost of thermoelectric plants increases, the price of the contract by availability increases. This occurs because when the fuel cost is high, the hydropower has priority over thermopower generation, and the hydropower generators have a higher opportunity cost to celebrate a contract by availability at a lower price, as they could liquidate the secondary energy in the spot market at a higher price. Note that the premium can be negative depending on the value of the unit variable cost, which implies that the price of the contract by availability is higher than the price of contract by quantity. In this case, the generators' opportunity cost of switch contracts is more significant. In addition, notice that the price variation of the contract by availability is lower in the second case. This occurs because the fuel price of this thermoeletric plant is already high, then its increase does not have a significant effect on thermopower dispatch. 


\section{4}

\section{Case 2: the system}

This section presents a more robust numerical example for the case of the Brazilian electric sector. In this case, the contractual model presented in column 5 of Table 4.1 is used in the analysis. Also, the simulations of the spot price and the power generation are considered here. Moreover, it is assumed that the contract of the hydropower generators will be formed by a mix of contracts by quantity and contracts by availability, in which the contract by quantity represents $80 \%$ of the portfolio and the contract by availability represents $20 \%$.

The results show that there is a probability of $88 \%$ of a GSF below 1 for the year 2016. In other words, this means that the hydrological risk is significant, the hydropower generation will be below the physical guarantee of the plant for most of the year, which means that the generators will have to buy the energy shortfall in the spot market. Figure 4.7 shows the monthly risk for the hydropower generators in the CCEE during the period of analysis for the current model. Note that in Brazil, the generators' risk is higher in the second semester, which coincides with the dry season in the Southeast of the country.

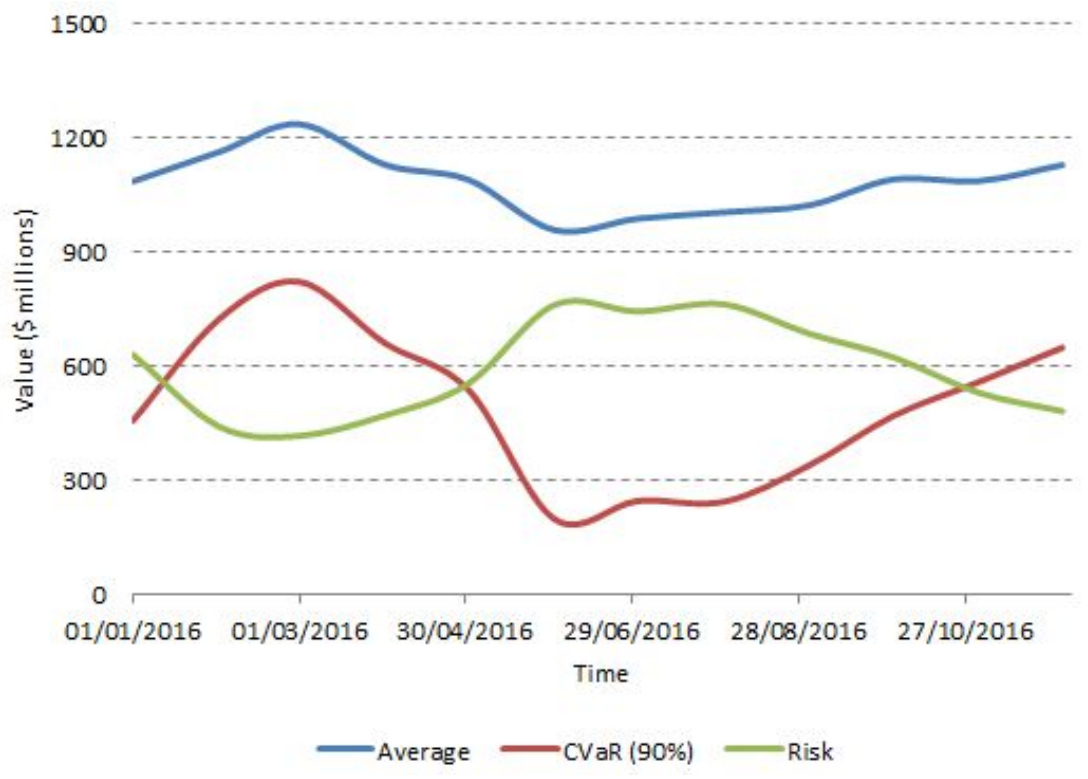

Figure 4.7: Hydropower generators' monthly risk in the CCEE.

Due to the recent history of drought and the lack of rain of recent times, the hydrological risk has become a serious problem for hydropower generators, that expect a negative value of about $\$ 2$ billion dollars in the CCEE. Since the generation has an opposite correlation with market prices (52), the financial deficit is substantial. Figure 4.8 shows the histogram of the 
hydropower generators' revenue in quarterly periods. The expected revenue for the year 2016 is nearly $\$ 13$ billion.

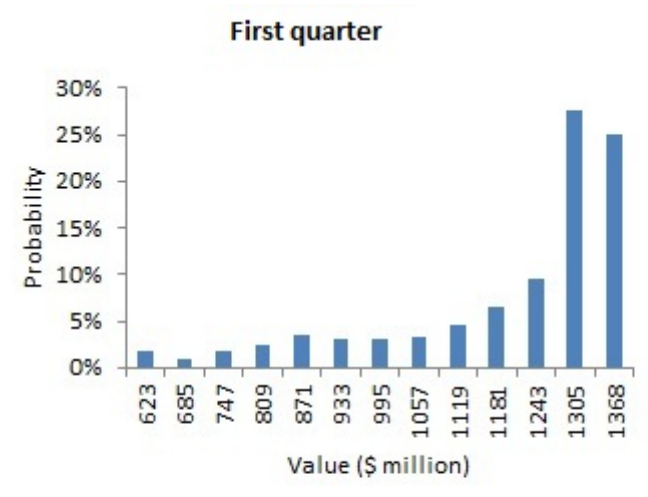

Third quarter

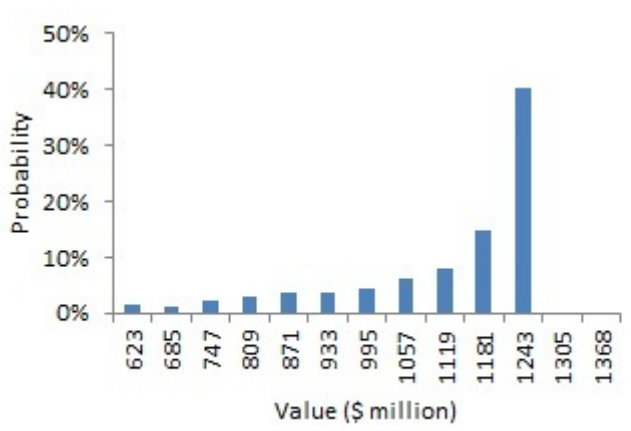

Second quarter

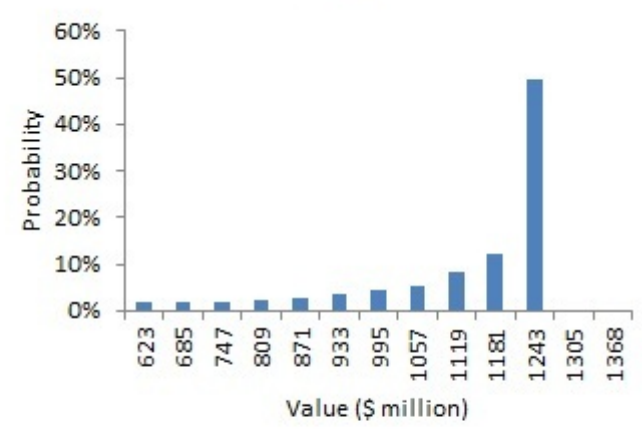

Fourth quarter

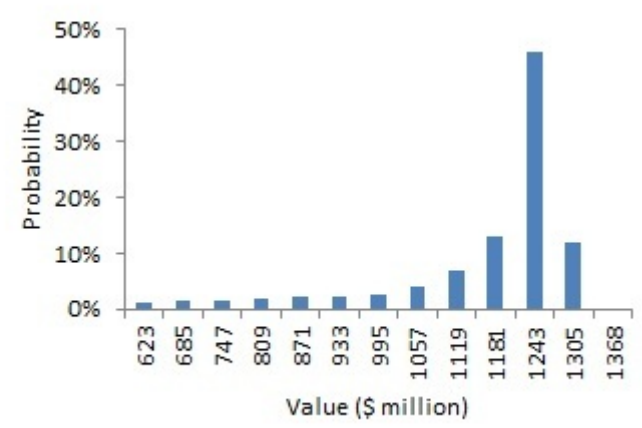

Figure 4.8: Quarterly distribution of generators' revenue.

In order to eliminate the hydrological risk the generators can opt for a contractual redesign in which, instead of being fully contracted in the form of contracts by quantity, they make a mix of contracts by quantity and availability. In this case, it is necessary to define the amount of energy and the price that will be negotiated in each contract type. As the physical guarantee of the hydropower plant is $53.2 \mathrm{GW}$, considering the weights of $80 \%$ for the contract by quantity and $20 \%$ for the contract by availability, the generators have a commitment to deliver $42.6 \mathrm{GW}$ of energy referring to the contract by quantity and 10.6 GW of energy referring to the contract by availability. The price of the contract by quantity is the same as before, $32.5 \$ / \mathrm{MWh}$, but the price of the contract by availability needs to be calculated. The first step to estimate this price is to calculate the price premium as in equation 3-31,

$$
\pi=\frac{E\left[r e s_{h}\right]}{q_{h}^{a}}=18.96 \$ / M W h
$$

Then, we use equation 3-32 to estimate the price of the contract by availability, 


$$
p_{h}^{a}=p_{h}^{f}-\pi=32.5-18.96=13.54 \$ / M W h
$$

Proceeding with these steps, a value of $13.54 \$ / \mathrm{MWh}$ is found for the price of the contract for water availability.

The captive consumers' total cost is the sum of the contract with the three energy sources plus their result in the CCEE. Figure 4.9 shows the monthly risk for the captive consumers in the CCEE during the year of 2016, considering the current model. Note that the captive consumers' risk follows an opposite movement of that of the hydropower.

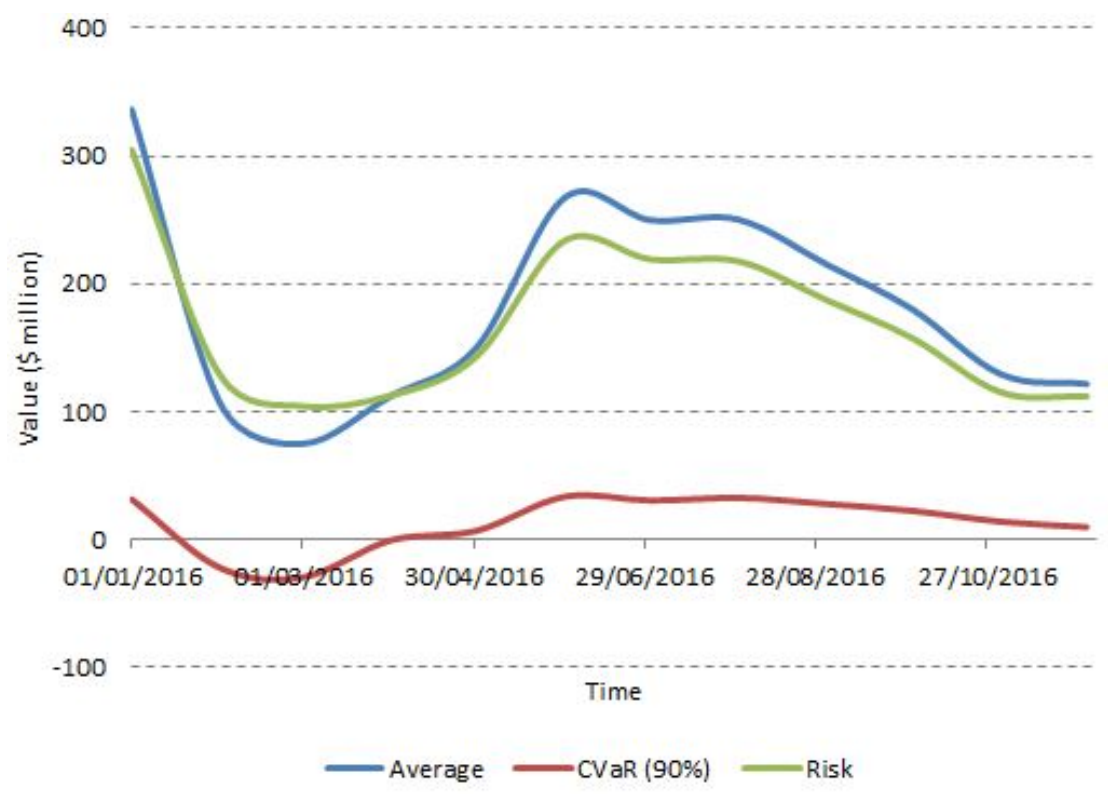

Figure 4.9: Consumers' monthly risk.

The expected result of the captive consumers in the CCEE is a positive value of $\$ 2,194$ billion dollars. The cost of the contracts with hydro, thermal and nuclear generators is, respectively, $\$ 15,180$ billion dollars, $\$ 4,517$ billion dollars and $\$ 3,077$ billion dollars. The total cost of the energy domestic generation for the consumers is, therefore, expected to be of about $\$-21$ billion dollars. Figure 4.10 shows the histogram of the captive consumers' cost in quarterly period. 

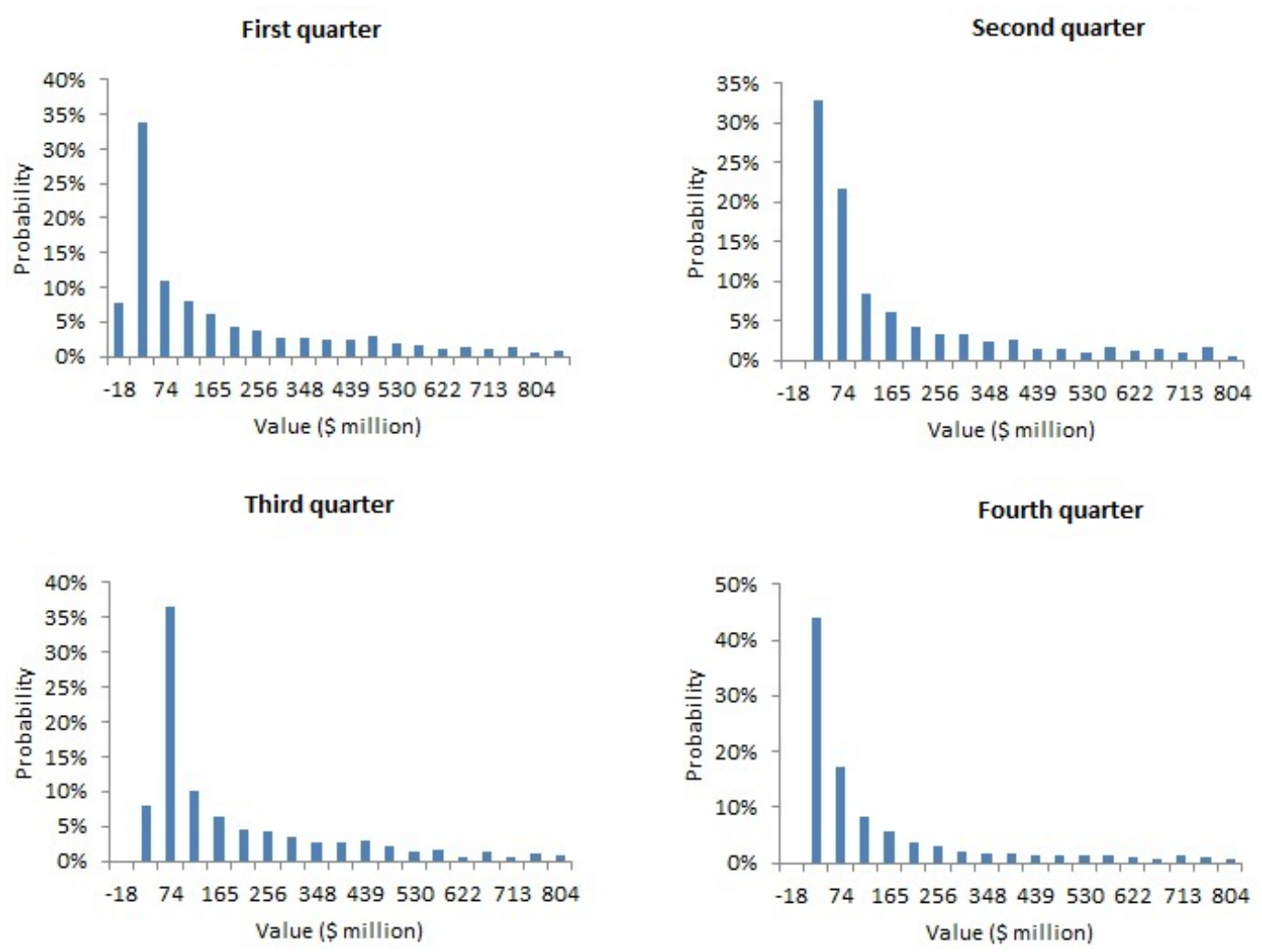

Figure 4.10: Quarterly distribution of consumers' result.

The changes in the expected revenue of the generators and in the expected consumers' costs due to the redesign of the contract model are presented in Table 4.7. This table shows both the results of the current model used by the hydropower generators and the proposed model of a mix of contracts by quantity and contracts by availability.

Observe that hydropower revenue is the same in both models, about $\$ 13$ US billion dollars, with the difference that in the portfolio the hydrological risk is completely mitigated once the result of hydropower in the CCEE becomes null. Also, note that as the contract by availability is cheaper than the contract by quantity, the cost of hydropower generation is reduced. In addition, note that as hydropower is no longer required to deliver an energy amount above the physical guarantee of the plant, the consumers' result in the CCEE is zero. Moreover, notice that the national system result remains unchanged between the models because the cancellation of hydropower results in the spot market is offset by the change in their result between the models.

It is important to note that any change in the price of the contract by water availability has an impact in the revenue of the hydropower generators and in the costs for the captive consumers. Depending on the change in the price of the contract by water availability, the generators' revenue may increase or decrease, which affects the captive consumers' costs. 
Table 4.7: Comparison between the two contract models

\begin{tabular}{lcccc}
\hline & & & \multicolumn{2}{c}{ Contract model } \\
\cline { 3 - 5 } Result & & & Current & Proposed \\
\hline $\begin{array}{l}\text { Price } \\
\text { Price quantity }\end{array}$ & $p_{h}^{f}$ & $\$ / \mathrm{MWh}$ & 32.5 & 32.5 \\
Price availability & $p_{h}^{a}$ & $\$ / \mathrm{MWh}$ & - & 13.54 \\
& & & & \\
Hydropower & & & & \\
Result in CCEE & $r e s_{h}$ & $\$$ million & $-2,194$ & 0 \\
Revenue & $R_{h}$ & $\$$ million & 12,986 & 12,986 \\
& & & & \\
Consumer & & & & \\
Hydro's cost & $c_{h}$ & $\$$ million & $-15,180$ & $-12,986$ \\
Thermal's cost & $c_{t}$ & $\$$ million & $-4,517$ & $-4,517$ \\
Nuclear's cost & $c_{n}$ & $\$$ million & $-3,077$ & $-3,077$ \\
Result in CCEE & $r e s_{c}$ & $\$$ million & 2,194 & 0 \\
Consumers' cost & $c_{c}$ & $\$$ million & $-20,579$ & $-20,579$ \\
& & & & \\
National System & & & & \\
Total cost & $c$ & \$ million & $-22,773$ & $-22,773$ \\
\hline
\end{tabular}

Figure 4.11 shows a sensitivity of the price premium for hydropower generators. An increase in the price premium, in this figure, is equivalent to a decrease in the price of the contract by availability, while a decrease in the price premium is equivalent to an increase in the price of the contract by availability. In other words, a price above the price estimated here, $13.54 \$ / \mathrm{MWh}$, for the contract by availability, raises the hydropower generators' revenue and the costs of captive consumers. In contrast, a price below $13.54 \$ / \mathrm{MWh}$ reduces the costs for the captive consumers and the hydropower generators' revenue.

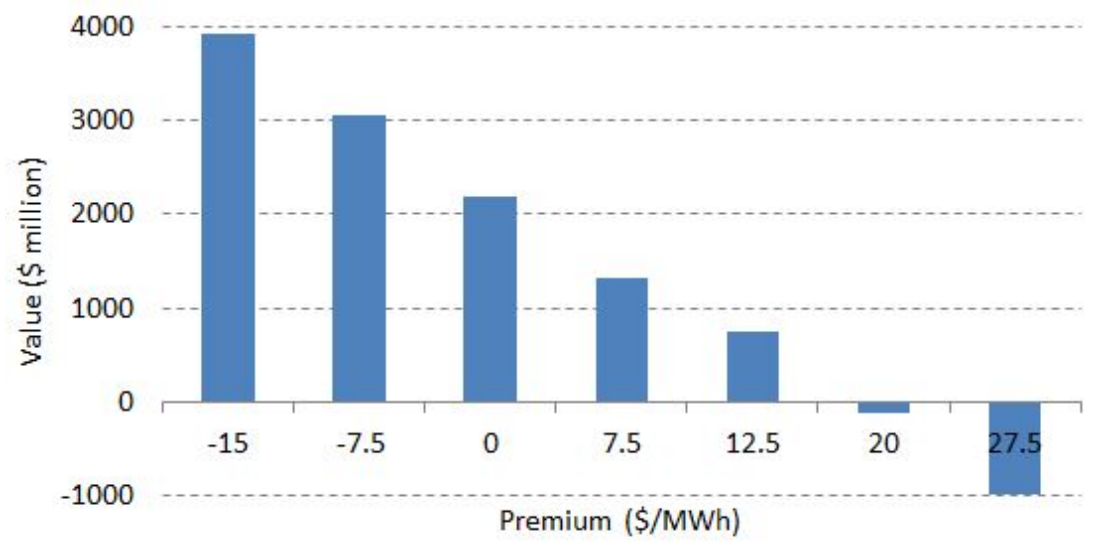

Figure 4.11: Sensitivity of hydropowers' revenue to the price premium.

The price estimated in this work for the contract of water availability is, therefore, the value that reduces the risk of the hydropower generators without overtaxing the system. In other words, for a price of $13.54 \$ / \mathrm{MWh}$ for the contract by availability, the generators' revenue doesn't change and the 
expected cost of hydropower generation for the consumers remain the same between the models.

It is important to note at this point that someone could argue that the fact the generators have no more a positive result in CCEE would imply that the hydrological risk was transferred to them. According to the current system rules, when the generators have energy deficit, the consumers have a positive balance in the spot market, which now, under the rule of the proposed model, doesn't exist. However, notice that the dominant situation in hydro-based systems is precisely the opposite of the recent drought. Also, the proposed model compensates the "losses" of the consumers in the CCEE by reducing the price of the contract by availability to a level below the contract by quantity. Furthermore, the consumer could benefit from the present model since they may have a tariff reduction in the long-term, as we will see in the next sections.

\section{5}

\section{Case 3: sensitivities}

\subsection{1}

\section{Demand and base energy}

Energy supply in Brazil relies heavily on renewable energy source and, consequently, it depends greatly on climatic conditions (39). The expectation of the rainfall level, therefore, influences the operation of the national power system. If there is an expectation of rain, the operator prefers to dispatch hydroeletric plants; otherwise, he may choose to preserve water for future use. Thus, the climatic change has an effect on the price of the contract by availability of hydroelectric utilities, which is the difference between the price of the contract by quantity and the price premium. The higher the premium price, the lower the price of availability, and vice versa.

Figures 4.12 and 4.13 show the sensitivity of the price premium to a change in the demand and in the base energy (also referred to in this thesis as nuclear or quantity energy). In general, it can be observed that the price premium is always positive in the analysis, which means that the price of the contract by availability is always lower than the price of the contract by quantity $\left(\pi>0 ; p_{h}^{a}<p_{h}^{f}\right)$. 


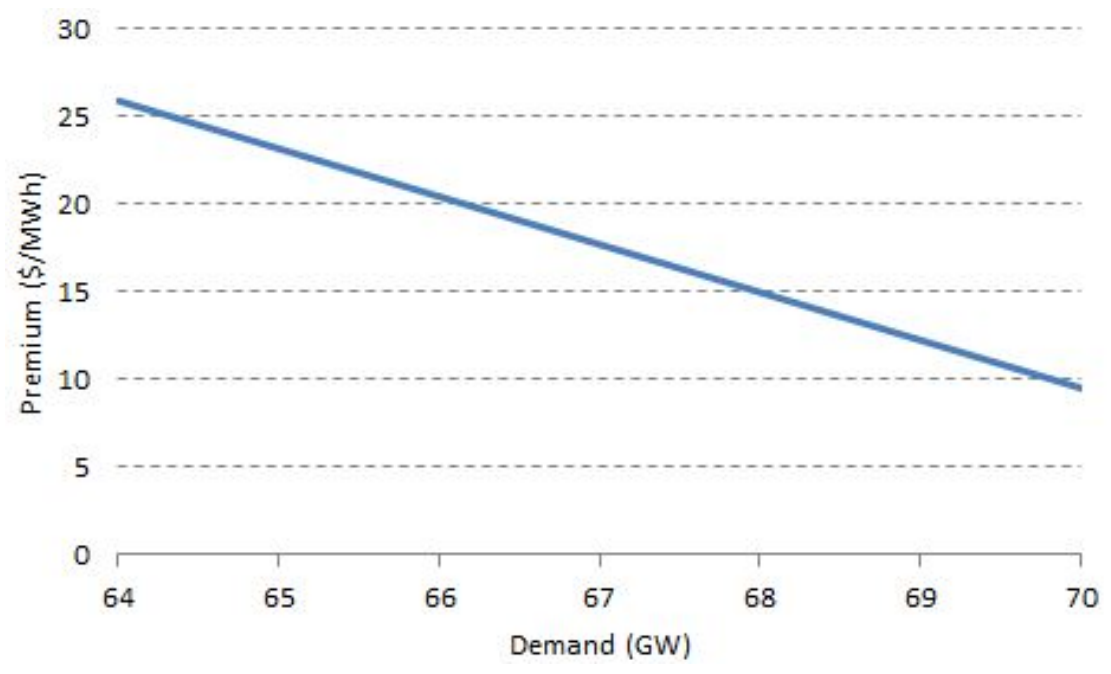

Figure 4.12: Sensitivity of the demand.

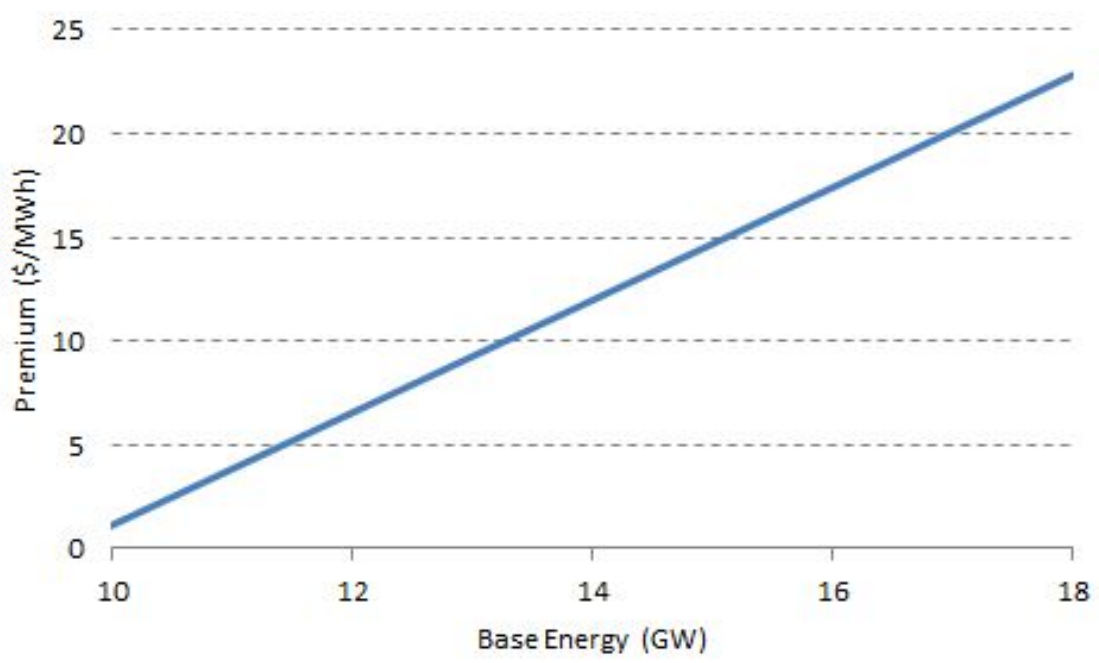

Figure 4.13: Sensitivity of the base energy.

Specifically, note in Figure 4.12 that an increase in demand decreases the price premium. When the national demand for electricity increases, the hydroelectric plants have preference to be dispatched by the National Operator, due to their low cost and flexibility. This happens regardless of the expected scenario of rainfall. In this case, the hydropower generators require a higher price to give up settling the energy excess (or secondary energy) in the spot market and change to a contract by water availability.

We observe from Figure 4.13 the opposite behavior of Figure 4.12, with respect to change in the base energy. In this figure, an increase of the base energy increases the price premium. When the energy from the base of the national system increases, ceteris paribus, the amount of energy required from hydroelectric utilities to meet the demand decreases. In this case, the hydropower generators accept a low price for the contract by availability to 
ensure revenue.

\subsection{2}

\section{Externalities for hydropower}

In addition to hydrological risk, hydropower generators face other externalities that negatively affect their generation. First, if on the one hand the inclusion of renewable sources, such as wind, solar and biomass, in the energy matrix is very important and strategic for the country, on the other hand, it reduces the generation of the power utility. As these sources are considered base energy, they have priority to be dispatched and, to a same demand, the amount of energy that the hydropower plant generates is reduced. Figure 4.14 shows the reserve energy dispatch during the year 2015. According to MME (97), the reserve energy was 2,621 MW in December 2016. As it happens in a scenario where the hydroelectric agent has no protection against this risk and needs to comply with the contract by quantity, the hydropower generators are subject to a significant financial loss in the spot market.

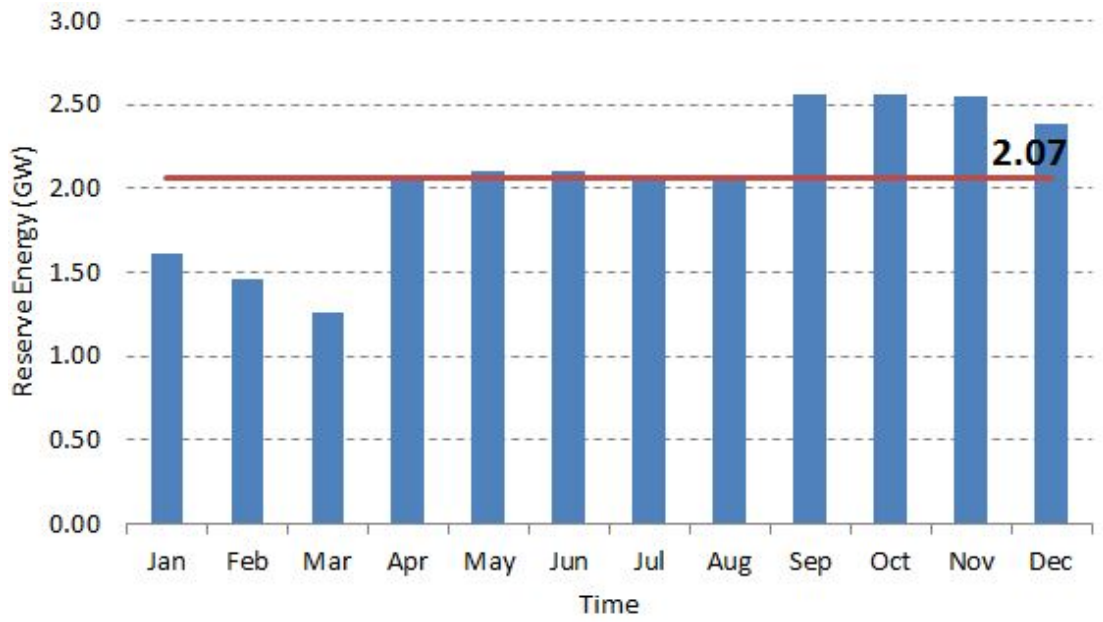

Figure 4.14: Reserve energy in 2015.

Moreover, besides the risk of other energy sources entering the base of the system, hydropower generators are suffering a reduction in its generation due to the Energy of Reserve. The Brazilian government in 2008 created the Energy of Reserve with the purpose to increase the security of the national energy supply. Nevertheless, the creation of the Energy of Reserve is another negative externality for the hydropower since this type of energy is a priority to hydroelectric generation, moving the generation down and causing the same problem as the previous case. Figure 4.15 shows that a variation in the Energy of Reserve does not change the costs for distributors, since this energy is funded by the government and it does not go into the consumers' account, but it reduces the revenue from the hydropower generators that produce less power. 


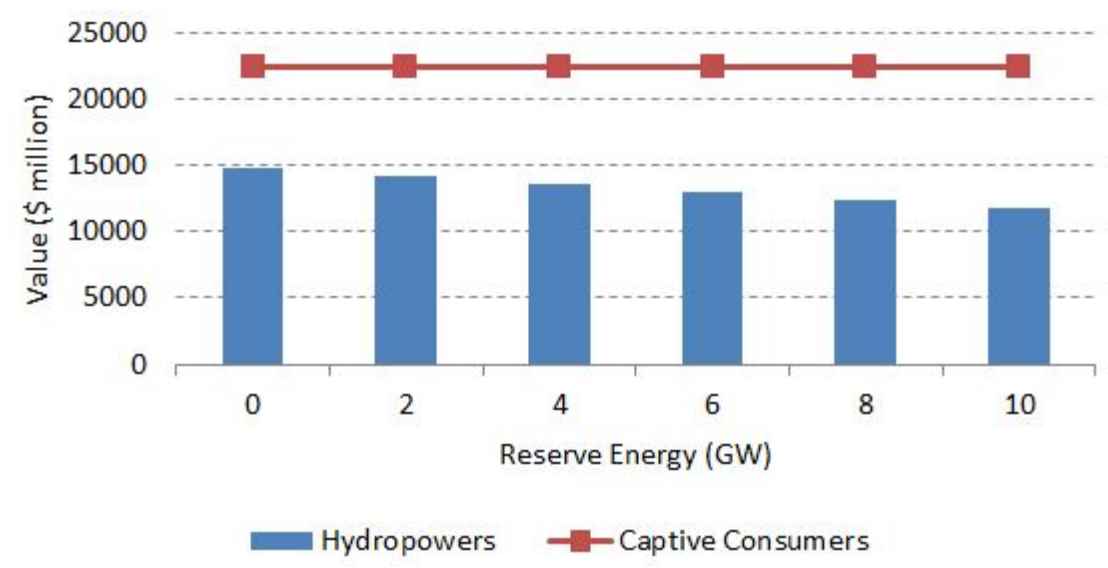

Figure 4.15: Impact of the reserve energy on revenue and cost.

Ceteris paribus, an increase in the Energy of Reserve together with a reduction of the demand may have a devastating effect on the hydropower generators accounts in the spot market. The increase in Energy of Reserve in recent years, coupled with the country's economic recession has led many hydropower generators to declare bankruptcy because they cannot afford the financial loss accumulated in the spot market. Figure 4.16 show how a change in the Reserve Energy and in the Demand impacts the generators in the spot market (CCEE). The red dot in this figure indicates the level of reserve energy in 2016.

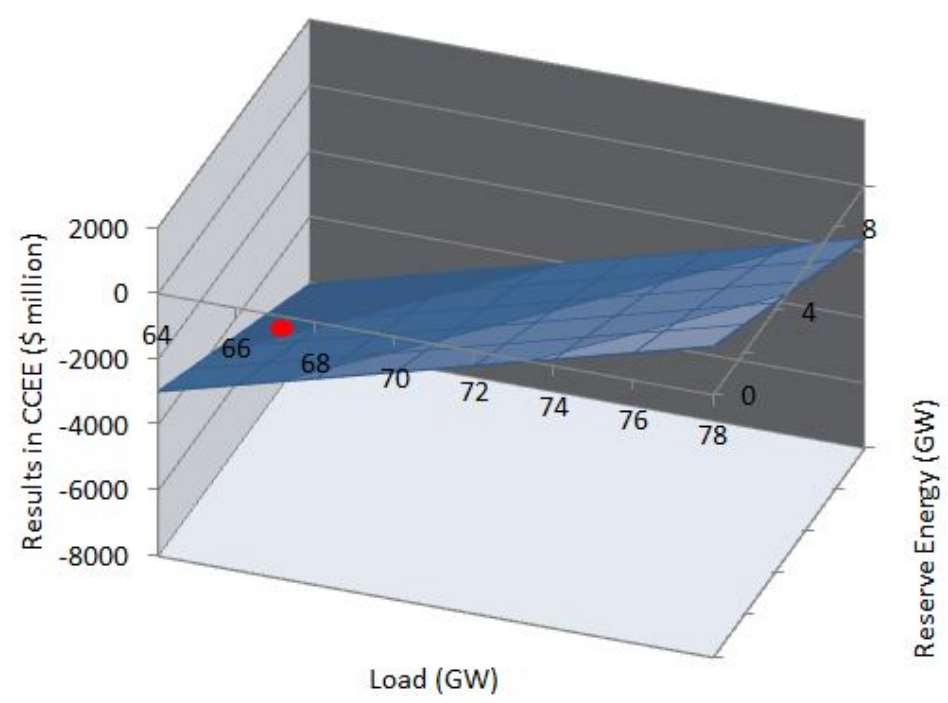

Figure 4.16: Sensitivity of the reserve energy and the demand.

Additionally, the national government has taken unexpected policies regarding the minimum flow limits of national rivers and regarding the dispatch of expensive thermals, to preserve water for future use, but that also contributes to reducing hydroelectric generation. In the last few years, 
the government reduced the minimum flow of the rivers and gave priority to the dispatch of very expensive thermoelectric plants. If the rainfall forecasts for the subsequent years continue to be pessimistic, the National Operator may choose to continue dispatching thermal power, even the most expensive, instead of hydropower, to preserve water for future use.

\subsection{3}

\section{Long-term energy tariff}

In the last few years, Brazilian consumers faced an increase in the electricity tariff. According to Bajay (42) the Brazilian electricity tariff escalation is due to rising marginal costs for generation because hydroeletric plants are located far from the main demand centers, resulting in high costs for transmission and environmental mitigation. The costs of power generation are, therefore, transferred to consumers, and the higher the risk these agents face, the higher the tariff.

The model of a mix of contracts by quantity and availability preserves the expected cost to the consumers and, consequently, the impact on the consumers' tariff is null in the short-term. However, when the expansion of the hydroelectric supply is observed, there may exist a positive effect of this contractual change in the long-term. Given that a more efficient mechanism of hydrological risk mitigation is created, the equity cost of the investors may fall which would lead distribution companies to buy cheaper energy and, consequently, charge the final consumers a lower energy tariff. According to Mattos (20), derivative operations increase the competitiveness of those in the electricity sector who may offer less costly contractual prices, since some risks involved would no longer be part of the formation of these prices because they were mitigated or eliminated. 


\section{Derivatives in Energy Markets}

Over time, derivatives are used to reduce the market exposure of agents (98). Their introduction in energy markets remote to the 1970s (23, 25) and since them, several instruments were developed to protect energy agents against undesirable price movement.

The pricing of energy derivatives, however, involves several challenges, which make these derivatives appear to be a new phenomenon (99). One of these challenges is the choice of an appropriate stochastic process. Another aspect is that most derivative products in commodity and electricity markets have a rather complex payoff structure. Also, the application of the noarbitrage approach is another critical issue for risk neutral valuation of derivative products. In electricity markets this condition is critical due to the non-storability of electrical power (99). Moreover, for a project to have option value, some conditions are required (100). First, the investment must be at least partially irreversible. Second, there must be sufficient flexibility in the project that allows the manager to operate depending on the state of nature that may occur in the future. Third, there must be uncertainty about the level of future cash flows that this project may generate (101).

When well understood and properly utilized, though, financial derivatives are beneficial to the sharing and controlling of undesired risks through properly structured hedging strategies $(27,102)$. Small hydropowers (SHPs) investments, for example, involve a multi-stage investment, regarding the construction and the operation steps, and can be evaluated under the real option theory (103). The entrepreneur can exercise an option to delay the beginning of the construction during a determined period of time, decide to invest in the next step or abandon the project. Fenolio and Minardi (104) shows that the option of postponing the investment in the construction of a SHP adds value to the project, since it could wait for a more favorable price moment to sell energy. The options were also used to evaluate wind farm and solar energy as sequential investments $(105,106)$, where each stage has a success/failure probability and involves a series of investments (107). By segregating the projects into stages, offering managerial flexibility (step advancement or abandonment), the project acquires great value making it 
even feasible.

There are various electricity financial/physical instruments traded among market participants in the over-the-counter markets, including plain vanilla options and exotic (i.e. non-standard) options like spark spread options, swing options, swaps and collars options $(108,25,109,110)$. Spark spread options are cross-commodity options paying out the difference between the price of electricity sold by generators and the price of the fuels used to generate it $(111,112)$. Electricity swing options provide their holder to repeatedly exercise the right to receive greater or smaller amounts of energy, subject to periodic constraints (113). According to Kaminski (109), when exercising a swing option, the daily quantity may vary (or, swing) between a minimum daily volume and a maximum volume. If the buyer misses the minimum-take quantity of any contract period, then a lump sum penalty or a payment making up the seller's revenue shortfall needs to be paid (i.e. take-or-pay). Due to their importance for this thesis, the swaps and collars are further explained in the next sections.

In the work of Kaminski and Gibner (114) an extensive introduction to the many exotic options traded at commodity exchanges is given. The authors point out that these options are useful due to their ability to capture complex structural characteristics of energy assets. Their pricing formulas, however, are not obvious and sometimes cannot even be determined analytically (115).

\section{1 \\ Swap}

The swap contract represents the exchange of financial flows in order to protect the buyer against undesirable variations. A swap contract can be understood as an agreement between two companies to exchange cash flow on a future date (116). Swaps allow companies to hedge against price swings once it is an agreement whereby a floating (or market) price is exchanged for a fixed price, over a specified period of time. The provider of swaps offers price insurance according to individuals' requirements, with guaranteed maximum and minimum prices according to need. For a swap to occur, it is necessary for the parties to present different risk propensities.

In the case of the electricity sector, energy captive consumers utilize swaps in order to fix or lock in their energy costs, while energy generators utilize swaps in order to lock in or fix their revenues. There are a few different types of swap contracts related with this sector. For example, generators that have contracts corrected by IGP-M and desire to change this index to dollar will do a swap of IGP-M x Dollar. Also, generators that have generation in different sub- 
markets can opt to change their exposure from a sub-market to another (30). An agent 01 (02) with sales contracts in the South (Southeast) sub-market, but with ballast in the Southeast (South) sub-market, is exposed to differences in the marginal costs of these sub-markets. These agents can mitigate this risk by a swap contract in which for each MWh transacted between the sub-markets the agent 01 transfers to agent 02 the value $\operatorname{Max}\left(p_{m, 1}-p_{m, 2}, 0\right)$, where $p_{m, 1}$ and $p_{m, 2}$ are the spot price in the sub-market 1 and 2 , respectively. In other words, a trader assumes the risk of this exposure in exchange for the addition of a percentage to the price of the sub-market of origin.

A swap can also be used to change fixed price and floating price of the electric power. An agent "A" having a floating price contract can find a agent " $\mathrm{B}$ " with a higher risk bias who is willing to take this float in exchange for a fixed payment. As result, "A" becomes free of risk by assuming a fixed payment to "B", which in turn assumes the fluctuation of the price in exchange for a direct remuneration of a certain percentage in cash (29). Figure 5.1 shows an example of financial flows in an energy rate swap agreement.

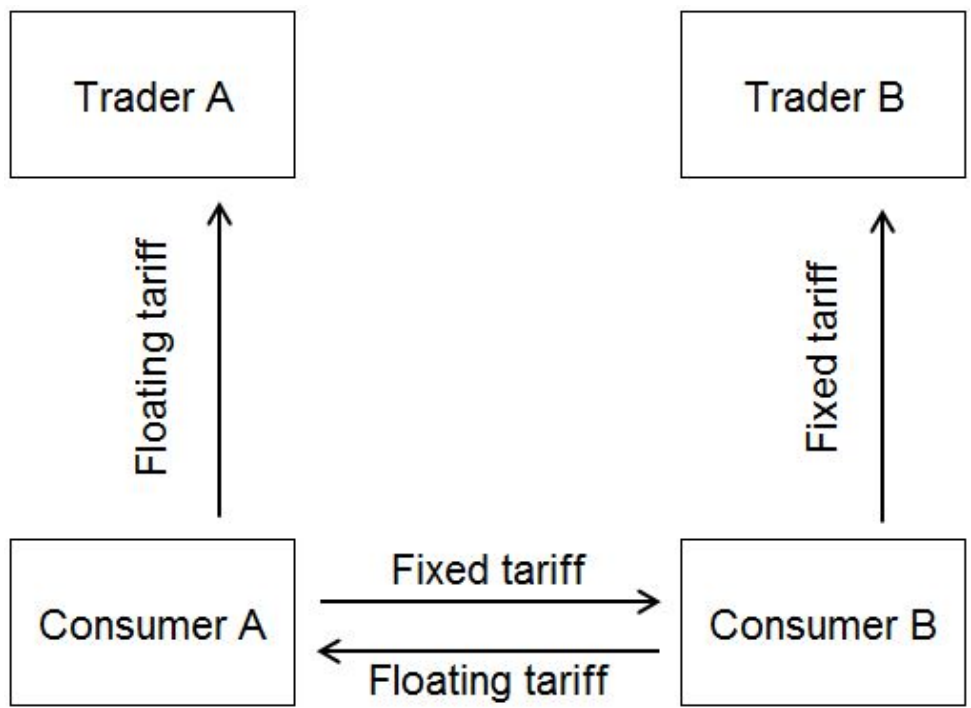

Source: Adapted from Martin (117).

Figure 5.1: Swap of energy tariff.

The swap price depends on the contract style and the model adopted. Margrabe (118) was the first author to develop the pricing equation for a European-type option to exchange one risky asset for another. The author assumes that the rate of return of two assets, with price $p_{i}(i=1,2)$, is given by equation $5-1$.

$$
d p_{i}=p_{i}\left[\alpha_{i} d \tau+v_{i} d z_{i}\right]
$$

Where $d z$ is a Wiener process, $\alpha$ is the percentage drift and $v$ is the percentage volatility. 
The exchange option is simultaneously a call option on asset one with exercise price $p_{2}$ and a put option on asset two with exercise price $p_{1}$, which can be exercised only at $\tau^{*}$. Then, the initial condition to the owner exercises his option is given by equation $5-2$.

$$
w\left(p_{1}, p_{2}, \tau^{*}\right)=\max \left(0, p_{1}-p_{2}\right)
$$

With the boundary condition,

$$
0 \leq w\left(p_{1}, p_{2}, \tau\right) \leq p_{1}
$$

The option buyer can hedge his position by selling $w_{1} \equiv \partial w / \partial p_{1}$ units of asset one and buying $-w_{2} \equiv \partial w / \partial p_{2}$ units of asset two.

The function $w\left(p_{1}, p_{2}, \tau\right)$ is the solution to the differential equation 5-3, which is given by equation $5-4$.

$$
\begin{gathered}
w_{3}+\frac{1}{2}\left[w_{11} v_{1}^{2} p_{1}^{2}+2 w_{12} v_{1} v_{2} \rho_{12} p_{1} p_{2}+w_{22} v_{2}^{2} p_{2}^{2}\right]=0 \\
w\left(p_{1}, p_{2}, \tau\right)=p_{1} N\left(d_{1}\right)-p_{2} N\left(d_{2}\right) \\
d_{1}=\frac{\ln \left(p_{1} / p_{2}\right)+\frac{1}{2} v^{2}\left(\tau^{*}-\tau\right)}{v \sqrt{\tau^{*}-\tau}} \\
d_{2}=d_{1}-v \sqrt{\tau^{*}-\tau}
\end{gathered}
$$

Where $N(\cdot)$ is the cumulative standard normal density function and $v^{2}=v_{1}^{2}-2 v_{1} v_{2} \rho_{12}+v_{2}^{2}$ is the variance of $\left(p_{1} / p_{2}\right)^{-1} d\left(p_{1} / p_{2}\right)$.

Since Margrabe (118) other authors have been studying the same problem of exchange assets, but with more increments. Wang, Song and Wang (119), for example, consider a valuation model for power exchange options with counterparty risk and jump risk. The power option is a European option to exchange the power value $S_{1}^{\beta_{1}}$ of one asset for the power value $S_{1}^{\beta_{1}}$ of another asset, with $\beta_{1}$ and $\beta_{2}$ as constants. In this case, the payoff at maturity $T$ with the counterparty risk has the form of equation 5-5.

$$
\left(S_{1}^{\beta_{1}}(T)-S_{1}^{\beta_{1}}(T)\right)^{+}\left(\mathbb{1}_{\left\{V(T) \geq L^{*}\right\}}+\frac{(1-\alpha) V(T)}{L} \mathbb{1}_{\left\{V(T)<L^{*}\right\}}\right)
$$

According to the authors, the option holder may suffer from losses when the counterparty defaults, where default events are triggered so long as the value $V$ of the writer's assets is less than a certain threshold $L^{*}$ at time $T$. $L^{*}$ roughly equals the amount of claims $L$ outstanding at $T(120)$. In the event of a credit loss, the recovery write-down on the nominal claim is $(1-\alpha) V(T) / L$, 
where $\alpha$ comprises the deadweight costs of the financial distress or bankruptcy. The ratio $V(T) / L$ represents the value of the assets of the writer available for dispensation to all creditors expressed as proportion of total debt obligations.

The initial fair price of power exchange options with counterparty risk is given by equation $5-6$.

$$
\begin{gathered}
P(0)=e^{-r T}\left\{E\left[\left(S_{1}^{\beta_{1}}(T)-S_{2}^{\beta_{2}}(T)\right)^{+} \mathbb{1}_{\left\{S_{1}^{\beta_{1}}(T) \geq S_{2}^{\beta_{2}}(T), V(T) \geq L^{*}\right\}}\right]\right\} \\
\left.+\frac{1-\alpha}{L} e^{-r T}\left\{E\left[V(T)\left(S_{1}^{\beta_{1}}(T)-S_{2}^{\beta_{2}}(T)\right)^{+} \mathbb{1}_{\left\{S_{1}^{\beta_{1}}(T) \geq S_{2}^{\beta_{2}}(T), V(T)<L^{*}\right.}\right\}\right]\right\}
\end{gathered}
$$

\section{2}

\section{Plain call and put}

Electricity call and put options offer their purchasers the right, but not the obligation, to buy or sell a fixed amount of underlying electricity at a prespecified strike price by the option expiration time. They have similar payoff structures as those of regular call and put options on financial securities and other commodities. The payoffs of an electricity call option and put option are

$$
\begin{aligned}
& \text { Payoff of an electricity call option }=\operatorname{Max}\left(p_{m, \tau}-k, 0\right) \\
& \text { Payoff of an electricity put option }=\operatorname{Max}\left(k-p_{m, \tau}, 0\right)
\end{aligned}
$$

where $p_{m, \tau}$ is the electricity market (spot) price at time $\tau$ and $k$ is the strike price.

Electricity call and put options are the most effective tools available to owners of hydroelectric plants for hedging price risk because electricity generation can be essentially viewed as call options on electricity, particularly when generation costs are fixed.

\section{3}

\section{Collar}

The buyer of a collar contract of electricity seeks to reduce the fluctuation of the spot price. The agent agrees to pay the spot price plus a percentage in exchange for cap and floor that reduce the price volatility. Often times, the options are structured in such a way that the premium of the purchased option is completely offset by the premium of the sold option, a structure known as a costless collar (121). Bettis, Bizjak and Lemmon (122) used a zero-cost collar option for flexibly hedging the asset price volatility risk of a company's 
shareholders. They concluded that insiders use the instruments of zero-cost collars and equity swaps primarily for reducing the risk associated with their equity holdings and human capital investments in the firm and that increasing the transparency of these transactions may provide valuable information to investors.

According to Shan, Garvin and Kumar (123) in revenue collar the concessionaire buys a floor (a put option) from the underwriter to receive the protection against revenue falling below the floor, and simultaneously sells a cap (a call option) to the underwriter to defray the cost of the floor. Figure 5.2 illustrates the zero-cost collar as presented by the authors. In this figure, line 1-2'-3' represents the revenue without the collar option, while lines 1'-2'3'-4' refer to the collected revenue with the collar option. The put option the concessionaire buys, secures its minimum revenue at level 2-2'. The call option it sells forfeits its right to retain the excess revenue beyond level 3-3', which is captured by the underwriter.

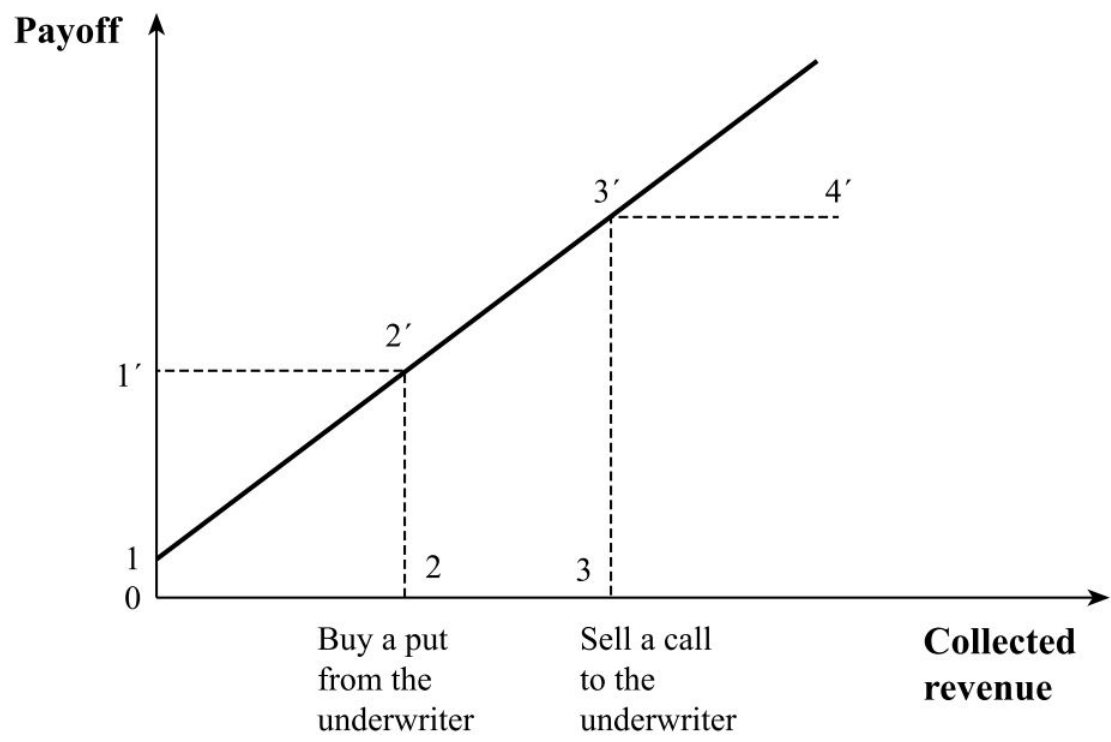

Source: From Shan, Garvin and Kumar (123).

Figure 5.2: Zero-cost collar.

A collar contract can be characterized by a zone where the contract is valued by the spot price plus a premium one, and two other bands valued by a floor or ceiling price (124), such as

$$
P=\left\{\begin{array}{cc}
\text { Floor }, & \text { spot price }<\text { floor } \\
\text { Cap, } & \text { spot price }>\text { cap } \\
\text { Spot price }+ \text { premium }, & \text { otherwise }
\end{array}\right.
$$

Where floor represents the minimum price of the contract and cap the maximum price of the contract. 
According to Wilhelm (99), a combination of caps and floors in energy markets is a collar that protects against high prices and foregoes returns from low prices giving the payoff intensity. In this case, cap options are European type contracts, where during the time interval $\left[\tau_{1}, \tau_{2}\right]$ the buyer owns the right to receive a cash flow at intensity $\left(\left(F_{s}(s)-K_{c}\right)^{+}\right)_{s \in\left[\tau_{1}, \tau_{2}\right]}$ with a price cap $K_{c}>0$ previously specified in the contract. The floor protects against low spot prices within $\left[\tau_{1}, \tau_{2}\right]$ ensuring a cash flow at intensity $\left(\left(K_{f}-F_{s}(s)\right)^{+}\right)_{s \in\left[\tau_{1}, \tau_{2}\right]}$ with a price floor $K_{f}>0$ at any time $s \in\left[\tau_{1}, \tau_{2}\right]$ of the contract. The collar is $\left(\left(F_{s}(s)-K_{c}\right)^{+}-\left(K_{f}-F_{s}(s)\right)^{+}\right)_{s \in\left[\tau_{1}, \tau_{2}\right]}$.

\section{4}

\section{Derivatives in the national electricity sector}

In Brazil, hedging instruments in the energy market are needed because of the high volatility of the electricity spot prices. The derivative increases the hedge possibilities available to agents to formulate their asset portfolios by ensuring greater stability to its financial flows. The application of these instruments, however, depends on the liquidity and the level of standardization of the market contracts, which are directly related to the evolution of the electricity derivatives market itself.

According to Domingues et al. (31), a scenario of drought in the Brazilian electricity market exposes investors to many uncertainties, both physical and financial, and which include institutional and political uncertainties. The authors present a new contribution to the analysis of the risk factors that guide the electricity market, providing more consistent subsidies to the decision makers. Also, the authors present some hedging strategies such as swap and collars in the electricity contracts that can be adopted by the companies to manage the risks arising from the volatility of the spot market.

The investment decisions of the national generators, traders, distributors and consumers of electricity involve risk management. The need to balance the sale and consumption of electricity forces the players to determine a priori their future level of consumption and the ability to honor their sales commitments, but the uncertainty regarding the future events causes the impossibility of perfect prediction. In addition, the excessive volatility of the market prices contribute to errors of expectations of the agents, exposing them to contractual risks. The adoption of derivatives, then, help these agents to mitigate financial risks, but they require that the players have different levels of risk aversion, i.e., the parties need to assume opposite positions regarding the transaction of the asset. 
Different derivative instruments are adopted in the formulation of contracts of energy sale in the country. Derivatives are used, for instance, to protect unexpected changes in input costs used in the sector by thermopower generators. For Studart (17), financial operations in the Brazilian electricity sector involve large amounts of resources and prolonged maturation, which significantly expose them to financial risks of the type of exchange risks and interest rate risks.

Tonelli (30) proposed a computational model, based on the portfolio theory, to manage the risks in the commercialization of electricity in Brazil. The author analyzed the contract environment of the energy sale in the country, the specific legislation of the sector, the most commercialized products and the risks involved in the performance of this activity. As result, Tonelli developed an automatic portfolio capable of recognizing, managing and optimizing various types of energy contracts, such as swap and collars, producing analysis to support decision making. The options studied by the author proved to be good risk control instruments to protect the generator against low spot prices.

According to Arfux (29), derivatives can stabilize the national generators' cash flows and control their profits from exposure to market risk, since they cover several stages of the productive process of companies in the electricity sector. The author developed a model to hedge energy agents against price fluctuations in the short-term, making possible to obtain profit. Also, Arfux models the portfolio composition of energy sales contracts through the Markowitz theory, considering the agents' risk propensity, the spot market, bilateral contracts and call and put options. The author also verifies the impact of different expectations of inflows on the portfolio of contracts. As a result, the paper determines the efficient composition of the portfolio that provides the highest expected return. The simulations showed that the derivative instruments are effective when used for agents to hedge against price volatility. The simulations also showed that controlled exposure to price volatility can bring profit to the trading agent.

Nonetheless, the use of derivatives to protect generators from energy shortage is underdeveloped in Brazil. This thesis, then, proposes some derivatives instruments to hedge the generators during these scenarios, which in general coincide with high spot prices. This is the mainly difference between this thesis and the current literature. In the other cases, the derivatives were developed to protect the generators' revenue against low spot prices. This thesis, however, is concerned with the financial losses that the hydropower generators face when the energy production falls below the contract and they need to buy energy in the market, at prevailing high spot prices, to fulfill their 
contract obligations. 


\section{6 \\ Options as Instruments in Electricity Contracts}

As hydropower projects have many uncertainties, options can provide strategies to investors manage their risks exposure. Swaps and collars, for example, are good instruments of risk control. In energy markets, these options are widely used to protect their holders against low spot prices. With options, an investor can be protected from adverse price movements, without giving up the potential to profit from favorable price movements (125).

The Brazilian energy market is characterized by the fact that most of the sales of hydropower are negotiated in long-term contracts by quantity. Therefore, in periods of adverse climatic conditions, as recently experienced in the country, generators are exposed to the hydrological risk, producing less than the contracts obligation and needing to buy the energy deficit in the spot market at very high prevailing prices to honor their contracts. In view of this, the design of the current energy options, which protect their holders against low spot prices, is somewhat counter-intuitive.

In this context, we propose to model in this section the options of swap and collar as hedge instruments during periods of severe drought, when hydropower generators are exposed to the hydrological risk and high market prices. In all cases, explicit pricing formulas are derived as European type derivatives and we determine the fair price of the energy derivative contract.

Our models aim to protect generators against high spot prices, i.e., low power generation, and because of this they have some particularities. We model the swap in such a way that the generator exchange energy flows with the captive consumer. In this case, the energy available for swapping is defined according to the amount of the plants' physical guarantee the generator wants to protect. On the other hand, the collar is separated into two cases, named collar and collar by difference (CBD). The collar is designed as a hybrid approach in which the buyer buys a call option and sells a put option, which places a cap on losses and a floor on gains. In this case, the power output for each year of the life of the power generation facility is projected to fall within the collar, i.e., between the ceiling and the floor. The collar is structured to accommodate expected volatility in annual production. The CBD is proposed in such a way that the generator buys a call, but another agent sells a put. 
The generators remain with the secondary energy in this case. In addition, we observe that in the collar the floor and the cap are defined by the same agent (generator) for different levels of energy, but in the CBD the triggers of cap and floor are equal for both agents (generator and agent).

The generator's choice for one of these models depends on its desired level of energy protection and risk aversion. These models, however, are not mutually exclusive, and therefore the generator could opt for more than one alternative. Moreover, the difference between the premiums of the collar and the CBD is constant for each defined trigger level, once it is given by the expected value of the secondary energy measured in the mechanism. Thus, for the same floor, the generator chooses between the collar and CBD comparing its valuation of the secondary energy with that implied in the pricing model. This range of hedge alternatives maximizes the possibilities of adherence of generators by working with different levels of risk limitation, without prejudice to the establishment of an adequate compensation to consumers.

\section{1}

\section{Swap}

Energy swaps are financial contracts that enable their holders to pay a fixed price for underlying electricity, regardless of the floating electricity price, or vice versa, over the contracted time period (27). In general, generators use this option to protect their revenue from short-term price swings, but generators with long-term contracts could also use the swap as a protection against energy shortfall due to some unexpected climatic variation, i.e., against the hydrological risk.

We propose a swap in which there is an energy exchange between a generator and a client with different risk aversion, where for each fixed megawatt (MW) delivered to the generator, the client receive a quantity of floating energy. This exchange is illustrated in Figure 6.1, where $Q_{\text {Fixed }}$ and $Q_{\text {Floating }}$ represent, respectively, fixed and floating energy quantity. This swap mechanism is derived from section 3 , but with the difference that in the present case the generator is committed with long-term energy contracts.

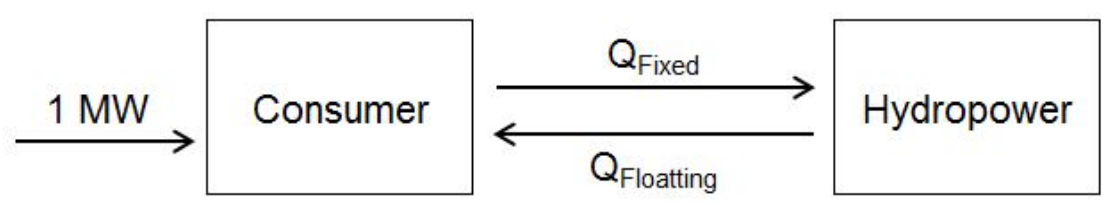

Figure 6.1: Swap derivative. 
According to our swap model, the generator receives fixed amounts of energy whenever it deliver floating quantities indexed to the GSF. The fixed and the floating quantities are represented in figure 6.2, where $F P$ is the factor of protection, i.e., the amount of energy from the contract by quantity that is equivalent to the minimum flow of the national rivers. The difference between the physical guarantee and the $F P$ is the floating amount, i.e, the energy that is available for swapping.
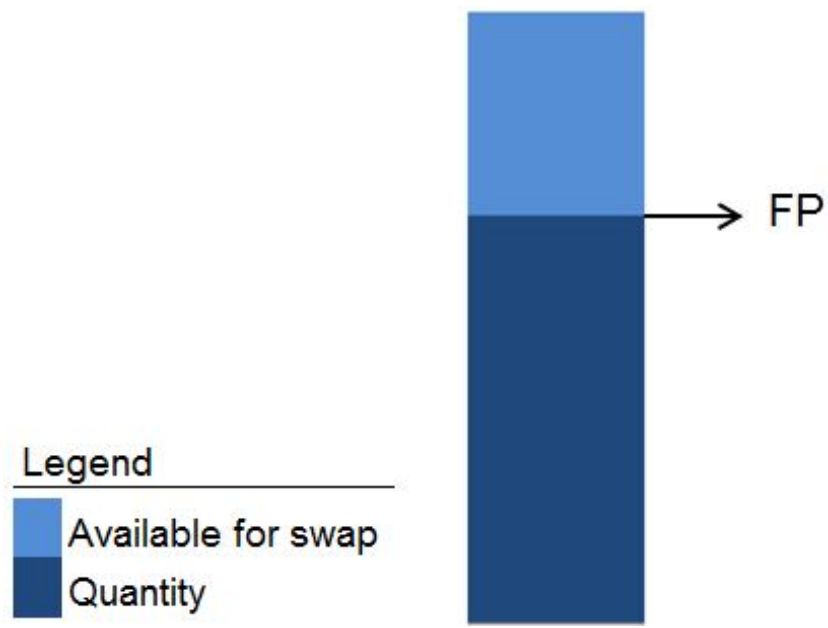

Figure 6.2: Factor of protection from the physical guarantee.

The swap mechanism is shown in Equation 6-1, where FFE indicates the factor of floating energy and FP refers to the factor of protection. The consumers receive the factor $F F E$ for each MW available to a hydroelectric plant. The uncertainty of the model is in the GSF factor.

$$
\begin{aligned}
F F E_{\tau} & =\frac{G S F_{\tau}-F P_{\tau}}{1-F P_{\tau}} \\
0 & \leq F P<1
\end{aligned}
$$

The generator's revenue $\left(R_{h}\right)$ is given by

$$
R_{h, \tau}=p_{h, \tau} \cdot q_{h, \tau}+\left(g_{h, \tau}-q_{h, \tau}\right) \cdot p_{m, \tau}
$$

Where $p$ and $q$ are respectively the price and energy quantity defined in the long-term contract and $g$ refers to the hyropower generation in a period of time $\tau$. The second part of this equation is the result of the spot market adjustment at the price $p_{m}$.

The result of generators in the spot market $\left(\right.$ res $\left._{h}\right)$, considering the swap contract, is shown in Equation 6-2. In this case, $P G$ refers to the physical guarantee in period $\tau, p_{m}$ represents the spot (market) price and $p_{a}$ is the price of the availability energy, which is calculated in this thesis as Equation $3-32$. 


$$
r e s_{h, \tau}^{*}=F F E_{\tau} \cdot\left(1-F P_{\tau}\right) \cdot P G_{h, \tau} \cdot p_{h, \tau}^{a}
$$

As result of the swap, both agents are in a hedged position. The client gets a guaranteed price over a specified period of time and the generator hedge their revenue over the same period.

\section{2}

\section{Collar}

In energy markets, a collar is used as an instrument similar to a power purchase agreement, where the agent uses the combination of buying an out-ofthe-money put and selling an out-of-the-money call, thus creating both a ceiling and a floor $(126)$. The sale price is given by $\min \left(\operatorname{cap}, \max \left(p_{m} \cdot(1+x)\right.\right.$, floor $\left.)\right)$, being $x$ the premium applied to the spot price $p_{m}(30)$. In general, their users are concerned with short-term prices oscillations (29).

In this thesis, we propose a collar that could be considered as outside of the box with respect to hedging. We propose this instrument to be used to protect the generators against energy shortfalls, which, in predominantly hydro-based countries, is associated with high energy prices in the market. In contracts by quantity, generators bid an energy price for the energy offered (127), then, if due to a drought or other reasons, they are short, the energy deficit must be bought in the market at the current high price. On the other hand, the energy excess or secondary energy $(S E)$ is sold in the market at low prices. Both generation situations are illustrated in the left side of Figure 6.3.

The collar is illustrated in the right side of Figure 6.3. Our collar is designed in such a way that the generators buy a call that guarantees them if the power generation stays below the floor, they have the right to buy the energy deficit for a set price. Also, the generators sell a put that when the generation gets above the cap, it gives the right to its owner to buy the secondary energy for a set price. Note that if the cap matches the floor, then the collar becomes a swap. The collar can be seen as an open swap, where in the middle, the hydropower agents are assuming the risk and at the extremes they mitigate the risk of one side, while deliver the upside of the other one. 

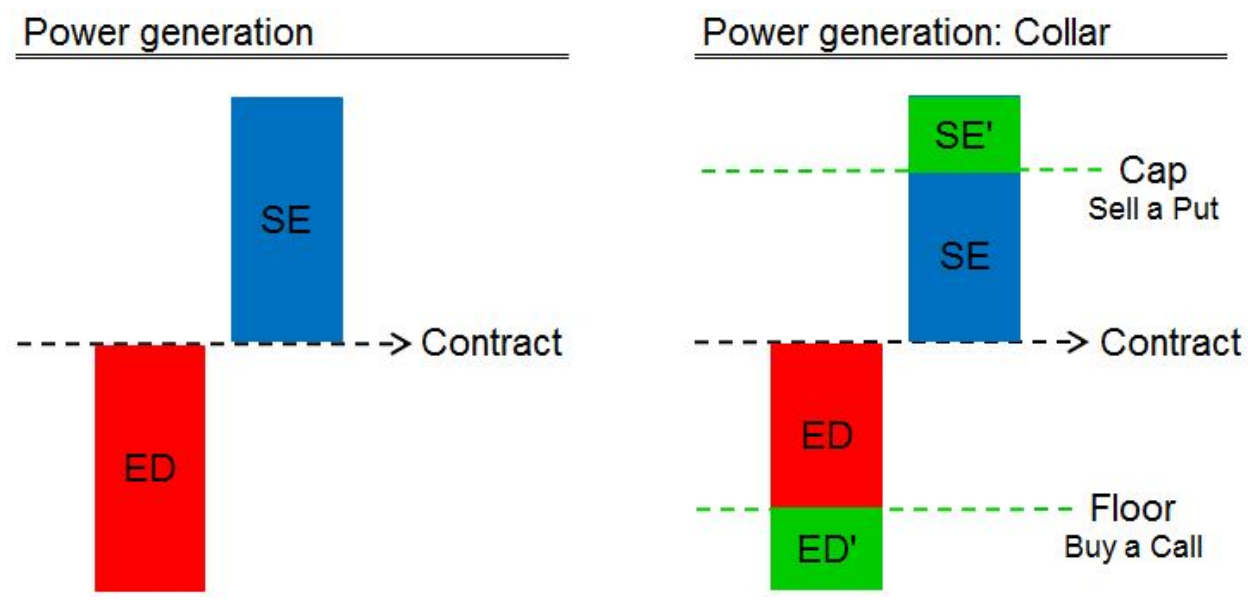

Figure 6.3: Collar design.

Figure 6.4 illustrates a situation where the plant's energy deficit coincides with high prices in the spot market, and the secondary energy occurs in a moment when the spot prices are low. Our collar idea is that when generation falls below a floor, the generators have the right to buy energy at a set price below the market price (named price-up, $p^{u}$ ). On the other hand, when there is secondary energy, i.e., the generation is above the cap, the generators sell this energy for a set price below the market price (named price-down, $p^{d}$ ). The combination of buying a call and selling a put forms the collar. This contract design is innovative compared to standard options, once it seeks to protect the generators against low production periods, when they face significant losses with high market prices. In addition, our methodology involves modeling uncertainties in price and power generation.

The fair value of this collar, then, follows by a combination of a call and a put, as presented in Equation 6-3.

$$
\operatorname{Collar}(\tau, F, C)=\operatorname{Cap}(\tau, C)-\operatorname{Floor}(\tau, F)
$$

where,

$$
\begin{gathered}
\operatorname{Cap}_{\tau \in T}=S E^{\prime} \cdot p^{d} \\
\operatorname{Floor}_{\tau \in T}=E D^{\prime} \cdot p^{u}
\end{gathered}
$$

In this case, $S E^{\prime}$ refers to the secondary energy of the green block of Figure 6.3, which is calculates as $g_{h}-C$, and $E D^{\prime}$ refers to the energy deficit of the green block of this figure, which is calculates as $F-g_{h}$. It is important to note that the market price may sometimes be higher or lower than the price set in the call or put contract. In such cases, the owner exercises the option for the lowest price between the contract price and the market price. 

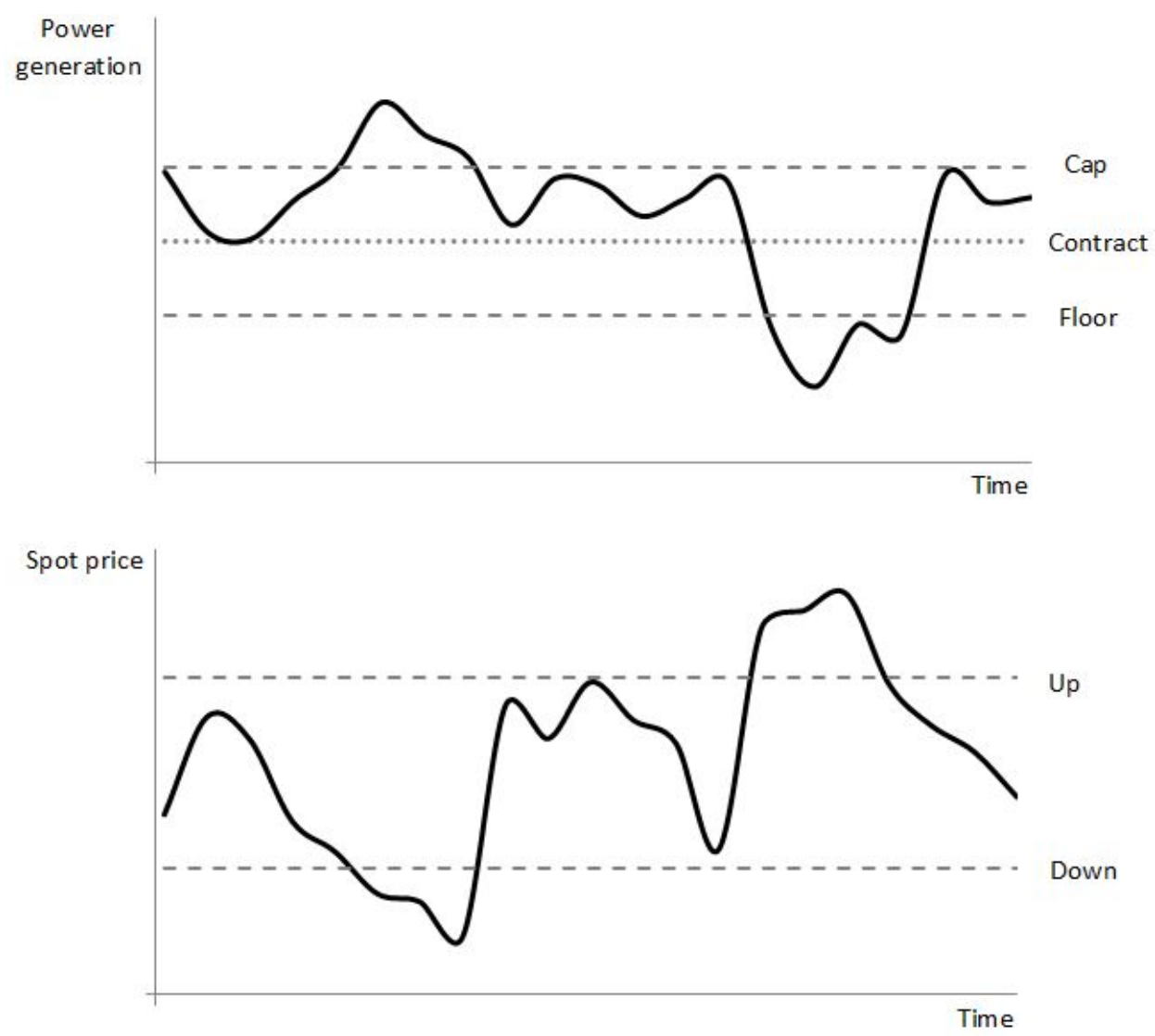

Figure 6.4: Collar contract.

Rewriting equations 6-4 to 6-5, we have the equations 6-6 to 6-7.

$$
\begin{gathered}
\operatorname{Cap}_{\tau \in T}=\operatorname{Max}(g-C, 0) \cdot \operatorname{Max}\left(p_{m}-p^{d}, 0\right) \\
\text { Floor }_{\tau \in T}=\operatorname{Max}(F-g, 0) \cdot \operatorname{Max}\left(p_{m}-p^{u}, 0\right)
\end{gathered}
$$

$C$ and $F$ are, respectively, the cap and floor energy amount and $g$ is the generation of the hydropower plant in a period $\tau$.

Another way to write the cap and the floor is in terms of the GSF, as presented in equations $6-8$ to 6-9

$$
\begin{gathered}
\operatorname{Cap}_{\tau \in T}=\operatorname{Max}(G S F-C, 0) \cdot G F \cdot \operatorname{Max}\left(p_{m}-p^{d}, 0\right) \\
\text { Floor }_{\tau \in T}=\operatorname{Max}(F-G S F, 0) \cdot G F \cdot \operatorname{Max}\left(p_{m}-p^{u}, 0\right)
\end{gathered}
$$

Where $C$ and $F$ are now written as a percentage of the plant's physical guarantee. The prices up and down are represented by $p^{u}$ and $p^{d}$, respectively. 


\section{3}

\section{Collar by difference}

We also propose in this thesis a hedge named collar by difference in which instead of a combination of buying a call and selling a put, the generator is interested in only buying the call. The plant's owner wants protection against energy deficit, but without giving up from part of its revenue. In this case, a call contract is established between the buyer of the position (the generator) and a trader. The sale of the put by another agent creates what we call the collar by difference. The collar by difference is formed when a trader performs a floor contract with a generator and a cap contract with a customer, where there is no gap between these triggers.

The behavior of the collar by difference can be understood from the design of the model for differences proposed by Oliveira (128) and Domingues (31), and presented in Figure 6.5. This figure is set in terms of the price, but the concept is similar to our for power generation triggers. According to their model, the trader undertakes to reimburse the difference to the customer if the spot price exceeds the exercise price $\left(S_{T 1}-P_{E}\right)$. Also, the trader reimburses the difference to the generator if the spot price is below the strike price $\left(P_{E}-S_{T 2}\right)$. In this figure, $S_{T 1}, S_{T 2}$ and $P_{E}$ are, respectively, the cap-price, the floor-price and the exercise price.

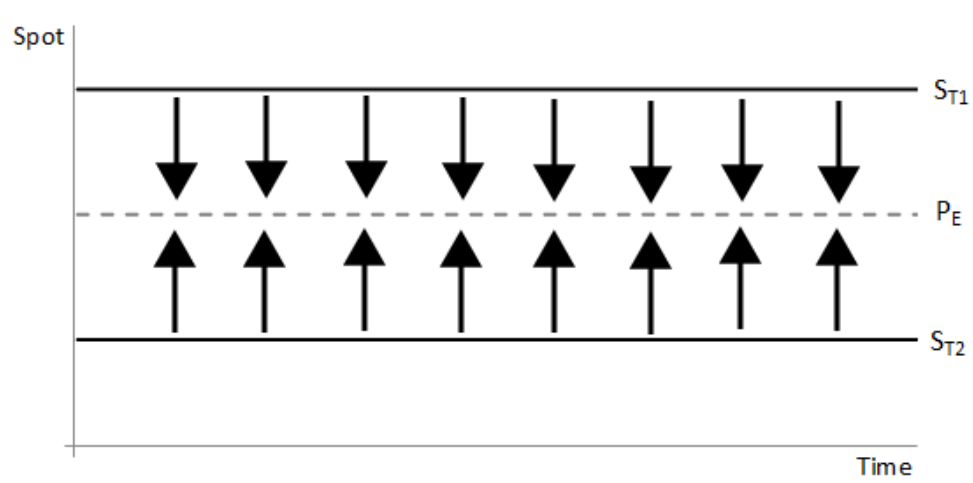

Figure 6.5: Collar by difference.

In our model we define the collar by difference in terms of power generation, not price. In this case, the trader undertakes to reimburse the difference to the generator if the generation is below the strike generation $\left(G_{E}-g\right)$. For this contract, the generator pays a fixed value (premium) to the trader. Also, the trader reimburses the difference to the customer if the generation exceeds the exercise generation $\left(g-G_{E}\right)$. The customer must pay a premium price to the trader. $G_{E}$ is the exercise value of power generation, which can be a cap or a floor depending on the contract modality, and $g$ is the hydropower generation. 
The amount that the generator receives from the trader, Floor, is shown in Equation 6-10.

$$
\text { Floor }_{\tau \in T}=\operatorname{Max}(F-g, 0) \cdot \operatorname{Max}\left(p_{m}-p^{u}, 0\right)
$$

The amount that the customer receives from the trader, Cap, is shown in Equation 6-11.

$$
\operatorname{Cap}_{\tau \in T}=\operatorname{Max}(g-C, 0) \cdot \operatorname{Max}\left(p_{m}-p^{d}, 0\right)
$$

Where $g$ is the registered generation and $C$ and $F$ are respectively the cap and floor energy amounts. Following Domingues (31), the premium that the customers and the generators must pay to the trader can be determined as the sum of Cap and Floor plus a profit margin defined by the trader. 


\section{7 \\ Numerical Example: option instruments}

This section numerically exemplifies the different strategies presented in section 6 to hedge hydropower generators in Brazil against high spot prices, i.e., low power generation. First, we present the results of a conventional power purchase agreement and the difficult of a contract by quantity in mitigating hydrological risk, and then we show the benefits of the proposed hedge instruments of swap, collar and collar by difference. The values in this section are in USD, considering an exchange of $\$ 3.5 \mathrm{BRL} / \mathrm{USD}$.

\section{1}

\section{The base case}

The owner of a hypothetical hydroelectric plant is seeking a contract to sell energy with low exposure to hydrological risk. It has a price requirement of $42.86 \$ / \mathrm{MWh}$ and is willing to negotiate between $80 \%$ and $100 \%$ of the plant's physical guarantee, which is $200 \mathrm{MW}$, in the contract. The monthly price and power generation simulations were performed in June 2015 for the year 2016 through the government model of Newave, which uses the Monte Carlo Simulation method.

The histogram of the GSF simulations for the year 2016 is presented in Figure 7.1. The monthly simulations were performed in June 2015 for the year 2016 through the Newave Deck. The minimum, average and maximum value of GSF are 0.60, 0.94 and 1.07, respectively.

Table 7.1 shows the results for the conventional contract by quantity considering that the plant's physical guarantee varies between $80 \%$ and $100 \%$. If, for example, the generator compromises $100 \%$ of its physical guarantee in the contract, then, the expected result in the spot market is $\$-628$ thousand, with a probability of $83 \%$ that the generation be below the contract. But, if the generator compromises only $80 \%$ of the physical guarantee, then the expected result in the spot market is $\$ 565$ thousand, with only $4 \%$ that the probability of the generation be below the contract. This table also presents some risk metrics for the different levels of the plant's physical guarantee. Note that the generator's risk is positively related to the amount of energy contracted. 


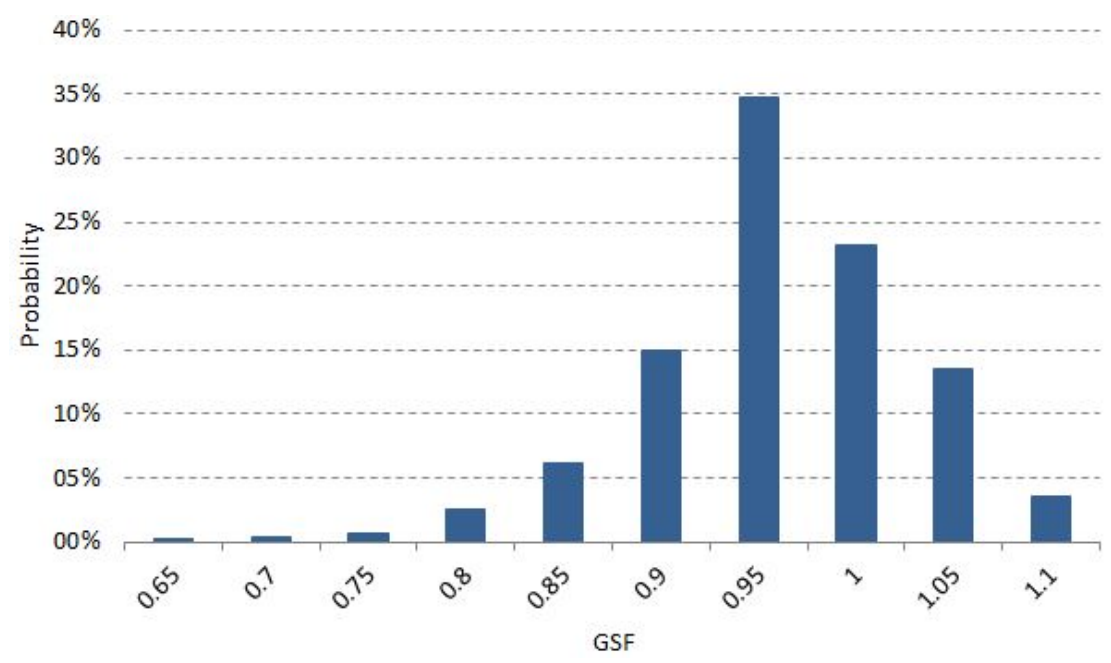

Figure 7.1: GSF histogram.

Table 7.1: Values at risk for different contract levels ( $\$$ millions)

\begin{tabular}{ccccccc}
\hline $\begin{array}{c}\text { Contract } \\
\%\end{array}$ & $\begin{array}{c}\text { Revenue } \\
\text { MM }\end{array}$ & $\begin{array}{c}\text { CCEE } \\
\text { MM }\end{array}$ & $\begin{array}{c}\text { Stand. } \\
\text { Dev. }\end{array}$ & $\begin{array}{c}\text { Risk } \\
\%\end{array}$ & $\begin{array}{c}\text { CVaR } \\
90 \%\end{array}$ & $\begin{array}{c}\text { CVaR } \\
95 \%\end{array}$ \\
\hline 100 & 5,663 & -628 & 1,004 & 83 & $-3,145$ & $-3,776$ \\
95 & 5,651 & -326 & 798 & 60 & $-2,346$ & $-2,960$ \\
90 & 5,639 & -23 & 629 & 25 & $-1,552$ & $-2,144$ \\
85 & 5,627 & 280 & 533 & 10 & -769 & $-1,328$ \\
80 & 5,615 & 582 & 550 & 4 & -169 & -519 \\
\hline
\end{tabular}

Figure 7.2 shows the distribution of the generator's revenue in the situations where the generator contracts $100 \%$ and $80 \%$ of the plant's physical guarantee. In this case, the expected value with $100 \%, \$ 5.66$ million, is higher than the value, $\$ 5.62$ million, for a lower level of the plant's physical guarantee.

The conventional contract, then, has a questionable degree of efficiency to mitigate risk. Despite the risk reduction in contracts in smaller contracts, this strategy also reduces the generator's expected revenue. Depending on the risk aversion of the generator, it may be willing to take more risk in exchange for higher revenue value, but, in this case, the financial loss could lead the generator to bankruptcy. 


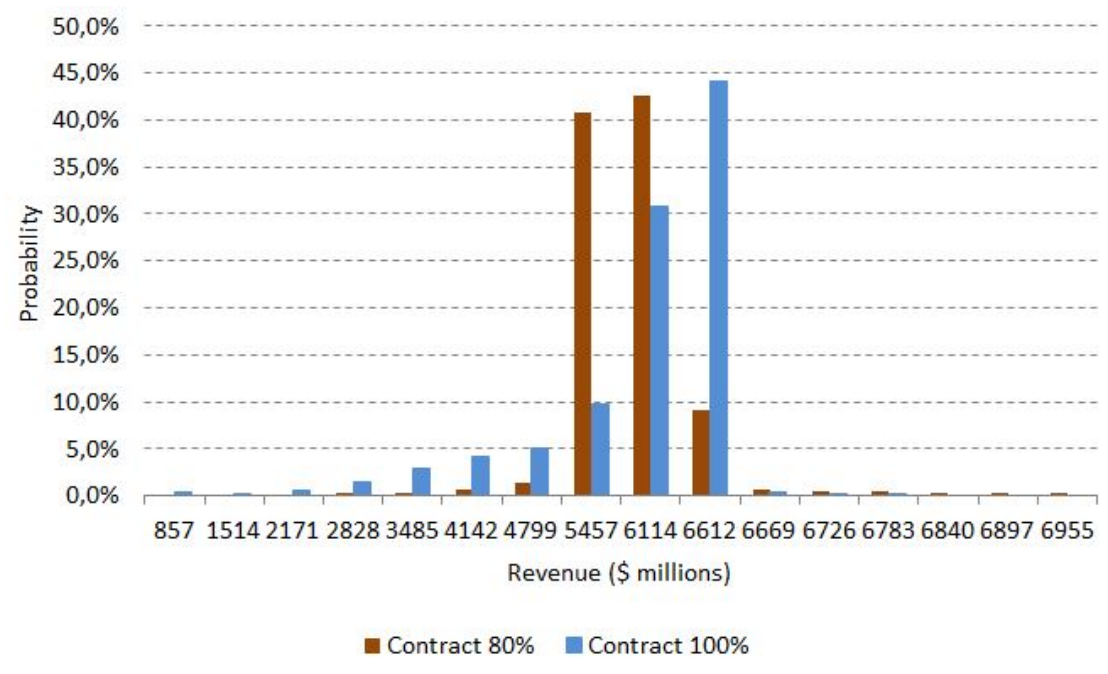

Figure 7.2: Distribution of results: base case.

\section{2}

\section{Swap result}

In the swap contract, the generator defines the protection factor, i.e., the amount of energy negotiated in the contract by quantity, and the part available for swapping. Table 7.2 provides an example where the factor of protection $(F P)$ is $80 \%$ of the plant's physical guarantee $(P G)$ and there are three different scenarios for the GSF; one in which the GSF is 1, another where GSF is 1.1 and a third in which the GSF is 0.8. The factor FFE corresponds to the percentage delivered by water availability in the swap contract and is calculated as in equation 6-1. According to this example, the swap would deliver $40 \mathrm{MW}$ in situation 1 (100\% of the availability), $60 \mathrm{MW}$ (150\% of the availability) in situation 2 and $0 \mathrm{MW}$ in situation 3.

Table 7.2: Dispatch of the contract by availability

\begin{tabular}{ccccccc}
\hline Data & MW & & & & & \\
\cline { 1 - 4 } PG & 200 & & & & & \\
FP & 160 & & & & Availability & Swap \\
& & & & & \\
& & GSF & FP & FFE & (MW) & (MW) \\
\cline { 2 - 5 } & & 1.0 & 0.8 & 1.0 & 40 & 40 \\
& & 1.1 & 0.8 & 1.5 & 40 & 60 \\
& & 0.8 & 0.8 & 0.0 & 40 & 0 \\
\hline
\end{tabular}

Figure 7.3 shows the swap result. The generator has an expected revenue of approximately $\$ 6.2$ million, which is $9.52 \%$ higher than the conventional contract's revenue with $100 \%$ of the plant's physical guarantee. The CVaR(90\%) and $\operatorname{CVaR}(95 \%)$ are respectively $\$ 21$ and $\$-270$ thousand, which means that this hedge reduces risk. In addition, we note that the 
dispersion of the results for the left side is much smaller with the swap than with other contract types.

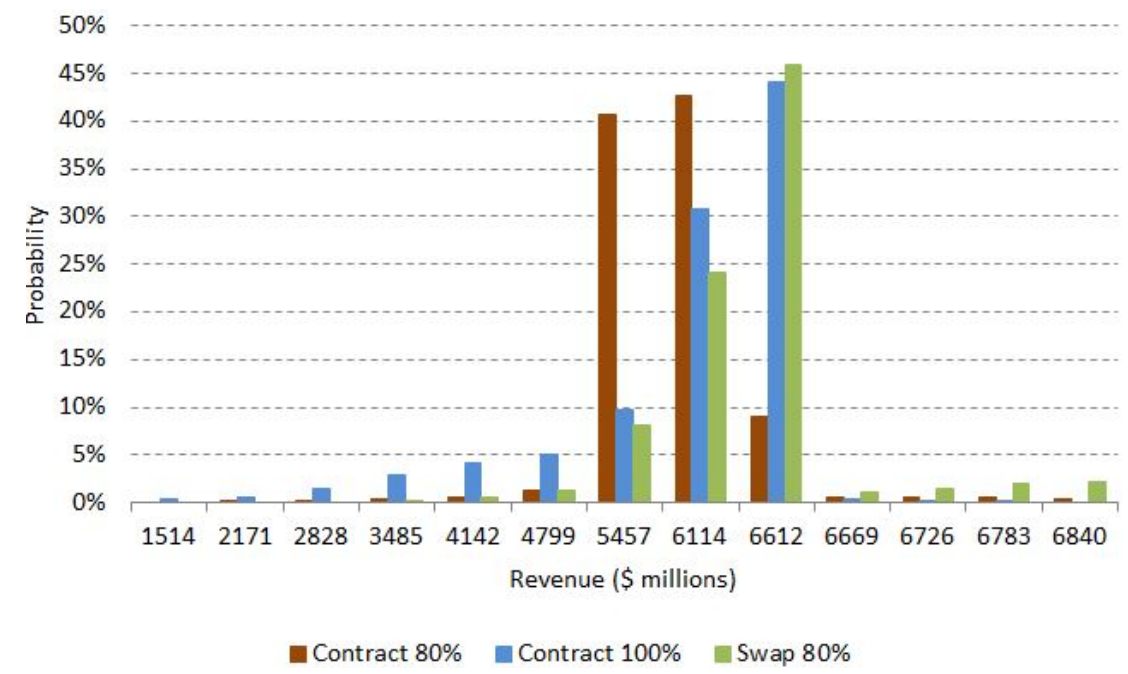

Figure 7.3: Distribution of results: swap case.

Table 7.3 shows a sensitivity of the protection factor for a range between 0.80 and 0.95 . It can be observed that as the protection factor decreases, i.e., the part available for the swap increases, the revenue with the swap increases and the swap price also increases. On the other hand, the swap price tends to decrease to zero as the protection factor increases. In other words, the value of the swap is negatively related to the protection factor, i.e., with the proportion fixed in the contract by quantity, since the part available for swap decreases when the protection factor increases.

Table 7.3: Results of the swap

\begin{tabular}{ccc}
\hline $\begin{array}{c}\text { Factor } \\
\text { FP }\end{array}$ & $\begin{array}{c}\text { Revenue } \\
\text { \$ million }\end{array}$ & $\begin{array}{c}\text { Swap } \\
\$ / \mathrm{MWh}\end{array}$ \\
\hline 0.80 & 6,202 & 3.62 \\
0.85 & 6,153 & 3.29 \\
0.90 & 6,055 & 2.63 \\
0.95 & 5,760 & 0.65 \\
\hline
\end{tabular}

The results suggest, therefore, that the swap is an efficient hedge mechanism for the hydropower generator, once it increases the expected revenue while mitigates risk. 


\section{3}

\section{Collar result}

The collar is a contract in which the generator defines a floor and a cap of energy. In this case, the generator buys a call that gives him the right that when the generation falls below the floor to buy the energy deficit at the price $p^{u}$ lower than the spot price in exercise. This strategy reduces its financial losses in the spot market. Alternatively, the generator sells a put that obligates him when the generation is above the cap to sell the secondary energy for a price $p^{d}$ lower than the spot price in exercise. The generator's gain with the sale of the secondary energy is minimized in this case. Figure 7.4 illustrates a collar in which the floor and the cap are respectively $180 \mathrm{MW}$ and $204 \mathrm{MW}$ and the low (p-down) and high (p-up) prices are $29 \$ / \mathrm{MWh}$ and $51 \$ / \mathrm{MWh}$.

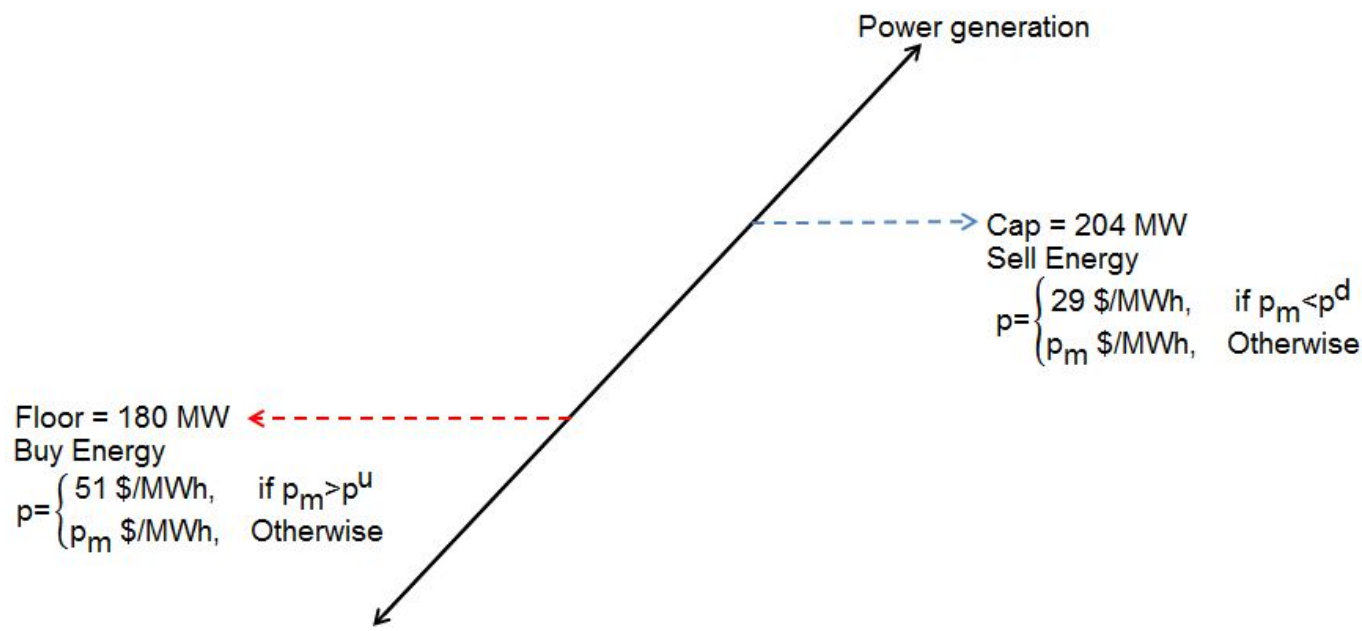

Figure 7.4: Collar boundaries.

Table 7.4 exemplifies the collar for two scenarios of the GSF. In the first case, shown in panel A, the GSF is 0.85 , indicating that the generation (170 MW) was below the physical guarantee (200 MW) in $30 \mathrm{MW}$. Of this amount, the generator has the right to buy 10MW, corresponding to the energy deficit below the floor $(180 \mathrm{MW})$, at a price of $51 \$ / \mathrm{MWh}$, if this price is lower than the spot price during the exercise period. In the second case, shown in panel B, the GSF is 1.03, indicating that generation (206 MW) was above the plant's physical guarantee $(200 \mathrm{MW})$ in $6 \mathrm{MW}$. Of this amount, the generator is obligated to sell $2 \mathrm{MW}$, corresponding to the secondary energy above the cap (204 MW), at a price of $\$ / \mathrm{MWh}$, if this price is lower than the spot price during the exercise period. On average, considering these results, the collar value is $\$ 40$ thousand. 
Table 7.4: Collar example

\begin{tabular}{|c|c|c|c|c|c|}
\hline \multicolumn{6}{|c|}{ Panel $A: G S F=0.85$} \\
\hline$P G$ & MW & 200 & & & \\
\hline Generation & MW & 170 & & & \\
\hline SPD & $\$ / \mathrm{MWh}$ & 14 & 57 & 86 & Average \\
\hline Cap & $\$$ & 0 & 0 & 0 & 0 \\
\hline Floor & $\$$ & 0 & -61 & -347 & -136 \\
\hline Collar & $\$$ & 0 & 61 & 347 & 136 \\
\hline \multicolumn{6}{|c|}{ Panel B: $G S F=1.03$} \\
\hline PG & MW & 200 & & & \\
\hline Generation & MW & 206 & & & \\
\hline SPD & $\$ / \mathrm{MWh}$ & 14 & 57 & 86 & Average \\
\hline Cap & $\$$ & 0 & -56 & -113 & -57 \\
\hline Floor & $\$$ & 0 & 0 & 0 & 0 \\
\hline Collar & $\$$ & 0 & -56 & -113 & -57 \\
\hline
\end{tabular}

Figure 7.5 shows the collar's behavior for the former boundaries and for the energy generation varying between $160 \mathrm{MW}$ and $214 \mathrm{MW}$ and the spot price varying between 17 \$ MWh and 109 \$/MWh. Note that an increase in both generation and spot price, decreases the collar's value. On the other hand, a energy reduction followed by an increase in prices, increases the collar's value. In the range of energy production between $180 \mathrm{MW}$ and $204 \mathrm{MW}$, the collar is null.

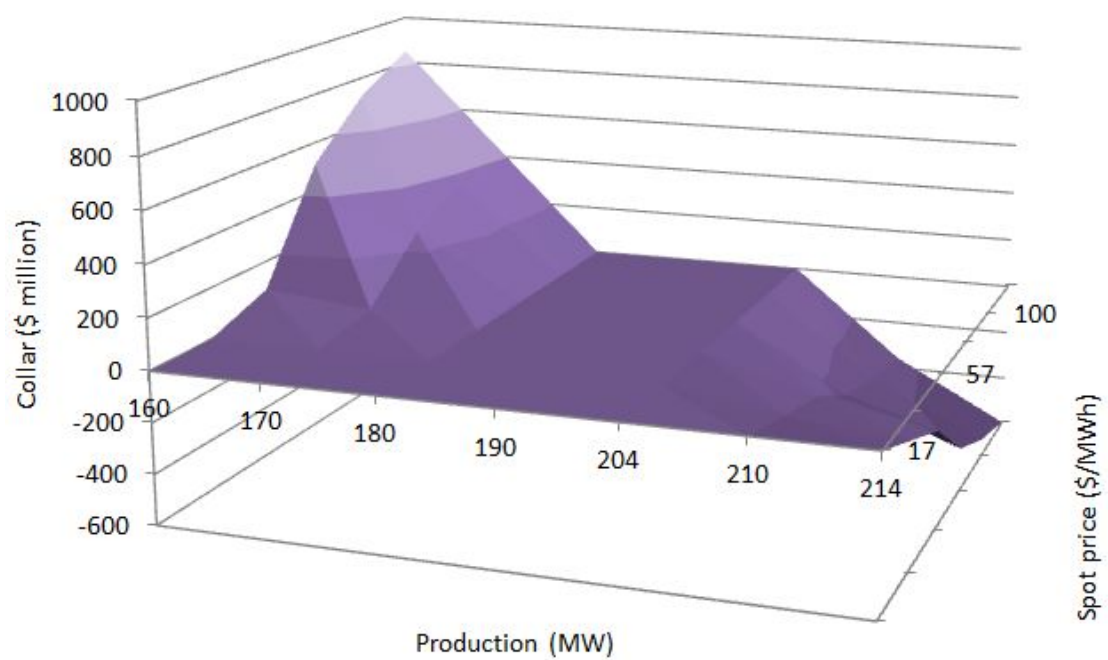

Figure 7.5: Collar sensitivity.

Considering the simulations for the year 2016, the collar's value is 0.38 $\$ / \mathrm{MWh}$ and the generator's revenue is $\$ 5.755$ millions, which is $1.62 \%$ higher than the conventional contract by quantity. The CVaR(90\%) and CVaR(95\%) of the collar contract are $\$-2,326$ and $\$-2,626$ thousand, respectively, which means that the risk of this contract is smaller than the risk of the conventional contract of $100 \%$. Figure 7.6 shows a comparison between the dispersion of the revenue with and without the collar contract. 


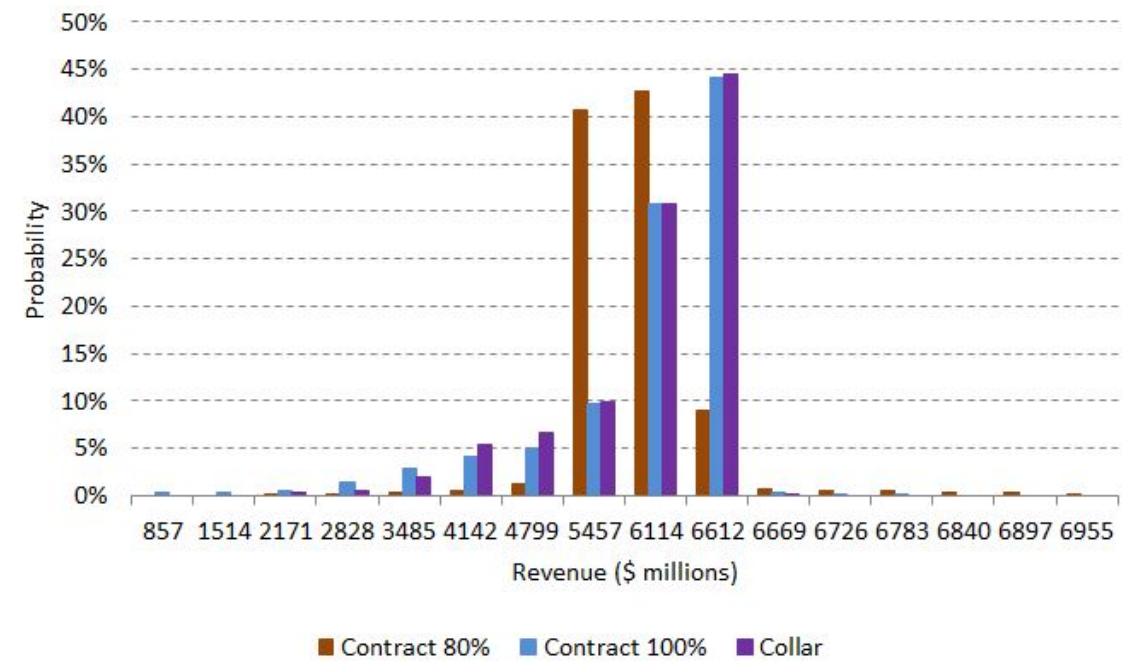

Figure 7.6: Distribution of results: collar case.

The results indicate that the proposed collar is an efficient risk control mechanism against the hydrological risk. We also observe from the analysis that if there is no gap between the floor and the cap, the generator has a traditional put or call contract, where the put protects the generator's revenue when the spot price falls short and the call protects the generator from buying energy with high market prices.

\section{4}

\section{Collar by difference (CBD) result}

A collar by difference is created when two agents seek distinct protections for the same product. In this case, the generator is interested in a call and another agent is interested in a put for the same strike. Consequently, if the trader makes a call contract with the generator and a put contract with a client, the collar by difference is formed. This contract differs from the former collar for two reasons. First, the contracts of call and put are formed with different agents. Second, the strike (cap and floor) is the same for both, i.e., if the power generation is below the strike the client reimburses the generator the difference $\left(G_{E}-g\right)$; otherwise, the generator reimburses the client $\left(G_{E}-P\right)$. $G_{E}$ is the energy generation strike. For this contract, both the generator and the client pay a premium to the trader.

Figure 7.7 shows the generator's results with the CBD when it makes a call contract with a floor of $180 \mathrm{MW}$ and a price of $51 \$ / \mathrm{MWh}$. The generator has an increase on revenue of approximately $1.64 \%$ compared to the conventional contract with $100 \%$ of the physical guarantee contracted. 


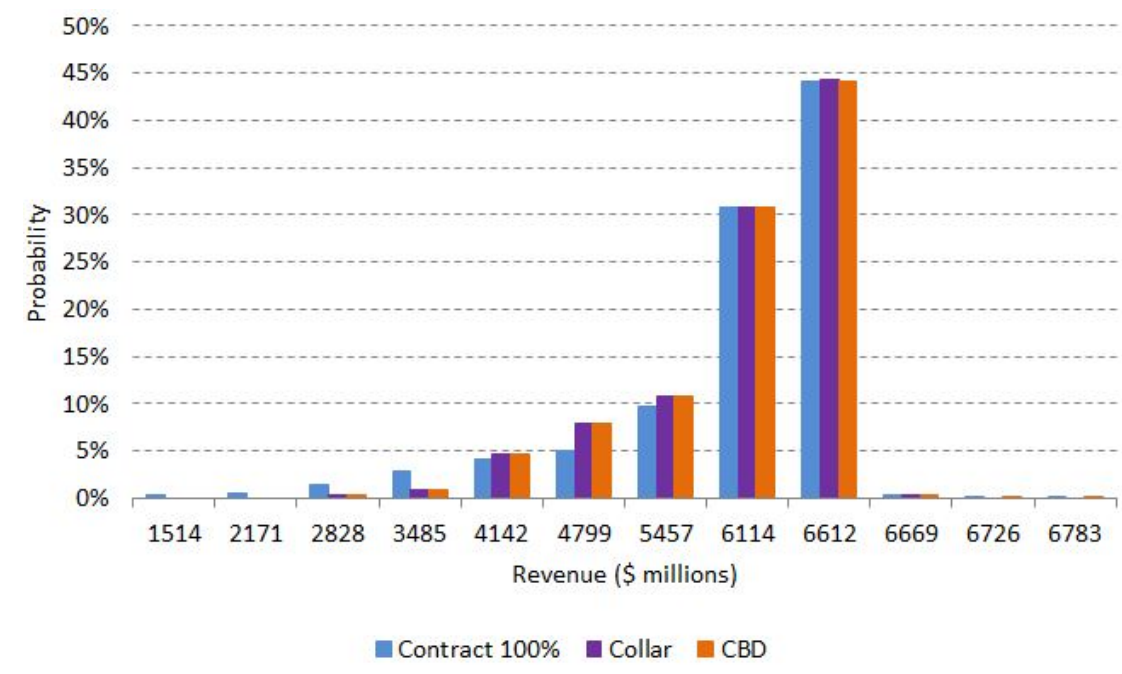

Figure 7.7: Distribution of results: CBD case.

The CBD value is $0.63 \$ / M W h$ with a $\operatorname{CVaR}(90 \%)$ and $\operatorname{CVaR}(95 \%)$ of $\$-2,285$ and $\$-2,598$ thousand, which means that the risk of this contract is less than the risk of the conventional contract by quantity. The client's result is not presented, since we are only interested in investigate the mitigation of the hydrological risk for hydropower agents.

\section{5}

\section{Comparing the models}

A comparison of the main results obtained with the proposed models is presented in Table 7.5. We note that all models show good performance to mitigate the hydrological risk of the hydropower generator. The results of the swap, however, is more significant than those of the collars, which is due to a few factors in the analysis. First, the swap is designed in such a way that the part available for swapping is proportional to the total volume of risk the generator is exposed in the market. Second, the collars triggers are set according to the average of the GSF simulations, so that the floor is for a protection level of $90 \%$ of the plant's physical guarantee.

Table 7.5: The models' result

\begin{tabular}{lccccc}
\hline & & Quantity & Swap & Collar & CBD \\
\hline Option & \$/MWh & & 3.62 & 0.38 & 0.63 \\
Revenue & \$ million & 5,663 & 6,202 & 5,755 & 5,756 \\
CVaR (95\%) & \$ thousand & $-3,776$ & -270 & $-2,626$ & $-2,598$ \\
\hline
\end{tabular}

Moreover, we observe from the results that the CBD premium is higher than the collar's premium. This happens because in the first case the generator buys a call to protect themselves from high spot prices when the generation is below the floor strike and in the second case the generator gives part of 
its revenue to obtain a reduction of the premium. In other words, while the generator keeps the secondary energy in the CBD, in the collar it doesn't happen.

Table 7.6 compares the results of the collar and the CBD for the generator. In panel A the floor $(180 \mathrm{MW})$ is kept constant while the cap varies between $200 \mathrm{MW}$ and $212 \mathrm{MW}$. In this case, an increase in the value of the collar is observed while the value of the CBD remains unchanged. In panel B, the reverse occurs, the cap (204 MW) is kept constant, while the floor varies between $160 \mathrm{MW}$ and $190 \mathrm{MW}$. In this case, both models have an increase in value. In panels C and D, the cap (204 MW) and floor (180 W) are kept constant, while the sensitivity occurs in prices. In panel $\mathrm{C}$ the high (up) price (51\$/MWh) is kept constant, while the low (down) price varies between 17 $\$ / M W h$ and $40 \$ / M W h$. In this case, the price of the collar increased, while the price of the CDB remained unchanged. In panel D the low price ( $\mathrm{p}$-down) (29 \$/MWh) is kept constant, while the high price (p-up) varies between 46 $\$ / M W h$ and $100 \$ / M W h$. In this case, there is a reduction of the value in both models.

Table 7.6: Comparison between collar and CBD

\begin{tabular}{lcccccccc}
\hline Panel $A$ & & & & & & & & \\
Cap & MW & 200 & 202 & 204 & 206 & 208 & 210 & 212 \\
Floor & MW & 180 & 180 & 180 & 180 & 180 & 180 & 180 \\
Collar & $\$ /$ MWh & 0.6175 & 0.6209 & 0.6228 & 0.6238 & 0.6243 & 0.6247 & 0.6247 \\
CBD & $\$ /$ MWh & 0.6247 & 0.6247 & 0.6247 & 0.6247 & 0.6247 & 0.6247 & 0.6247 \\
\hline Panel $B$ & & & & & & & & \\
Cap & MW & 204 & 204 & 204 & 204 & 204 & 204 & 204 \\
Floor & MW & 160 & 166 & 170 & 176 & 180 & 186 & 190 \\
Collar & $\$ /$ MWh & 0.0971 & 0.1832 & 0.2729 & 0.4661 & 0.6228 & 0.8850 & 1.0787 \\
CBD & $\$ /$ MWh & 0.0990 & 0.1851 & 0.2748 & 0.4680 & 0.6247 & 0.8869 & 1.0806 \\
\hline Panel & $C$ & & & & & & & \\
$p^{d}$ & $\$ /$ MWh & 17 & 23 & 29 & 31 & 34 & 37 & 40 \\
$p^{u}$ & $\$ /$ MWh & 51 & 51 & 51 & 51 & 51 & 51 & 51 \\
Collar & $\$ /$ MWh & 0.6167 & 0.6204 & 0.6228 & 0.6235 & 0.6239 & 0.6242 & 0.6244 \\
CBD & $\$ /$ MWh & 0.6247 & 0.6247 & 0.6247 & 0.6247 & 0.6247 & 0.6247 & 0.6247 \\
\hline Panel $D$ & & & & & & & & \\
$p^{d}$ & $\$ /$ MWh & 29 & 29 & 29 & 29 & 29 & 29 & 29 \\
$p^{u}$ & $\$ /$ MWh & 46 & 49 & 51 & 57 & 71 & 86 & 100 \\
Collar & $\$ /$ MWh & 0.6961 & 0.6593 & 0.6228 & 0.5511 & 0.3823 & 0.2298 & 0.0929 \\
CBD & $\$ /$ MWh & 0.6980 & 0.6613 & 0.6247 & 0.5530 & 0.3842 & 0.2317 & 0.0948 \\
\hline
\end{tabular}

Observe that the variations of both the cap and the low price don't change the $\mathrm{CDB}$ value, once this is a contract in which the generator only fixes the floor and the high price, which corresponds to the energy deficit's trigger they will buy at the ceiling price. The collar, on the other hand, is sensitive to changes in all the four parameters: cap, floor, high price and low 
price. The most significant variations of the collar's value occur for changes in the floor and in the low price. The magnitude of the difference of the premium between these two options is defined according to the determination of these four parameters.

Finally, notice that the choice of one of these models by the generator will depend on your risk preferences. In the present example, the swap's value was higher than the values of the $\mathrm{CBD}$ and the collar, but this result may vary depending on the parameters of the models. In a pessimistic scenario of affluence of the Brazilian rivers, generators may prefer the swap contract, where they pay a higher premium, but the protection is also higher. However, in a more optimistic scenario, generators could opt for one of the collars contracts. In addition, these models are not mutually exclusive and therefore could be included together in an energy trading portfolio. 


\section{8 \\ Conclusion}

The recent drought in Brazil evidenced the need for hydropower agents to have more instruments to manage the hydrological risk. The predictions of the inflow of Brazilian rivers only aggravate the situation. The expected GSF for 2017 and 2018 are $79.5 \%$ and $88.5 \%$, which means the electricity crises is far from over. Meanwhile, consumers suffer from rising energy tariffs and without see a viable solution for the short-term. In this context, we developed four mechanisms to control the hydrological risk and showed how they could be applied to the national electricity sector. The presentation of our models was separated into two main parts. In the first part (composed of sections 2, 3 and 4), we developed a new design of energy sales by water availability. In the second part (composed of sections 5,6 and 7), we proposed a new approach for the models of swap, collar and collar by difference.

Section 2 presented the particularities of the Brazilian national interconnected system and the conventional models of power and purchase agreements. The national generators can sell their energy in contracts by quantity or availability, depending on the energy source. Hydropower generators sell their energy in contracts by quantity in which they undertake to deliver a fixed amount of energy for a certain price, assuming the hydrological risk. Thermopower generators sell their energy in contracts by availability and pass the hydrological risk to consumers. These contracts are backed by the plants' physical guarantee, which is the maximum they can generate even in case of severe hydrological restrictions.

Due to the national territorial extension, the operation of the SIN is centralized by the ONS and, consequently, the hydropower generators have no control over their plants' operation and must fulfill any energy deficit, which exposes them to risks associated with the system operation and the hydrological condition. The MRE was created to mitigate these risks. This mechanism relocates energy among the MRE participants and ensure compliance with the contract of the participating agents. However, the MRE is a weak risk control instrument in the occurrence of a significant and persistent climatic variation. The drought of recent years in the country led several generators declaring default, which forced the government to proposes 
a renegotiation of the hydrological risk. The energy contracting rules that allowed this problem to arise in the first place, though, are still in force. The technique of the conditional value at risk can be used to measure the risk exposure of these agents.

Section 3 introduced the first model proposed in this thesis. We proposed a new design of energy sale for hydropower generators with new energy, since it's unfeasible to reformulate active contracts. Our model recognizes that national's hydrothermal system provides a natural operational flexibility to switch energy source according to supply conditions, and incorporate this flexibility into hydropower contracts. The model proposes that only the firm energy is contracted by quantity, while the difference between the plant's physical guarantee and the firm energy is contracted by availability. The price of the contract by quantity is calculated as in the conventional way. The price of the contract by availability is calculated taking the expected value of the consumers' total cost. We assume that a very high price could overtax the system, while a very low price would make the contract non-profitable for generators. The difference between the prices of both contracts is the premium price, which is given by the expected result of the hydropower generators in the CCEE divided by the amount of energy traded in the contract by water availability.

Section 4 showed some numerical examples for the model presented in section 3. We assumed in the analysis that the energy demand for 2016 is nearly $66.5 \mathrm{GW}$ and is met by hydro, thermal and nuclear generators. Also, we generated two thousand monthly price and power generation series using the Newave model. Furthermore, we separated the results into three cases. We start with a simplified case of one hydro and two thermals, with different variable unit cost, to understand the dynamics of the model, then we advance to the entire system to show the calculation of the price of the contract by availability, and finally we end with some sensitivity analyzes to check the coherence of the model under different scenarios.

Regarding the results, in the first case, we considered a fixed demand of $66 \mathrm{GW}$ and a contract of $50 \mathrm{GW}$ with the hydropower generators, where 42 GW is due to firm energy and $8 \mathrm{GW}$ can be contracted by availability, at price of $32.5 \$ / M W h$. The results showed an increase of the hydropower generators' revenue followed by a risk reduction. As the price of both contracts were the same, we also observed an increase in the total cost of captive consumers. In the second case, we considered an over-contracting of the SIN $10.5 \%$ above the required energy demand, where the contract with the hydropower generators 
was $53.2 \mathrm{GW}$, of which $80 \%(42.6 \mathrm{GW})$ was contracted by quantity at a price of $32 \$ / \mathrm{MWh}$ and $20 \%(10.6 \mathrm{GW})$ was contracted by availability at a price of $13.54 \$ / \mathrm{MWh}$. The results showed a mitigation of the hydrological risk for different prices of the contracts by quantity and availability. The price of the second contract is less than the first in such a way that the generators' revenue, the consumers' total cost and the system result remains unchanged. In the third case, we analyzed the model's behavior due to a change in the demand, the base energy and the reserve energy. We also discussed the impact of the proposed model in long-term energy tariffs. The results showed that an increase in the demand raises the contract price by water availability. On the other hand, an increase in the base energy and the reserve energy reduces this price. Besides, a reduction in demand and an increase in the reserve energy imply a reduction in the financial results of the generators in the CCEE, which could be substantially negative.

In summary, under the portfolio of contracts by quantity and availability, the hydrological risk is mitigated, once the GSF is fixed in 1 and the generators' result in the CCEE is zero. By assuming the contract by quantity is set according to the firm energy, the risk of a financial loss due to a climatic factor is reduced from $5 \%$ to $1 \%$, which is the risk of the flow of Brazilian rivers. In addition, neither the consumers' costs nor the system cost is changed between the models, considering the proposed price by availability. Moreover, there is no (complete) transfer of the hydrological risk to the consumer, since they no longer buy secondary energy in the spot market, which is the predominant situation in the country.

Section 5 presented a literature review of energy derivatives and their use to minimize the risk exposure of the market participants. Also, this section discussed some works developed by Brazilian researchers to control risk in the national energy market. The most common derivatives are plain call and put, swap and collar, each one with its specificity. Plain call and put options have a regular structure of financial securities. In this case, the holder has the right to buy or sell a fixed amount of underlying electricity at a prespecified strike price by the expiration time. The swap is an agreement between two agents to exchange cash flow on a future date. In the collar option, the holder accepts to pay a premium price in exchange for defining a cap and a floor that reduce the price volatility. In most cases, these derivatives are presented to protect energy agents against the low price oscillation in the short-term. So, the literature exposed an opportunity field for this thesis develop a hedge mechanism against low power generation.

Section 6 introduced the three other models proposed in this thesis. In 
this section, we developed the derivative models of swap, collar and collar by difference (CBD) for hydropower generators that already have a commitment with long-term contracts. The swap model is derived from the model presented in section 3, but for hydroelectric plants in operation. In this case, the generator defines the protection factor, which is equivalent to the amount of firm energy defined in section 3, and the difference between the plant's physical guarantee and the factor of protection is the part available for swapping. From these, a factor of floating energy is estimated, where for each MW delivered to the generator, the client receive a quantity of floating energy. The collar model is developed in terms of power generation, which is considered as outside of the box. In this case, the generator buys a call and sells a put. Sot that, if the generation falls below the minimum level of the floor, then the collar gives the generator the right to buy the energy deficit for a price below the spot price. On the other hand, if generation is above the maximum level of the cap, then the generator sell the secondary energy at a price below the market price. Between the boundaries, the energy is settled at the current spot price. The CBD is modeled in such a way that the cap is defined by one agent and the floor is defined by another. The CBD is set by a trader that receives a premium from each client. In this case, as the generator seeks protection against the GSF risk, the generator defines a floor on which if the generation falls below this limit, the financial deficit will be limited to a maximum purchase price of energy.

Section 7 showed some numerical examples for the models developed in section 6. We used the Monte Carlo simulation method through the Newave model to generate two thousand monthly energy price series and two thousand monthly power series for the year 2016. In all cases, we assumed a hydroelectric plant with $200 \mathrm{MW}$ of physical guarantee and a contract price of $42.86 \$ / \mathrm{MWh}$. Also, we analyzed the expected revenue and the risk for this generator of sale between $100 \%$ and $80 \%$ of its physical guarantee in the conventional contract by quantity. The swap results were presented considering a $20 \%$ of the plant's physical guarantee available for swapping. In this case, the generator's revenue increased of approximately 9.5\% compared to the conventional model with $100 \%$ of the physical guarantee contracted by quantity, for the payment of a premium of $0.68 \$ / M W h$. We observed that the swap value decreases as we pushed the protection factor from 0.80 to 0.95 , since the part available for the swap reduces as we increases this factor. The collar results were generated considering a protection of $90 \%$ of GSF, i.e., for a floor of $180 \mathrm{MW}$ with a price of $51 \$ / \mathrm{MWh}$ and a cap of $204 \mathrm{MW}$ at price of $29 \$ / \mathrm{MWh}$. In this case, the premium was $0.38 \$ / \mathrm{MWh}$ and we observed an increase in the generator's revenue of approximately $1.62 \%$, compared to the contract by quantity with 
$100 \%$ of the plant's physical guarantee. The CBD results were calculated for the floor parameters of the collar, which are $180 \mathrm{MW}$ and at a price of $51 \$ / \mathrm{MWh}$. In the CBD model, the floor is equal to the cap of the other agent. In this case, we also noted an increase in the generator's revenue of approximately $1.64 \%$, compared to the conventional contract with $100 \%$ of the physical guarantee.

In summary, the option models added value to the hydroelectric investment and mitigated the hydrological risk. In the analysis, the swap had the highest impact on revenue compared with the collars models. Also, this model presented the highest premium value. The difference between the swap and the collars is due to the fact of the first model mimic the model introduced in section 3, where the protection level is established with respect to the firm energy of the sector. The collars are estimated considering a risk protection close to the expected GSF. Despite of the small difference in variation of the generator's revenue, the premium of the CBD is considerably higher than the collar. In the CBD, the generator pays a premium to buy a call that protects them from the energy deficit, while in the collar the generator accept a small revenue in exchange of reduction of the premium. The difference between these two models, then, is given by the expected value of the secondary energy. Ceteris paribus, we observed that variations in both the high and the low-price do not impact the CBD value. However, the collar's value increases with the elevation of these parameters. On the other hand, we noticed that an increase in the floor increases the value of the collar and the CBD, while an increase in the low price decreases the value of both models. Also, we observed that the difference between the CBD and the collar decreases with an elevation of the cap and the low price. A change in the floor and in the high price does not change the gap between both models. Finally, we notice that the generator will choose among these models according to its risk preferences, being able to opt for more than one alternative, since they are not mutually exclusive.

The four novel models of risk control developed in this thesis are simple to implement and can provide relevant economic insights to the decision making process under market uncertainty. Besides hydropower generators, governments of predominantly hydro-based energy systems, such as Brazil, would be interested in these techniques, once they are responsible for controlling energy auction in the country. Also, consumers could benefit from these risk instruments as the secondary energy is transferred to them and in the long-term they may reduce the energy tariff, since they eliminate a significant portion of the plant's (hydrological) risk. Lastly, these models may be of interest to researchers, once we present a new contract design and a new approach to existing option models. 
Suggestions for future work include the simulations of energy prices and generation of the system under other stochastic processes, such as the mean reversion model, for instance. Also, different discount rates could be used to calculate the expected value of the generators' revenue and the financial results of the spot energy market. In addition, future research could consider the use of utility functions to measure whether the utility of the generators increases with the proposed risk control tools developed in the present thesis. Moreover, different risk aversion measures for the generators could be used. 


\section{References}

[1] ROSA, L. P.; SCHAEFFER, R. Global warming potentials: the case of emissions from dams. Energy Policy, v. 23, n. 2, p. 149-158, 1995.

[2] SANTOS, M. A. D.; ROSA, L. P.; SIKAR, B.; SIKAR, E.; SANTOS, E. O. D. Gross greenhouse gas fluxes from hydro-power reservoir compared to thermo-power plants. Energy Policy, v. 34, n. 4, p. 481-488, 2006.

[3] FERNANDES, B.; CUNHA, J.; FERREIRA, P. The use of real options approach in energy sector investments. Renewable and Sustainable Energy Reviews, v. 15, n. 9, p. 4491-4497, 2011.

[4] ANSAR, A.; FLYVBJERG, B.; BUDZIER, A.; LUNN, D. Should we build more large dams? the actual costs of hydropower megaproject development. Energy Policy, v. 69, p. 43-56, 2014.

[5] MOREIRA, A.; ROCHA, K.; DAVID, P. Thermopower generation investment in brazil-economic conditions. Energy Policy, v. 32, n. 1, p. 91-100, 2004.

[6] BARROSO, L. A.; ROSENBLATT, J.; GUIMARAES, A.; BEZERRA, B.; PEREIRA, M. V. Auctions of contracts and energy call options to ensure supply adequacy in the second stage of the brazilian power sector reform. IEEE Power Engineering Society General Meeting, 2006.

[7] VALOR. Valor econômico. http://www.valor.com.br/empresas/ 4129026/calote-na-ccee-atinge-r-460-mi, July 2015.

[8] VALOR. Valor econômico. http: //www. valor . com.br/empresas/4960280/ risco-hidrologico-pode-custar-r-39-bi-hidreletricas, July 2017.

[9] BARROSO, L.; TRINKENREICH, J.; GRANVILLE, S.; LINO, P.; PEREIRA, M. Avaliação de estratégias de redução de risco hidrológico para empresas com portfólios predominantemente hidroelétricos. XVII Seminário Nacional de Produção e Transmissão de Energia Elétrica, Uberlândia, 2003.

[10] Melo, J. L.; AlveS, A. C. B.; BRigatTo, G. A.; NeGReTE, L. P. Mercado de energia elétrica: Volatilidade do preço spot e risco da geração 
hidrelétrica com despacho centralizado. VI Simpósio Brasileiro de Sistemas Elétricos, 2016.

[11] BRITO, M. C. T. Análise da repactuação do risco hidrológico das usinas hidrelétricas participantes do mecanismo de realocação de energia. Dissertação. Universidade Federal do Rio de Janeiro, 2016.

[12] SOARES, F. H. N. Operação de usinas térmicas contratadas por disponibilidade: uma avaliação dos impactos setoriais sob as óticas técnica, econômica e financeira. Tese. Universidade de São Paulo, 2009.

[13] LOIOLA, U. B. D. Os instrumentos de derivativos nos mercados futuros de energia elétrica. Florianópolis, Dissertação de Mestrado - UFSC, 2002.

[14] FERNANDES, G.; GOMES, L. L.; BRANDãO, L. E. T.; VASCONCELOS, G. F. R. Contractual switch reformulation in hydropower sales contracts: An application in the brazilian electricity sector. 20th Annual International Conference, 2016.

[15] FERNANDES, G.; GOMES, L. L.; BRANDãO, L. E. T.; VASCONCELOS, G. F. R. Ca proposal of reformulation of hydropower sales contracts in the brazilian electricity sector. IAEE International Association for Energy Economics, 2016.

[16] RODRIGUES, R. D. B. Gerenciamento de risco no setor elétrico brasileiro através do uso de derivativos. Dissertação. Universidade Federal do Rio de Janeiro, 2007.

[17] STUDART, R. Securitização, derivativos e investidores institucionais: um novo padrão de financiamento de longo prazo. Financiamento do Setor Elétrico Brasileiro. Editora Garamont, Rio de Janeiro, 1998.

[18] CorreiA, T. B.; MUNhOZ, F. C.; AZEVEdo, E. M.; CORREIA, P. B. Contratos de opções no mercado brasileiro de energia elétrica. Anais do Congresso Latino-Americano de Geração e Transmissão de Energia Elétrica, Águas de São Pedro, 2003.

[19] CARVALHO, F. D. Sistema financeiro internacional: tendências e perspectivas. Financiamento do Setor Elétrico Brasileiro: Inovações Financeiras e Novo Modo de Organização Industrial. Editora Garamont, Rio de Janeiro, p. 71-102, 1998.

[20] MATTOS, M. C. Operações de swap no mercado de energia. Dissertação. Universidade Federal de Pernambuco, 2008. 
[21] SILVA, N.; DE ARAÚJO, L. Derivativos: definições, emprego e risco. São Paulo: Atlas, 2000.

[22] MARINS, A. C. Mercados derivativos e análise de risco. AMSO2, 2004.

[23] STOFT, S.; BELDEN, T.; GOLDMAN, C.; PICKLE, S. Primer on electricity futures and other derivatives. Ernest Orlando Lawrence Berkeley National Laboratory Report LBNL-41098, Berkeley, CA, USA, 1998.

[24] WERON, R. Energy price risk management. Physica A: Statistical Mechanics and its Applications, v. 285, n. 1, p. 127-134, 2000.

[25] EYDELAND, A.; WOLYNIEC, K. Energy and power risk management: New developments in modeling, pricing, and hedging. John Wiley \& Sons, 2003. v. 206.

[26] SIOSHANSI, F. P. The emergence of trading and risk management in liberalized electricity markets. Energy Policy, v. 30, n. 6, p. 449-459, 2002.

[27] DENG, S.-J.; OREN, S. S. Electricity derivatives and risk management. Energy, v. 31, n. 6, p. 940-953, 2006.

[28] BLANCO, C.; GRAY, J.; HAZZARD, M. Power price simulation using hybrid models. The Risk, 2003.

[29] ARFUX, G. A. B. Gerenciamento de riscos na comercialização de energia elétrica com uso de instrumentos derivativos: uma abordagem via teoria de portfólios de markowitz. Dissertação, Universidade Federal de Santa Caratina, 2004.

[30] TONELLI, A. V. P. Modelo computacional para gestão de riscos na comercialização de energia elétrica. Dissertação. Universidade Federal de Itajubá, 2006.

[31] DOMINGUES, E. G. Análise de risco para otimizar carteiras de ativos físicos em geração de energia elétrica. Universidade Federal de Itajubá, 2003.

[32] ABRADEE. Associação brasileira de distribuidores de energia elétrica. http: //www.abradee.com.br/setor-eletrico/leiloes-de-energia, May 2017.

[33] CORREIA, T. B.; MELO, E.; DA COSTA, A. Análise e avaliaçao teórica dos leilões de compra de energia elétrica proveniente de empreendimentos existentes no brasil. Revista EconomiA, v. 7, n. 3, p. 98-119, 2006. 
[34] MME. Ministério minas e energia. http://www.mme.gov.br/programas/ leiloes_de_energia/menu/inicio.html, May 2017.

[35] CCEE. Câmara de comercialização de energia elétrica. https: //www. ccee.org.br/portal/faces/pages_publico/onde-atuamos/ comercializacao?_afrLoop=604385203511454\#\%40\%3F_afrLoop\% 3D604385203511454\%26_adf.ctrl-state\%3Dcxhm0wn8p_4, May 2017.

[36] ABESCO. Associação brasileira das empresas de serviços de conservação de energia. http://www.abesco.com.br/pt/novidade/ os-riscos-da-geracao-hidroeletrica-no-brasil/, July 2015.

[37] MAIER, S.; STREET, A.; MCKINNON, K. Risk-averse portfolio selection of renewable electricity generator investments in brazil: An optimised multimarket commercialisation strategy. Energy, v. 115, p. 1331-1343, 2016.

[38] ANDERSON, E. J.; HU, X.; WINCHESTER, D. Forward contracts in electricity markets: The australian experience. Energy Policy, v. 35, n. 5, p. 3089-3103, 2007.

[39] LUCENA, A. F. P. D.; SZKLO, A. S.; SCHAEFFER, R.; DE SOUZA, R. R.; BORBA, B. S. M. C.; DA COSTA, I. V. L.; JÚNIOR, A. O. P.; DA CUNHA, S. H. F. The vulnerability of renewable energy to climate change in brazil. Energy Policy, v. 37, n. 3, p. 879-889, 2009.

[40] ANDRADE, A. L.; SANTOS, M. A. D. Hydroelectric plants environmental viability: Strategic environmental assessment application in brazil. Renewable and Sustainable Energy Reviews, v. 52, p. 1413-1423, 2015.

[41] ANEEL. Agência nacional de energia elétrica, nota técnica no 038/2015srg-srm/aneel. http://www.aneel.gov.br/aplicacoes/audiencia/ arquivo/2015/032/documento/nt_038___srg_srm_deslocamento_ do_mre-srm_final-18-5-2015-r2.pdf, Nov. 2015.

[42] BAJAY, S. V. Integrating competition and planning: a mixed institutional model of the brazilian electric power sector. Energy, v. 31, n. 6, p. 865-876, 2006.

[43] CUNHA, P. C. F. Por que o gsf virou pesadelo? Boletim de Conjuntura, , n. 7 , p. $9-10,2015$.

[44] NOBRE, C. A.; MARENGO, J. A.; SEluCHI, M. E.; CUARTAS, L. A.; ALVES, L. M. Some characteristics and impacts of the drought and water 
crisis in southeastern brazil during 2014 and 2015. Journal of Water Resource and Protection, v. 8, n. 02, p. 252, 2016.

[45] PRADO, F. A.; ATHAYDE, S.; MOSSA, J.; BOHLMAN, S.; LEITE, F.; OLIVER-SMITH, A. How much is enough? an integrated examination of energy security, economic growth and climate change related to hydropower expansion in brazil. Renewable and Sustainable Energy Reviews, v. 53, p. 1132-1136, 2016.

[46] ZHONG, P.; ZHANG, W.; XU, B. A risk decision model of the contract generation for hydropower generation companies in electricity markets. Electric Power Systems Research, v. 95, p. 90-98, 2013.

[47] CCEE. Câmara de comercialização de energia elétrica. https: //www.ccee.org.br/portal/faces/oquefazemos_menu_lateral/ liquidacao?_afrLoop $=712097476530018 \# \% 40 \% 3 \mathrm{~F}$ _afrLoop $\%$ 3D712097476530018\%26_adf.ctrl-state\%3D155www8lfz_17, Nov. 2015.

[48] ANEEL. Agência nacional de energia elétrica. cadernos temáticos da aneel: Energia assegurada. http://www2.aneel.gov.br/aplicacoes/ noticias/Output_Noticias.cfm?Identidade=8904\&id_area=, Nov. 2015.

[49] EPE. Empresa de pesquisa energética, plano decenal de expansão de energia 2024. http://www.epe.gov.br/PDEE/Relat\%C3\%B3rio\% 20Final\%20do\%20PDE $\% 202024$.pdf/, 2015.

[50] SUOMALAINEN, K.; PRITCHARD, G.; SHARP, B.; YUAN, Z.; ZAKERI, $\mathrm{G}$. Correlation analysis on wind and hydro resources with electricity demand and prices in new zealand. Applied Energy, v. 137, p. 445-462, 2015.

[51] GOMES, L. L.; BRANDÃO, L. E.; PINTO, A. C. F. Carteiras otimização de contratos de energia elétrica através da medida dá ômega. Revista Brasileira de Finanças, v. 8, n. 1, p. 45-67, 2010.

[52] CAPORAL, A.; BRANDÃO, L. E. T. Valuation of a power plant with the real options approach. Brazilian Business Review (English Edition), v. 5, n. 2, 2008.

[53] IPEA. Instituto de pesquisa econômica aplicada, notas técnicas. http://repositorio.ipea.gov.br/bitstream/11058/5774/1/NT_ n01_Expansao-setor-brasileiro-energia_Dimac_2003-set.pdf, Sept. 2003. 
[54] GOMES, L. L.; LUIZ, I. G. Valor adicionado aos consumidores livres de energia elétrica no brasil por contratos flexíveis: Uma abordagem pela teoria das opções. Revista Eletrônica de Administração, v. 15, n. 2, p. 307-333, 2009.

[55] OLIVEIRA, D. L. Aavaliação de projeto de cogeração a partir de biomassa florestal: Uma abordagem pela teoria de opções reais. Dissertação. Pontifícia Universidade Católia do Rio de Janeiro, 2012.

[56] GEBREGIORGIS, A. S.; HOSSAIN, F. Hydrological risk assessment of old dams: case study on wilson dam of tennessee river basin. Journal of Hydrologic Engineering, v. 17, n. 1, p. 201-212, 2011.

[57] NAGY, I. V.; ASANTE-DUAH, K.; ZSUFFA, I. Hydrological dimensioning and operation of reservoirs: practical design concepts and principles. Springer Science \& Business Media, 2013. v. 39.

[58] LEHNER, B.; CZISCH, G.; VASSOLO, S. The impact of global change on the hydropower potential of europe: a model-based analysis. Energy Policy, v. 33, n. 7, p. 839-855, 2005.

[59] VAN VLIET, M. T.; WIBERG, D.; LEDUC, S.; RIAHI, K. Power-generation system vulnerability and adaptation to changes in climate and water resources. Nature Climate Change, 2016.

[60] VAN VLIET, M. T.; VÖGELE, S.; RÜBBELKE, D. Water constraints on european power supply under climate change: impacts on electricity prices. Environmental Research Letters, v. 8, n. 3, p. 035010, 2013.

[61] KOCH, H.; VÖGELE, S.; HATTERMANN, F. F.; HUANG, S. The impact of climate change and variability on the generation of electrical power. Meteorologische Zeitschrift, v. 24, p. 173-188, 2015.

[62] POCH, L.; CONZELMANN, G.; VESELKA, T. An analysis of the effects of drought conditions on electric power generation in the western united states. DOE NETL Rept 2009-1365, 2009.

[63] HARTO, C.; YAN, Y.; DEMISSIE, Y.; ELCOCK, D.; TIDWELL, V.; HALLETT, K.; MACKNICK, J.; WIGMOSTA, M.; TESFA, T. et al. Analysis of drought impacts on electricity production in the western and texas interconnections of the united states. Technical report, Argonne National Laboratory, 2012. 
[64] KIMMELL, T.; VEIL, J. Impact of drought on us steam electric power plant cooling water intakes and related water resource management issues. Argonne National Laboratory, 2009.

[65] CHANGE, I. P. O. C. Climate change 2007: impacts, adaptation and vulnerability. Genebra, Suíça, 2001.

[66] BROWN, O.; CRAWFORD, A. Assessing the security implications of climate change for west africa. IISD, Winnipeg, Manitoba, 2008.

[67] GESEL. Grupo de estudos do setor elétrico: problemas no cálculo das garantias físicas para os leilões de energia nova. http://www.gesel.ie.ufrj. br/app/webroot/files/publications/04_TDSE11.pdf, Sept. 2009.

[68] EPE. Empresa de pesquisa energética. http://www.epe.gov.br/ geracao/Documents/Estudos_26/NT\%20-\%20metodologia $\% 20 \mathrm{de} \% 20$ c\% C3\%A1lculo\%20da\%20GF\%20para\%20novas\%20usinas.pdf, July 2008.

[69] FÂNZERES, B.; STREET, A. Cálculo da curva de disposição a contratar de geradores hidrelétricos: Uma abordagem robusta ao preço de curto-prazo. XXI SNPTEE, 2011.

[70] ROSIM, S. O. Geração de energia elétrica - um enfoque histórico e institucional das questões comerciais no brasil. Dissertação. Universidade de São Paulo, 2008.

[71] SANTANA, E. A. A incompletude dos contratos, o direito de propriedade e o design de modelos: o caso da indústria de energia elétrica do brasil. Anais do XXXIV Encontro Nacional de Economia, 2006.

[72] SOKEI, C. T. Modelo de sazonalização da energia assegurada de usinas hidrelétricas utilizando algoritmos genéticos. Dissertação. Universidade de São Paulo, 2008.

[73] LIMA, D. A.; BARROSO, L. A. N.; DE AGUIAR, A. S.; DAVID, S. P. A. M.S.; GRANVILLE, S. S.; LEAL, J. E. Energia para renováveis com repartição de suas cotas baseada no método do benefício marginal considerando a volatilidade da produção de seus participantes.

[74] FONSECA, F. Estratégias de sazonalização da garantia física de pchs em portfolios pch e biomassa. Rio de janeiro, 2009.

[75] ANEEL. Agência nacional de energia elétrica. http://www.aneel.gov . br/sala-de-imprensa-exibicao-2/, May 2017. 
[76] MEDIDA. Medida provisória no 688, de 18 de agosto de 2015 - dou de 18/08/2015 - convertida em lei. http://sislex.previdencia.gov.br/ paginas/45/2015/688.htm, Aug. 2015.

[77] NOTA. Nota técnica $n^{\circ}$ 238/2015-srm-srg/aneel: critérios para anuência e as demais condições de repactuação do risco hidrológico, nos termos da medida da medida provisória $\mathrm{n}^{\circ} 688$, de 18 de agosto de 2015 - mp 688. http://www2.aneel.gov.br/aplicacoes/audiencia/arquivo/ 2015/032/resultado/nt_238_2015-srm-srg_rev2.pdf, Oct. 2015.

[78] LEl. Lei $\mathrm{n}^{\circ}$ 13.203, de 8 de dezembro de 2015. http://www.planalto. gov.br/ccivil_03/_Ato2015-2018/2015/Lei/113203.htm, Dec. 2015.

[79] RESOLUÇÃO. Resolução normativa $\mathrm{n}^{\circ} 684$, de 11 de dezembro de 2015: critérios para anuência e as demais condições para repactuação do risco hidrológico de geração hidrelétrica por agentes participantes do mecanismo de realocação de energia. http://www2 . aneel .gov.br/aplicacoes/audiencia/arquivo/2015/ 032/resultado/48500.006210-2014-19_resolucao.pdf, Dec. 2015.

[80] JIN, Y.; JORION, P. Firm value and hedging: Evidence from us oil and gas producers. The Journal of Finance, v. 61, n. 2, p. 893-919, 2006.

[81] LIU, M.; WU, F. F. Portfolio optimization in electricity markets. Electric Power Systems Research, v. 77, n. 8, p. 1000-1009, 2007.

[82] ILIADIS, N. A.; PERIRA, V.; GRANVILLE, S.; FINGER, M.; HALDI, P.-A.; BARROSO, L.-A. Benchmarking of hydroelectric stochastic risk management models using financial indicators. 2006 IEEE Power Engineering Society General Meeting, p. 8-pp, 2006.

[83] JORION, P. Value at risk: nova fonte de referência para o controle do risco de mercado. Bolsa de Mercadorias \& Futuros, 1998.

[84] BENNINGA, S.; WIENER, Z. Value-at-risk (var). matrix, v. 32, p. s33, 1998.

[85] ARTZNER, P.; DELBAEN, F.; EBER, J.-M.; HEATH, D. Coherent measures of risk. Mathematical finance, v. 9, n. 3, p. 203-228, 1999.

[86] ROCKAFELLAR, R. T.; URYASEV, S. Conditional value-at-risk for general loss distributions. Journal of banking \& finance, v. 26, n. 7, p. 1443-1471, 2002. 
[87] ROCKAFELLAR, R. T.; URYASEV, S. Optimization of conditional valueat-risk. Journal of risk, v. 2, p. 21-42, 2000.

[88] STREET, A. On the conditional value-at-risk probability-dependent utility function. Theory and Decision, v. 68, n. 1, p. 49-68, 2010.

[89] STREeT, A.; BARROSO, A. Notas de aula. PUC-Rio, 2015.

[90] SáNCHEZ, J. C. M. Estudo da negociação de contratos bilaterais de energia em sistemas predominantemente hidráulicos. Tese. Universidade de Brasília, 2008.

[91] AUSUBEL, L. M.; CRAMTON, P. Using forward markets to improve electricity market design. Utilities Policy, v. 18, n. 4, p. 195-200, 2010.

[92] CCEE. Câmara de comercialização de energia elétrica. http://www . ccee. org.br/, Jan. 2016.

[93] ONS. Operador nacional do sistema. http://www.ons.org.br/, 2015.

[94] SOARES, L. B. Seleção de projetos de investimento em geração de energia elétrica. 2008. Tese (Doutorado em Física) - Dissertação de Mestrado apresentada ao Programa de Pós-Graduação em Engenharia de Produção da PUC-Rio, Rio de Janeiro, 2008.

[95] CCEE. Câmara de comercialização de energia elétrica, relatório de mercado. https://www.ccee.org.br/portal/faces/pages_publico/ o-que-fazemos/infomercado?_afrLoop $=949504964050148 \# \% 40 \% 3 \mathrm{~F}$ afrLoop\%3D949504964050148\%26_adf.ctrl-state\%3Dopep472gm_4/, 2016.

[96] ONS. Operador nacional de sistema, programa mensal da operação. http: //www.ons.org.br/operacao/programa_mensal_operacao.aspx/, 2016.

[97] MME. Ministério de minas e energia, boletim de monitoramento do sistema elétrico brasileiro. http://www.mme.gov.br/documents/10584/ 3308684/Boletim+de+Monitoramento+do+Sistema+El\%C3\%A9trico+ -+Janeiro-2016.pdf/5977c97c-c5bf-433c-9c0a-b92cb32df517/, 2016.

[98] HULL, J. C. Options, futures, and other derivatives. Pearson Education India, 2006. 
[99] WILHELM, M. Modeling, pricing and risk management of power derivatives. Tese. ETH Zurich, 2007.

[100] TRIGEORGIS, L. Real options: Managerial flexibility and strategy in resource allocation. MIT press, 1996.

[101] VERNON, R. International investment and international trade in the product cycle. The quarterly journal of economics, p. 190-207, 1966.

[102] VENETSANOS, K.; ANGELOPOULOU, P.; TSOUTSOS, T. Renewable energy sources project appraisal under uncertainty: the case of wind energy exploitation within a changing energy market environment. Energy Policy, v. 30, n. 4, p. 293-307, 2002.

[103] NORONHA, J.; LIMA, J.; FERREIRA, T. Análise de investimentos em geração hidráulica utilizando a teoria das opções reais. Congresso Brasileiro de Planejamento energético-CBPE, v. 5, 2006.

[104] FENOLIO, L. M. D. S.; MINARDI, A. M. A. F. Applying real options theory to the valuation of small hydropower plants. Revista de Economia e Administração, v. 8, n. 3, 2009.

[105] DYKES, K.; NEUFVILLE, R. D. Real options for a wind farm in wapakoneta, ohio: incorporating uncertainty into economic feasibility studies for community wind. Paper submitted for the World Wind Energy Conference of, 2008.

[106] GILBOA, Y.; GUO, X. Real option analysis of a large-scale space solar power venture. Michigan J. Bus, v. 4, n. 2, p. 121-142, 2011.

[107] MÉNDEZ, M.; GOYANES, A.; FERNANDEZ, P. L. Real options valuation of a wind farm. Annual International Real Options Conference, 2009.

[108] CLEWLOW, L.; STRICKLAND, C. Energy derivatives: pricing and risk management. Lacima Publ., 2000.

[109] KAMINSKI, V. The challenge of pricing and risk managing electricity derivatives. The US Power Market, v. 3, p. 149-71, 1997.

[110] PILIPOVIC, D. Energy risk: Valuing and managing energy derivatives. McGraw Hill Professional, 2007.

[111] DENG, S.-J.; JOHNSON, B.; SOGOMONIAN, A. Exotic electricity options and the valuation of electricity generation and transmission assets. Decision Support Systems, v. 30, n. 3, p. 383-392, 2001. 
[112] DENG, S.-J. Valuation of investment and opportunity-to-invest in power generation assets with spikes in electricity price. Managerial Finance, v. 31, n. 6, p. $95-115,2005$.

[113] JAILLET, P.; RONN, E. I.; TOMPAIDIS, S. Valuation of commodity-based swing options. Management science, v. 50, n. 7, p. 909-921, 2004.

[114] KAMINSKI, V.; GIBNER, S. Exotic options. Managing energy price risk, 1995.

[115] CARMONA, R.; DURRLEMAN, V. Pricing and hedging spread options. Siam Review, v. 45, n. 4, p. 627-685, 2003.

[116] DE SOUZA, Z. J. O mercado futuro de eletricidade em new york. Rio de Janeiro, Dissertação de Mestrado. UFRJ, 1999.

[117] MARTIN, J. M. M. Mecanismos de avaliação de contratos de compra e venda de energia em ambiente competitivo. Florianópolis, SC. Dissertação de Mestrado. UFSC/PGEEL, 2002.

[118] MARGRABE, W. The value of an option to exchange one asset for another. The journal of finance, v. 33, n. 1, p. 177-186, 1978.

[119] WANG, X.; SONG, S.; WANG, Y. The valuation of power exchange options with counterparty risk and jump risk. Journal of Futures Markets, 2016.

[120] KLEIN, P. Pricing black-scholes options with correlated credit risk. Journal of Banking \& Finance, v. 20, n. 7, p. 1211-1229, 1996.

[121] FERNANDES, G.; GOMES, L.; VASCONCELOS, G.; BRANDÃO, L. Mitigating wind exposure with zero-cost collar insurance. Renewable Energy, v. 99, p. $336-346,2016$.

[122] BETTIS, J. C.; BIZJAK, J. M.; LEMMON, M. L. Managerial ownership, incentive contracting, and the use of zero-cost collars and equity swaps by corporate insiders. Journal of financial and quantitative analysis, v. $36, \mathrm{n}$. 03, p. 345-370, 2001.

[123] SHAN, L.; GARVIN, M. J.; KUMAR, R. Collar options to manage revenue risks in real toll public-private partnership transportation projects. Construction Management and Economics, v. 28, n. 10, p. 1057-1069, 2010.

[124] SANTOS, F. F. G. D. Gerenciamento de riscos: otimização multiobjetivo e análise de portfólio de compra e venda de energia. Minas Gerais, Dissertação de Mestrado - UFMG, 2013. 
[125] ARSHI, A. A. Energy swaps as profit motive instruments in oil markets. OPEC Energy Review, v. 16, n. 2, p. 201-216, 1992.

[126] VANDER LINDEN, D. Denomination of currency decisions and zero-cost options collars. Journal of Multinational Financial Management, v. 15, n. 1, p. 85-98, 2005.

[127] MORENO, R.; BARROSO, L. A.; RUDNICK, H.; MOCARQUER, S.; BEZERRA, B. Auction approaches of long-term contracts to ensure generation investment in electricity markets: Lessons from the brazilian and chilean experiences. Energy Policy, v. 38, n. 10, p. 5758-5769, 2010.

[128] OLIVEIRA, A. D. Reforma do setor elétrico-que podemos aprender com a experiência alheia. Rio de Janeiro, UFRJ, Grupo de Energia, 1997. 


\section{Premium values of hydrological renegotiation}

The premium for each level of protection is shown in Table A.1. The premium amounts will be updated annually by the variation of the Broad Consumer Price Index (or Índice de Preço ao Consumidor Amplo - IPCA). Also, this table shows that the reimbursement to the generating agents and the term of postponement of the premium for its amortization vary according to the desired level of protection.

Table A.1: Products for the renegotiation of the hydrological risk in the ACR, a result to be reimbursed with the renegotiation and the term of postponement of payment of the risk premiums.

\begin{tabular}{|c|c|c|c|c|c|c|}
\hline \multirow[t]{2}{*}{$\begin{array}{c}\text { Product } \\
\text { Class }\end{array}$} & \multirow[t]{2}{*}{$\begin{array}{c}\text { Factor } \\
\mathrm{f}\end{array}$} & \multirow[t]{2}{*}{ Product } & \multirow{2}{*}{$\begin{array}{l}\text { Unit } \\
\text { risk } \\
\text { premium } \\
\mathrm{R} \$ / \mathrm{MWh}\end{array}$} & \multirow{2}{*}{$\begin{array}{c}\text { Result to be reimbursed } \\
\text { concerning the effects of } \\
\text { renegotiation in } 2015 \\
\mathrm{R} \$ / \mathrm{MWh}\end{array}$} & \multicolumn{2}{|c|}{$\begin{array}{l}\text { Deadline for payment } \\
\text { of the premium starting January } 2016 \\
\text { for reimbursement of the result of } 2016\end{array}$} \\
\hline & & & & & Completed years & Remaining months \\
\hline \multirow{12}{*}{$\mathrm{P}$} & 0 & P100 & 12.75 & 30.30 & 2 & 10 \\
\hline & 1 & P99 & 11.75 & 28.40 & 2 & 11 \\
\hline & 2 & P98 & 10.75 & 26.51 & 2 & 11 \\
\hline & 3 & P97 & 10.00 & 24.36 & 2 & 11 \\
\hline & 4 & P96 & 9.00 & 22.46 & 2 & 12 \\
\hline & 5 & P95 & 8.25 & 20.30 & 2 & 11 \\
\hline & 6 & P94 & 7.50 & 18.42 & 2 & 11 \\
\hline & 7 & P93 & 6.75 & 16.61 & 2 & 11 \\
\hline & 8 & P92 & 6.00 & 14.76 & 2 & 11 \\
\hline & 9 & P91 & 5.50 & 13.02 & 2 & 10 \\
\hline & 10 & P90 & 4.75 & 11.63 & 2 & 11 \\
\hline & 11 & P89 & 4.25 & 10.22 & 2 & 11 \\
\hline \multirow{12}{*}{ SP } & 0 & SP100 & 9.5 & 33.55 & 4 & 6 \\
\hline & 1 & SP99 & 8.50 & 31.65 & 4 & 10 \\
\hline & 2 & SP98 & 7.50 & 29.76 & 5 & 3 \\
\hline & 3 & SP97 & 6.50 & 27.86 & 5 & 9 \\
\hline & 4 & SP96 & 5.50 & 25.96 & 6 & 7 \\
\hline & 5 & SP95 & 4.75 & 23.80 & 7 & 2 \\
\hline & 6 & SP94 & 4.00 & 21.92 & 8 & 2 \\
\hline & 7 & SP93 & 3.25 & 20.11 & 9 & 10 \\
\hline & 8 & SP92 & 2.50 & 18.26 & 13 & 3 \\
\hline & 9 & SP91 & 2.00 & 16.52 & 17 & 3 \\
\hline & 10 & SP90 & 1.25 & 15.13 & \multicolumn{2}{|c|}{ Do not pay premium } \\
\hline & 11 & SP89 & 0.75 & 13.68 & \multicolumn{2}{|c|}{ Do not pay premium } \\
\hline SPR & 0 & SPR100 & $0 \%$ of the pri & Depends of the price & Depends & of the price \\
\hline
\end{tabular}

As seen in Table A.1, the Product P97, for example, is a product in which the generating agent keeps the secondary energy and the consumer assumes the monthly GSF below 0.97. In this case, the generating agent pays a monthly premium of $10.00 \mathrm{R} \$ / \mathrm{MWh}$, after 2 years, to receive a reimbursement of 24.36 $\mathrm{R} \$ / \mathrm{MWh}$. On the other hand, if the generating agent chooses the Product SP97, he will have the same level of protection, but will not have the gains with the secondary energy. In this case, he will pay a lower premium of 6.50 
$\mathrm{R} \$ / \mathrm{MWh}$, after a period of five years, and will receive a reimbursement of $27.86 \mathrm{R} \$ / \mathrm{MWh}$. 